\title{
PHENYLALANINE REQUIREMENT IN CHILDREN WITH CLASSICAL PKU DETERMINED BY INDICATOR AMINO ACID OXIDATION
}

By

Clenda Courtney-Martin

A thesis submitted in conformity with the requirements

for the degree of M.Sc.

Graduate Department of Nutritional Sciences

University of Toronto

() Copyright by Glenda Courtney-Martin 1999 
National Library

of Canada

Acquisitions and

Bibliographic Services

395 Wellington Street

Ottawa ON KIA ONA

Canada
Bibliothèque nationale

du Canada

Acquisitions et

services bibliographiques

395, rue Wellington

Ottawa ON K1A ONA

Canada
The author has granted a nonexclusive licence allowing the National Library of Canada to reproduce, loan, distribute or sell copies of this thesis in microform, paper or electronic formats.

The author retains ownership of the copyright in this thesis. Neither the thesis nor substantial extracts from it may be printed or otherwise reproduced without the author's permission.
L'auteur a accordé une licence non exclusive permettant à la Bibliothèque nationale du Canada de reproduire, prêter, distribuer ou vendre des copies de cette thèse sous la forme de microfiche/film, de reproduction sur papier ou sur format électronique.

L'auteur conserve la propriété du droit d'auteur qui protège cette thèse. $\mathrm{Ni}$ la thèse ni des extraits substantiels de celle-ci ne doivent être imprimés ou autrement reproduits sans son autorisation. 


\title{
PHENYLALANINE REQUIREMENT IN CHILDREN WITH CLASSICAL PHENYLKETONURIA DETERMINED BY INDICATOR AMINO ACID OXIDATION
}

\author{
Master of Science, 1999 \\ Glenda Courtney-Martin \\ Graduate Department of Nutritional Sciences \\ University of Toronto
}

\section{ABSTRACT}

Phenylketonuria (PKU) is a disorder of aromatic amino acid metabolism, Which results from a genetic mutation of the phenylalanine hydroxylase enzyme (PAH). PAH is the rate limiting enzyme which catalyzes the initial reaction in which phenylalanine is converted to tyrosine, or completely oxidized to $\mathrm{CO}_{2}$ and $\mathrm{H}_{2} \mathrm{O}$. Although dietary restriction of phenylalanine is the main treatment in PKU, present estimates of requirements are based on plasma phenylalanine levels and growth. The present study aimed to more precisely determine phenylalanine requirement using Indicator Amino Acid Oxidation (IAAO), with L- $\left[1-{ }^{13} \mathrm{C}\right]$ lysine as the indicator. Breath ${ }^{13} \mathrm{CO}_{2}$ production $\left(\mathrm{F}^{13} \mathrm{CO}_{2}\right)$ was used as the endpoint. The mean phenylalanine requirement was estimated using a two-phase linear regression crossover analysis, which identified a breakpoint of the $\mathrm{F}^{13} \mathrm{CO}_{2}$ at $14 \mathrm{mg} \cdot \mathrm{kg}^{-1}$. day ${ }^{-1}$. The safe population requirement was found to be $19.5 \mathrm{mg}^{\mathrm{kg}}{ }^{-1}$ .day ${ }^{-1}$. This study suggests that the current recommended phenylalanine intake for children with PKU is too high. 


\section{DEDICATION}

To Okan whose patience and generous spirit, made this possible. And to Kimberly, who was and is my inspiration. 


\section{ACKNOWLEDGEMENTS}

I am grateful to Dr. P.B. Pencharz and Dr. R.O. Ball for their love of teaching and for giving me the opportunity to learn from them.

Sincere thanks to the members of m.y advisory committee: Dr. J.T.R. Clarke and Dr. S. Cunnane for their assistance and advice.

I thank the PKU clinic staff: Valerie Austin and Wanda Schoonheyt for their invaluable help and support in patient recruitment, and throughout the study.

The advice and support of Mahroukh Rafii, Susan Roberts, Jane Thorpe and Sandra Parker are gratefully acknowledged. These individuals helped to make this a pleasant learning experience.

Thanks to Joanne McHugh for her encouragement and cheerful manner.

I thank the kitchen staff, especially Linda Chow who faithfully prepared the diets for each study day.

Finally, I give my heartfelt thanks to the children who participated in the study. I am also grateful to their parents for transporting and encouraging them. Without them this study would have been impossible. 


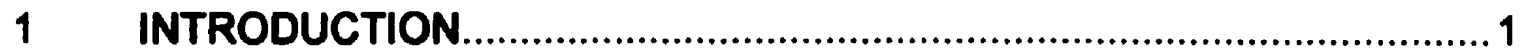

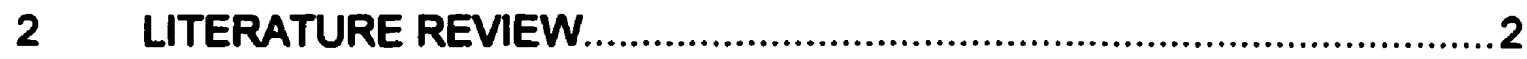

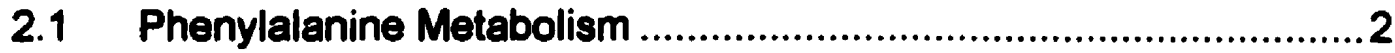

2.2 Clinical Features in Classical Phenylketonuria (PKU) ...................5

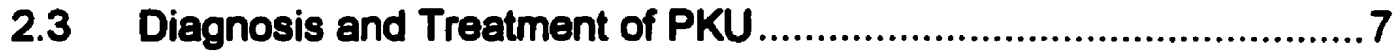

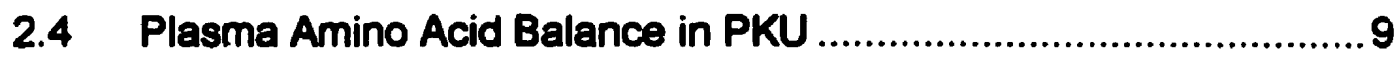

2.5 Aromatic Amino Acid Requirement In Normal Humans ...............12

2.6 Phenylalanine Requirement in Classical PKU ...........................15

2.7 Methods for Determining Amino Acid Requirements....................18

2.7.1 Nitrogen Balance .......................................................... 18

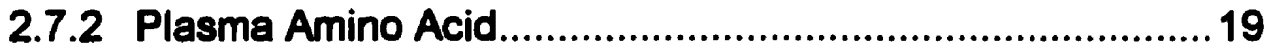

2.7.3 Direct Amino Acid Oxidation ............................................20

2.7.4 Indicator Amino Acid Oxidation ......................................21

3 RATIONALE, OBJECTIVES AND HYPOTHESIS ...............................24

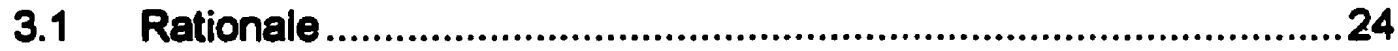

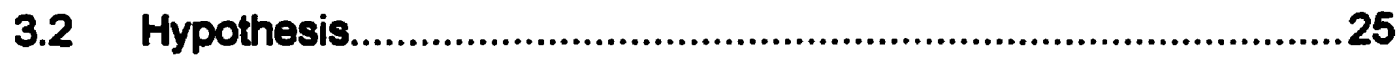

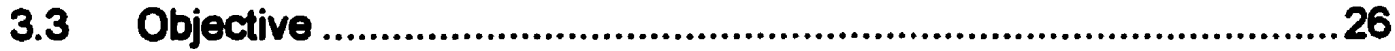

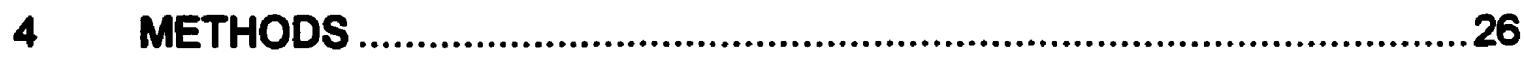

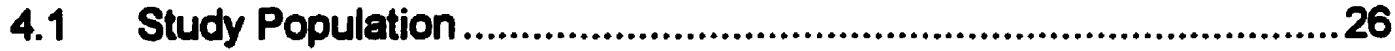

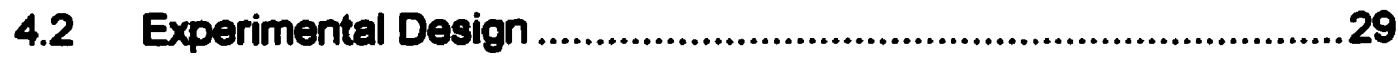




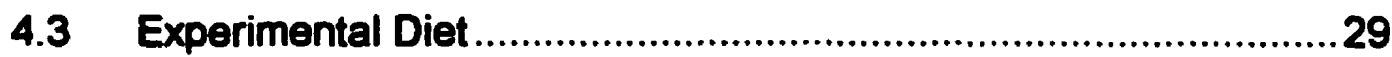

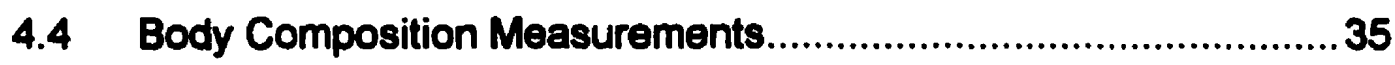

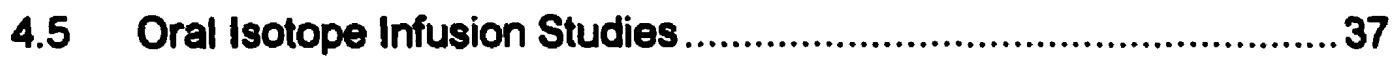

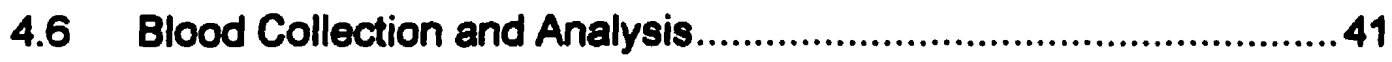

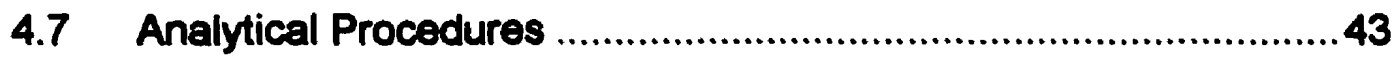

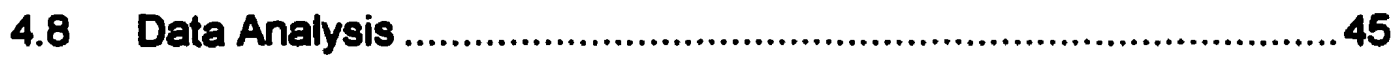

$5 \quad$ RESULTS

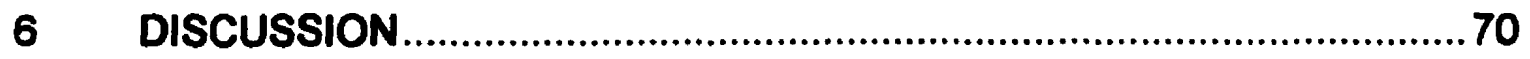

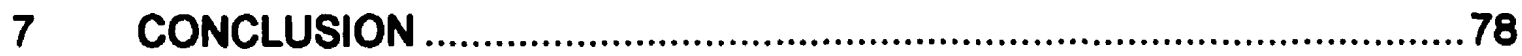

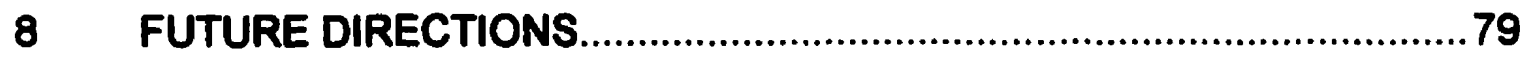

9 REFERENCES

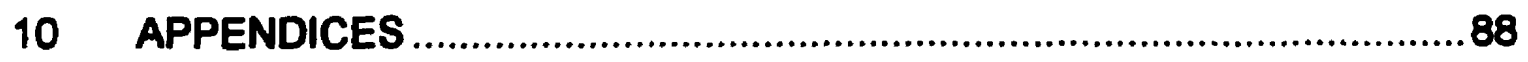

10.1 Research Information Form (for patients less than 16 years) .......88

10.2 Research Information Form (for children $7-15$ years) ..................91

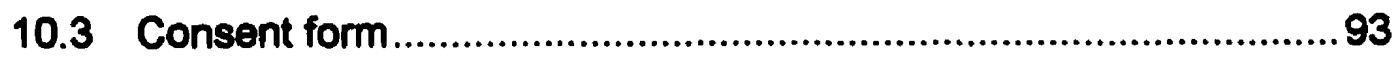

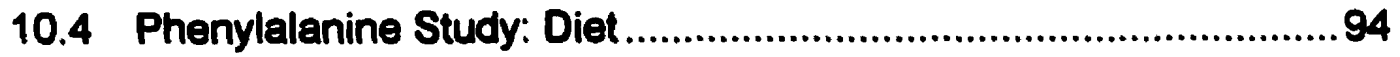

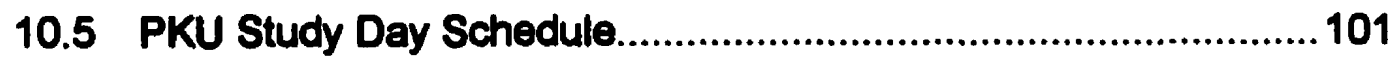

10.6 Body Composition Data Form ................................................. 103

10.7 Details of Linear Regression Crossover Model (Breakpoint

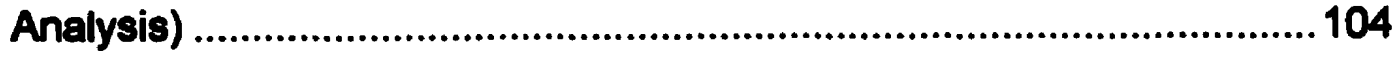




\section{LIST OF TABLES}

Table 4.1 Subject Characteristics of Children with Phenylketonuria (PKU) who participated in the Phenylalanine Requirement Study..........28

Table 4.2 Composition of L-Amino Acid Mixture .........................................31

Table 4.3 Nutrient Intake of Children with Phenylketonuria During Six-Day

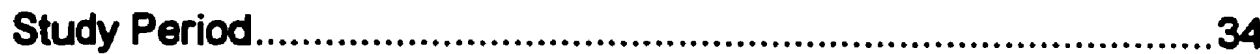

Table 5.1 Weight $(\mathrm{kg})$ of Children with Phenylketonuria During Study Period 53

Table 5.2 Height $(\mathrm{cm})$ of Children with Phenylketonuria During Study Period 54

Table 5.3 Comparison of Mean Fat Free Mass (FFM) as Determined by Bioelectrical Impedance (BIA) and Skinfolds (SF) .....................55

Table $5.4 \mathrm{CO}_{2}$ Production Rates $\left(\mathrm{mL}\right.$. $\mathrm{min}^{-1}$ ) of Subjects on Study Days ......56

Table 5.5 Effect of Phenylalanine Intake on Mean Lysine Flux, Oxidation and $\mathrm{F}^{13} \mathrm{CO}_{2}{ }^{1}$

Table 5.6 Individual Phenylalanine Requirements for 5 Children with

Classical Phenylketonuria (PKU) Based on $\mathrm{F}^{13} \mathrm{CO}_{2}$

Table 5.7 Fasting, Fed and Percentage Change in Phenylalanine

Concentration on Each Study Day for Each Individual Subject.....64

Table 6.1 Summary of Current Recommended Daily Aromatic Amino Acid (Phenylalanine plus Tyrosine) Requirement in Healthy Children and Children with Phenylketonuria (PKU) .................................71 


\section{LIST OF FIGURES}

Figure 2.1 The Metabolic Pathways and their Relative Importance for Outflow of L-phenylalanine in the Normal Steady State: $1=$ The Hydroxylation Reaction Mediated by PAH (major); 2 = The Transamination Reaction (minor); 3 = The Decarboxylation

Reaction (minor)

Figure 4.1 Phenylalanine Requirement Study Day Protocol .........................38

Figure 4.2 Stochastic Model for Amino Acid Kinetics ....................................46

Figure 4.3 Typical Study Day ${ }^{13} \mathrm{CO}_{2}$ Enrichment in Breath..........................50

Figure 4.4 Typical Study Day ${ }^{13} \mathrm{C}$-Lysine Enrichment in Urine ......................51

Figure 5.1 Effect of Phenylalanine Intake on Individual Rate of ${ }^{13} \mathrm{CO}_{2}$ Release $\left(\mathrm{F}^{13} \mathrm{CO}_{2}\right)$ in Children with Phenylketonuria .59

Figure 5.2 Effect of Phenylalanine Intake on Mean Rate of ${ }^{13} \mathrm{CO}_{2}$ Release $\left(\mathrm{F}^{13} \mathrm{CO}_{2}\right)$ in Children with Phenylketonuria .61

Figure 5.3 Mean Fasted and Fed-State Plasma Phenylalanine Concentration .66

Figure 5.4 Individual Fed State Plasma Phenylalanine Concentration in Response to Varying Phenylalanine Intakes. .67

Figure 5.5 Relationship Between Phenylalanine Intake and Mean Difference (Fed Minus Fasted) in Plasma Phenylalanine Concentration .68 
Figure 5.6 Relationship Between Phenylalanine Intake and Individual Difference (Fed Minus Fasted) in Plasma Phenylalanine 


\section{ABBREVIATIONS}

Amino acid

AA

Atom percent

AP

Atom percent excess

APE

Bioelectrical impedance analysis

BIA

Carbon dioxide

$\mathrm{CO}_{2}$

Continuous flow isotope ratio mass spectrometry

CF-IRMS

Direct amino acid oxidation

DAAO

Fat free mass

FFM

Gas chromatography mass spectrometry

GCMS

Gas chromatography flame ionization detection

GC/FID

Gas chromatography

GC

Height

HT

Indicator amino acid oxidation

IAAO

Intelligence quotient

1Q

Kilo-calorie

kcal

Massachusetts Institute of Technology

MIT

Mole percent excess

MPE

Nicotinamide adenine dinucleotide

NAD

Nitrogen

$\mathbf{N}$

Phenylalanine

PHE

Phenylketonuria

PKU

Phenylalanine hydroxylase

PAH 
Resistance

Reactance

Flux

Ideal body weight

Rate of Production of ${ }^{13} \mathrm{CO}_{2}$

Rate of carbon dioxide production

Skinfold

Standard error of the mean

Tyrosine

Weight

World Health Organization
$\mathbf{R}$

$x_{c}$

Q

LBW

$\mathrm{F}^{13} \mathrm{CO}_{2}$

$\mathrm{VCO}_{2}$

SF

SEM

TYR

WT

WHO

xi 


\section{INTRODUCTION}

Phenylketonuria (PKU) is an inherited disorder of phenylalanine metabolism caused by impaired phenylalanine hydroxylase (PAH) activity (Elsas \& Acosta, 1988). PAH is the rate limiting enzyme which catalyzes the reaction in which phenylalanine is converted to tyrosine, the first step in the oxidation of phenylalanine to $\mathrm{CO}_{2}$ and $\mathrm{H}_{2} \mathrm{O}$. The disease is clinically expressed at about three to six months of age and is characterized by developmental delay, microcephaly, abnormal electroencephalogram, eczema, musty body odor, and hyperactivity (Elsas \& Acosta, 1988). If untreated, irreversible mental retardation occurs. However with the introduction of newborn screening, which is done worldwide using the Guthrie test, the low phenylalanine diet can be initiated soon after birth and these severe complications avoided.

PKU has been classified (Scriver et al, 1989) into three different categories: classical PKU, variant PKU and non-PKU hyperphenylalaninemia. The three different classes reflect the degree of impairment of PAH activity with classical being the most severe. This form of PKU (classical) is the subject of this research. PKU affects 5 to 190 cases per million live births in the general population (Scriver et al, 1989). However, there is great ethnic and geographic variation in its incidence.

PKU was discovered by Folling in 1934 (Folling, 1934) and was the first genetic disease to be effectively treated by nutritional means (Scriver et al, 1989). Since it's discovery, the low phenylalanine diet has been the mainstay of 
treatment in PKU. Implementation soon after birth usually prevents most of the overt clinical manifestations of PKU. Nevertheless, there is a considerable body of evidence which suggests that neuropsychological and cognitive functions at the end of treatment are not quite normal in PKU patients (Thompson et al, 1993, Smith et al, 1990, Thompson et al, 1990, Thompson et al, 1991).

Although dietary phenylalanine restriction remains the main treatment in

PKU, present estimates of requirements are based on plasma phenylalanine levels and growth rate in relation to dietary intake. However, amino acid requirements can be more sensitively and accurately estimated using isotope tracer methods. Therefore, the objective of this present study, was to more precisely determine phenylalanine requirement for one group of individuals with classical PKU; prepubertal children between the ages of 6 to 13 years using the technique of indicator amino acid oxidation.

\section{LITERATURE REVEW}

\subsection{Phenylalanine Metabolism}

Phenylalanine is an indispensable amino acid, which indicates that it can only be obtained from the diet. This indispensable amino acid is utilized for two main purposes: tissue protein synthesis and hydroxylation to form tyrosine (Elsas \& Acosta, 1988). Its flux through the plasma compartment comprises an 
input and an outflow component (Scriver et al, 1989). Sources of input include exogenous (dietary) and endogenous (proteolysis). Sources of outflow include protein synthesis, hydroxylation to tyrosine and conversion to minor metabolites (Scriver et al, 1989). Consequently, a disturbance in any of these components of flux of phenylalanine, could lead to a disturbance on phenylalanine metabolism and homeostasis.

The most important single determinant of phenylalanine homeostasis in humans is the hydroxylation reaction (Scriver et al, 1989). This reaction plays two important roles in mammalian metabolism: (1) It is an obligatory and rate limiting step in the catabolic pathway that leads to the complete oxidation of phenylalanine to $\mathrm{CO}_{2}$ and water, and (2) It provides the organism with an endogenous supply of the dispensable amino acid, tyrosine (Scriver et al, 1989). Figure 2.1 illustrates the various pathways of phenylalanine metabolism.

Because the hydroxylation reaction modified by the enzyme phenylalanine hydroxylase (PAH) is the major pathway of phenylalanine metabolism, any defect in this enzyme as seen in PKU leads to an accumulation of phenylalanine in the plasma over and above the normal values. When this occurs, as it does in PKU, pathway two (2) (Figure 2.1), which in the normal individual is a very minor pathway becomes a more active pathway. The resultant metabolites, which are usually present in the plasma of normal individuals in very minor amounts, reach abnormally high levels with their consequent excretion in urine. 


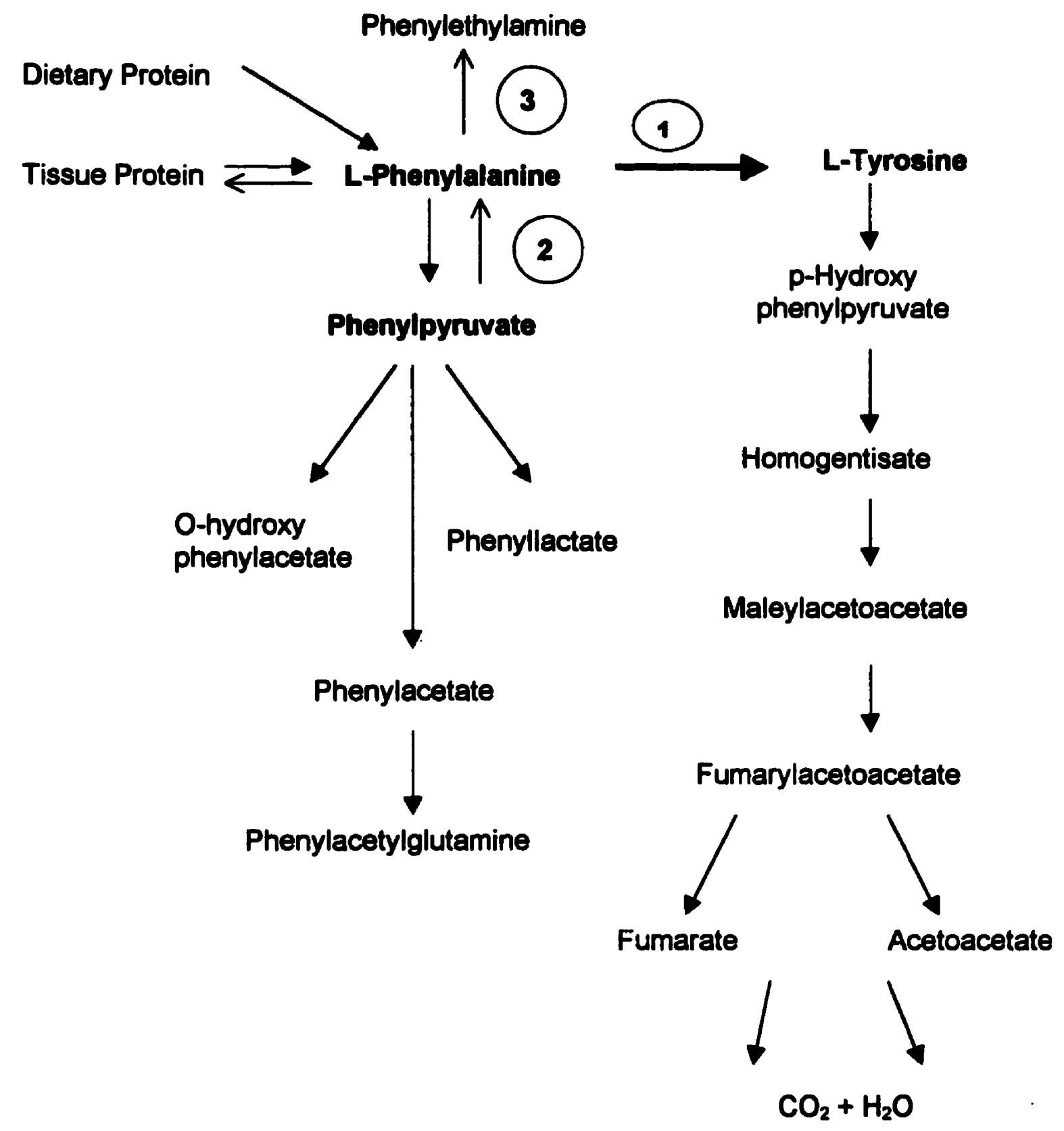

Figure 2.1 The Metabolic Pathways and their Relative Importance for Outflow of L-phenylalanine in the Normal Steady State: 1 = The Hydroxylation Reaction Mediated by PAH (major); 2 = The Transamination Reaction (minor); 3 = The Decarboxylation Reaction (minor) 
In the normal individual, the plasma concentration of phenylalanine is around $58 \pm 15, \mu \mathrm{M}$ (mean \pm SD), $62 \pm 18 \mu \mathrm{M}$, and $60 \pm 13 \mu \mathrm{M}$ in adults, children and adolescents respectively, (Scriver et al, 1989). Gender affects the value only in the adolescent period with males having higher values than females (Scriver et al, 1989). From these values it is obvious that in the normal individual, plasma levels of phenylalanine are very tightly regulated and change only to a small extent over the life span.

In the PKU individuals on the other hand, plasma levels of phenylalanine are usually above $1200 \mu \mathrm{M}$ (if untreated) and are the main criteria (plasma phenylalanine levels) used for the classification of the different types of hyperphenylalaninemias; upon diagnosis, individuals with classical PKU, variant PKU and non-PKU hyperphenylalaninemia usually have plasma phenylalanine levels of $>1200 \mu \mathrm{M},<1200 \mu \mathrm{M}$, and $<1000 \mu \mathrm{M}$ respectively (Scriver et al, 1989).

\subsection{Clinical Features in Classical Phenylketonuria (PKU)}

The clinical phenotype in PKU is not as prominent today as it was $30-40$ years ago, because that aspect of the disease is prevented to a large extent by early diagnosis and treatment. Nevertheless, despite early diagnosis and treatment, there are a number of studies which show that the outcome in PKU is still not quite normal (Thompson et al, 1990, 1991, 1993, Smith et al, 1990, Holm \& Knox, 1979). Despite early treatment, children with PKU tend to have IQs 
below those of their first-degree relatives and an educational performance inferior to their siblings. In addition, these data suggest that mild neurological impairment occurs in children with PKU despite early treatment. Children with PKU are also more prone to behavioral disorders than normal children (Scriver et al, 1989).

A number of dermatological manifestations occur in the untreated PKU individual including eczema, pigment dilution and scleroderma-like lesions (Scriver et al, 1989). Growth is also affected with impaired postnatal physical growth, leading to decreased stature and microcephaly (Scriver et al, 1989). Holm et al, (1979), however, have shown that physical growth characterized as height, weight, and head circumference during the first year of life were comparable in PKU children who had been started on dietary management before 4 months, when compared to normal children.

By far the most serious consequence of PKU is mental retardation. Other signs and symptoms largely improve when the hyperphenylalaninemia and other biochemical abnormalities are brought under control. However, once the mental retardation is established, a low phenylalanine diet seems ineffective in reducing its effects (Scriver et al, 1989). Treatment therefore should begin between the first and the third week of life if maximum benefits are to be gained (Scriver et al, 1989). 


\subsection{Diagnosis and Treatment of PKU}

In order to optimize treatment in PKU, the disease must be identified, diagnosed and treated appropriately before the clinical symptoms become apparent. Worldwide, PKU is diagnosed through newborn screening programs run by the various public health departments within the different countries. The screening test most widely used around the word is the Guthrie test (Elsas \& Acosta, 1988) because of its ease of application. Using this test, one laboratory can effectively screen 20,000 to 200,000 samples per year (Elsas \& Acosta, 1988).

Based on the Guthrie test, a capillary blood sample (dried on filter paper) is analyzed for its phenylalanine content by microbiologic inhibition assay. Although semiquantitative in nature, its cost and simplicity makes it a widely used test. Nevertheless, there are a number of other methods which are more quantitative including the fluorometric and enzymatic methods which can measure phenylalanine in amounts down to zero (Scriver et al, 1989), with a lower coefficient of variation than the Guthrie test.

The treatment for PKU is mainly the dietary restriction of phenylalanine. In addition due to the blocked metabolic pathway, tyrosine becomes an indispensable amino acid and is supplemented in PKU (Elsas \& Acosta, 1988). The diet for PKU is semi-synthetic in nature, in which the main form of protein is provided by an amino acid formula containing either small amounts, or totally deficient in phenylalanine. Protein intake cannot be curtailed sufficiently by itself to prevent hyperphenylalaninemia without causing deficiency of other 
indispensable amino acids. This is because natural proteins contain 2.4 to $9 \%$ by weight of phenylalanine (Elsas \& Acosta, 1988). Several low phenylalanine or phenylalanine free products are available. These products are fortified with vitamins and minerals. In addition to the amino acid (protein) formula, the diet for PKU is made up of low protein foods, which contain small amounts of phenylalanine and adequate energy from fats and carbohydrates.

The main objectives of nutrition support in the child with classical PKU are (1) to maintain blood phenylalanine concentrations that will allow optimum growth and brain development by supplying adequate energy, protein and other nutrients while restricting phenylalanine and supplementing tyrosine intake (Elsas \& Acosta, 1988), and (2) to keep blood levels of phenylalanine as close to normal as possible.

Whereas excess accumulation of phenylalanine in the plasma leads to all of the conditions stated previously in section 2.2, excess restriction is also harmful and has been shown to produce growth failure, skin rashes, bone changes and mental retardation (Hanley et al, 1970, Elsas \& Acosta, 1988). In addition the amount of phenylalanine associated with elevated plasma phenylalanine is only slightly greater that the intake associated with normal plasma levels (Ruch et al, 1982). Assessment of the requirement in this population however is purely empirical and is dependent on plasma phenylalanine in response to dietary intake and on growh; height and weight, head circumference and evaluation of development using developmental scales (Elsas \& Acosta, 1988). 
The plasma amino acid concentration represents a static measurement and provides no information about the movement of phenylalanine into and out of proteins (Denne, 1992). In addition, plasma amino acid concentration is influenced by a number of factors other than dietary amino acid intake, some of which include acute infection with resultant tissue catabolism, inadequate intake of phenylalanine, inadequate protein and energy, decreased rate of release of phenylalanine from existing protein and increased protein synthesis (Denne, 1992). Consequently, plasma amino acid concentrations represent a very gross measure of requirements and may not represent an accurate measure of phenylalanine needs.

\subsection{Plasma Amino Acid Balance in PKU}

One of the characteristics of PKU is a disturbance in the plasma amino concentration of several amino acids, both indispensable and dispensable. Thus Whereas phenylalanine concentration is grossly elevated, a number of amino acids are present in concentrations below that seen in normal individuals (Efron et al, 1969, Brodehl et al, 1970, Wapnir \& Lifshitz, 1974, Byrd et al, 1975, Clemens et al, 1993). Some of the amino acids affected are tryptophan, leucine, methionine, threonine, proline, alanine, ornithine, histidine, glutamine, and asparagine. 
The authors listed above have each investigated one or more reasons as to why plasma amino acids are low in PKU. The following are some of the reasons that have been investigated for possible explanations as to why this anomaly in plasma amino acid occurs:

- Increased phenylalanine levels

- Increased excretion of amino acids (other than phenylalanine)

- Decreased absorption of amino acids (other than phenylalanine)

- Excess accumulation of amino acids in cells

In a study designed to determine whether increased concentration of phenylalanine itself, was responsible for the depressed amino acid concentrations in PKU, the effects of intravenous infusion of phenylalanine on plasma amino acid levels were studied in 3 subjects; 2 with PKU and 1 mentally retarded but without PKU (Efron et al, 1969). The results showed that the concentration of many plasma amino acids, both indispensable and dispensable decreased significantly with elevation of plasma phenylalanine. All three subjects had a similar response even if the PKU subjects already had lower plasma amino acid. Before infusion, the non-PKU subject had a normal plasma amino acid profile. Urinary excretion of the amino acids was also measured before and after infusion of the phenylalanine to determine whether the depressed plasma amino acid was due to decreased renal tubular reabsorption in the presence of excess phenylalanine. There was no change in 
amino acid reabsorption with increases in plasma phenylalanine. Therefore, the depressed level of amino acids observed, was not due to a decrease in renal tubular reabsorption.

Efron et al (1969) did not study tryptophan. However, in another study an inverse relationship was found between serum phenylalanine and tryptophan excretion in a study looking at urinary tryptophan metabolites in relation to phenylalanine intake and plasma phenylalanine levels (Byrd et al, 1975). The authors suggested that the reason for the relationship was because phenylalanine and tryptophan compete for the same carrier sites in the kidney.

At about the same time, intestinal transport the aromatic amino acids was studied in one PKU and three healthy control subjects (Wapnir \& Lifshitz, 1974). Measurements were done while the PKU subject was on a normal diet (plasma phenylalanine $\approx 1800 \mu \mathrm{M}$ ) and after being on a low phenylalanine diet for one month (plasma phenylalanine $\approx 840 \mu \mathrm{M}$ ). The results show that there was a significant decrease in tryptophan absorption in untreated PKU when compared to controls. When treated with a low phenylalanine diet, rates of tryptophan absorption increased and were higher than that of controls. Nevertheless, plasma tryptophan was lower than controls even after being treated with a low phenylalanine diet for one month. Although the results are interesting, only one PKU subject was studied. In addition, the study was not of a long enough duration to assess whether lower levels of plasma phenylalanine 
(within recommended treatment ranges) would have resulted in normal plasma tryptophan.

There is some evidence which suggests that excess plasma phenylalanine can contribute to increased catabolism of various amino acid thus lowering their plasma concentration (Lipovac et al, 1979). In their study conducted in weanling rats in which hyperphenylalaninemia was experimentally induced, the results showed that there was increased catabolism of amino acids specifically in the liver during extended periods of hyperphenylalaninemia. This was determined through the measurement of a number of tissue enzymes. In addition, tissue and plasma phenylalanine and tyrosine, were measured.

\subsection{Aromatic Amino Acid Requirement In Normal Humans}

The phenylalanine requirements of normal humans have been estimated by a number of methods. Methods used include growh (in infants) (Holt \& Snyderman, 1967), nitrogen (N) balance in young men, (Rose et al, 1955), women, (Leverton et al, 1956) and children (Nakagawa et al, 1962), and direct oxidation (Zello et al, 1990, House et al, 1997, Basile-Filho et al, 1997, 1998). Current recommendations are based on $\mathrm{N}$ balance studies (FAOMHO/UNU, 1985). Present estimates for phenylalanine plus tyrosine are $125,69,22-27$, and $14 \mathrm{mg} / \mathrm{kg} /$ day for infants 3-4 months, children 2 years, school boys 10-12 years, 
and adults respectively. Data are lacking on phenylalanine requirements for children 2-10 years old.

Using $\mathbf{N}$ balance, the phenylalanine requirement was estimated, with and without tyrosine, in 13 women and 9 men (Burrill \& Schuck, 1964). With no tyrosine in the diet, the women required $600-700 \mathrm{mg}$ and the men required $900-$ $1000 \mathrm{mg}$ of phenylalanine.day ${ }^{-1}$. When Leverton's Zone of Equilibrium (retention of $0 \pm 5 \%$ of the $N$ intake) (Leverton et al, 1965) was applied, all the men and women were maintained within the equilibrium zone with intakes of 400-500 mg of phenylalanine and $200 \mathrm{mg}$ of tyrosine.day ${ }^{-1}$. However, they were not all in positive $\mathrm{N}$ balance. With $400 \mathrm{mg}$ tyrosine, the men needed $500-600$ $\mathrm{mg}$ of phenylalanine. day ${ }^{-1}$ but the women stored $\mathrm{N}$ at $300-400 \mathrm{mg}$ of phenylalanine. The authors concluded that tyrosine has a replacement value of $50 \%$ for men when fed at $200-400 \mathrm{mg}_{\text {day }}{ }^{-1}$ and a replacement value of $35-40 \%$ for women when fed at $200 \mathrm{mg}^{-\mathrm{day}^{-1}}$ and $\mathbf{5 0 \%}$ replacement value when fed at $400 \mathrm{mg}^{\mathrm{day}}{ }^{-1}$.

Estimates of phenylalanine requirement in adult males in the presence of excess tyrosine was made using direct amino acid oxidation (Zello et al, 1990). In that study, the mean phenylalanine requirement was estimated to be 9.1 $\mathrm{mg} \cdot \mathrm{kg}^{-1}$.day $\mathrm{y}^{-1}$. The tyrosine requirement of adult males was also estimated in the same lab using indicator amino acid oxidation (Roberts, 1998). The mean tyrosine requirement was estimated at $6.0 \mathrm{mg}^{\mathrm{kg}} \mathrm{g}^{-1} \cdot \mathrm{day}^{-1}$. The resultant mean and safe level of aromatic amino acid requirement was 15 and $21 \mathrm{mg}^{\mathrm{kg}^{-1}}$.day ${ }^{-1}$. 
This represents a balance of requirement between the aromatic amino acids of 60:40 (phenylalanine:tyrosine).

Similarly, House et al, (1997), using the direct oxidation technique estimated the phenylalanine requirements in the presence of excess tyrosine, of TPN fed neonatal piglets. The mean phenylalanine requirement estimate was $0.45 \mathrm{~g} \cdot \mathrm{kg}^{-1} . \mathrm{day}^{-1}$. When combined with the results from a previous study on tyrosine requirements in the same lab, the authors concluded that phenylalanine and tyrosine contributed to 54 and $46 \%$ respectively of the total aromatic amino acid requirement.

Similar ratios of phenylalanine to tyrosine have also been found in the fetal body (Widdowson, 1981). In her analysis of the amino acid make-up of the fetal body, Widdowson (1981) found that phenylalanine and tyrosine represented 282 and $199 \mathrm{mg}$ per gram of total amino $\mathrm{N}$ in the free and bound amino acid pool of the fetal body. This represents a ratio of 59:41 phenylalanine to tyrosine.

Based on the factorial approach, protein requirement equals the quantity of protein needed for growth plus the quantity needed to replace obligatory losses (Denne, 1992). This same approach can be applied to the requirement for the indispensable amino acid; phenylalanine. The main routes of obligatory losses are irreducible (obligatory) oxidation, losses from skin and GI tract, urinary excretion, irreversible modification and synthesis of non-protein substances (Fuller \& Garlick, 1994). It can be assumed that in PKU because the defective enzyme means reduced or no oxidative losses, the dietary requirement 
for phenylalanine would be less than in the normal individual. In a study looking at the decreased requirement in PKU (Ruch et al, 1982), it was found that the average dietary phenylalanine required to maintain plasma levels between 345 to $430 \mu \mathrm{M}$ in classical PKU was 68,58 and $50 \%$ of estimated normal requirement of $47-90 \mathrm{mg} \cdot \mathrm{kg}^{-1}$. day ${ }^{-1}$ (Holt \& Snyderman, 1967) for 0 to 4,4 to 12 and 12 to 24 month aged infants respectively.

\subsection{Phenylalanine Requirement in Classical PKU}

Presently, data on requirement estimates for normal children between the ages of 2 to 10 years is lacking. Using $\mathbf{N}$ balance (Nakagawa et al, 1962, 1964), the phenylalanine requirements of 10-12 year old boys were estimated. The results from these studies showed that the lowest level of phenylalanine (in the absence of tyrosine) required to keep all boys in positive balance was $27 \mathrm{mg} . \mathrm{kg}^{-}$ '.day'. Current recommendations are based on these estimates, (FAOMHO/UNU,1985). Given the methodological problems with the $\mathrm{N}$ balance technique (section 2.7.1), those estimates are believed to be too low.

Using growth and $\mathrm{N}$ retention as the criteria of adequacy, Holt and Snyderman, (1967) estimated the phenylalanine requirements of infants, in the presence of tyrosine to be between 47-90 mg. $\mathrm{kg}^{-1}$. day ${ }^{-1}$. They concluded, based on their experiences with 27 PKU patients, that the phenylalanine requirements in infants with PKU were not different from that of normal infants. However, in 
their study, they failed to classify the PKU patients into different groups based on enzyme activity. In addition, clinics using Holt and Snyderman's estimates of phenylalanine requirement to treat children with PKU saw very high plasma phenylalanine levels, above target treatment levels, in those children (Berry et al, 1970).

In a retrospective study looking at the phenylalanine intakes of two children with PKU (Kindt \& Holversen, 1980), the authors concluded that there was no difference between the requirements of normal children and those of the 2 PKU children they studied. This conclusion was reached although one of the children's phenylalanine intake was $55 \%$ of the requirement estimated by Holt \& Snydeman, (1967) (47-90 mg.kg ${ }^{-1}$. day $\left.^{-1}\right)$ for normal children. In addition, the child's plasma phenylalanine was maintained around $800 \mu \mathrm{M}$ despite the aim to keep levels between 242 and $484 \mu \mathrm{M}$. The intake needed to keep the plasma phenylalanine of the other child within the treatment range was $72 \%$ of the requirement estimated by Holt \& Snyderman, (1967) for normal children.

In another retrospective study (Ruch et al, 1982), the authors evaluated the intake of 2 classical and 4 variant PKU children who were followed for 2 years. They compared phenylalanine intake of those PKU children to current requirement estimates (Holt \& Snyderman, 1967) and to estimates from the PKU collaborative study (Acosta et al, 1977) at 0 to 4, 4 to 12, and 12 to 24 months. There was an inverse relationship with age and phenylalanine requirement as found in previous studies (Holt \& Snyderman, 1967, Kindt et al, 1980) of phenylalanine requirements of normal and PKU children. Although the children 
in the study were in fairly good control (plasma phenylalanine 340 to $430 \mu \mathrm{M}$ ), intakes of phenylalanine required to achieve such a level of control was 68,58 and $50 \%$ of the estimated normal requirement for phenylalanine in these children. Children with variant PKU needed greater amounts of phenylalanine in order to achieve similar plasma phenylalanine levels as children with classical PKU. They concluded that this reflected an increased ability to catabolize the amino acid.

In a recent study in which phenylalanine oxidation rate was measured in vivo using $L-\left[1-{ }^{13} \mathrm{C}\right]$ phenylalanine, (Treacy et al,1997) these authors found that when ${ }^{13} \mathrm{C}$ phenylalanine oxidation was expressed as a $\%$ of dose, subjects with classical PKU were able to oxidize only $0-3 \%$ of the ${ }^{13} \mathrm{C}$ phenylalanine, whereas those with variant PKU, had increased oxidation of $0.9-10.8 \%$ relative to normal control subjects. This study underlines the importance of proper classification of patients when studying requirement in a PKU population. The study's usefulness is also underlined by the fact that they were able to detect a difference in oxidation rates between obligate heterozygotes and the control subjects.

From that study, it seems obvious that individuals with classical PKU have very little if any, ability to oxidize phenylalanine. Because obligatory losses are a part of the dietary requirements for an amino acid and because obligatory oxidation forms the largest part of obligatory losses, it follows that the dietary phenylalanine requirement estimates in children with classical PKU should be lower than the phenylalanine requirement in normal children. The dietary 
requirements for phenylalanine therefore, in children with classical PKU should correspond to the requirements for growth and other losses (previously listed) minus oxidative losses.

\subsection{Methods for Determining Amino Acid Requirements}

\subsubsection{Nitrogen Balance}

Nitrogen balance is still the most widely used method for estimating amino acid requirements. It is based on a balance between the estimates of nitrogen intake and nitrogen output. Current estimates of requirements for amino acids in adults are based on nitrogen balance (FAOMHO/UNU, 1985). While these studies have made valuable contributions to present knowledge of amino acid requirements, they have been criticized on a number of methodological difficulties (Matthews, 1992, Fuller \& Garlick, 1994, Young \& Bier, 1987).

The difficulties with nitrogen balance have been described in detail elsewhere (Fuller \& Garlick, 1994). Briefly, nitrogen balance is insensitive and provides no information about the turnover of nitrogen within the body. Most importantly, nitrogen balance tends to underestimate requirements because of underestimation of losses and overestimation of intake. In addition, due to long periods of adaptation needed to measure nitrogen balance, and the need to feed subjects diets that are deficient or excessive in the amino acids of study, nitrogen balance is unsuitable for use in vulnerable groups like children with PKU. 


\subsubsection{Plasma Amino Acid}

Free amino acids have been described as the currency of protein metabolism (Munro, 1970). It follows that protein metabolism can be regulated by variations in the free amino acid supply to the tissues. In the body of the fasting rat, individual free amino acids differ widely in their pool sizes, with the indispensable amino acids having the smallest pool sizes. Gut and skeletal muscle are the largest reservoir of free amino acids accounting for 50 to $80 \%$ of the total free amino acid in the animal (Munro,1970). In contrast plasma contains only a very small proportion of the total free amino acids in the body, from 0.2 to $6 \%$ (Munro, 1970). Because the plasma pool is so small, changes occurring therein may not be representative of the changes occurring in the free amino acid pool of the body. Nevertheless, because of its accessibility, plasma is frequently sampled for free amino acid determination (Munro, 1970).

The use of plasma amino acid as an estimate of requirement represents a static measurement which provides no information about the movement of amino acid into and out of proteins. In addition, many factors unrelated to nutritional intake may influence plasma amino acid including fever, reduced absorption, decreased rate of release from existing protein, increased synthesis or increased used of amino acid for gluconeogenesis (Denne, 1992). However, When used in conjunction with other methods, for example nitrogen balance or kinetics, plasma amino acids concentration can provide valuable information about amino acid and protein intakes. 


\subsubsection{Direct Amino Acid Oxidation}

Direct amino acid oxidation has been utilized extensively by the MIT group in the estimation of amino acid requirements in the adult human. This method measures the oxidation rates of an amino acid (using stable isotopes) in response to graded intakes of that amino acid. The technique is based on the concept that amino acid in excess of that needed for protein synthesis is oxidized (Zello et al, 1995). When an amino acid is provided in deficient amounts, most of that amino acid is conserved for protein synthesis and the oxidation rate remains low and constant. As the intake of that amino acid is increased above requirement for protein synthesis, oxidation also increases (Zello et al, 1995). Based on this method, requirements for only the amino acids that lose their $\mathrm{CO}_{2}$ in breath upon oxidation can be measured.

This method has been criticized (Millward \& Rivers, 1986) on the grounds that the requirement estimates are too high. Another criticism was that due to the increase in pool size of the test amino acid there is excessive dilution of the tracer, which can cause the requirement estimate to be erroneous. The question of whether prior adaptation to a particular level of amino acid affect the requirement estimate has been addressed by Zello et al (1990) who found that prior adaptation to different levels of intakes (at least in the short term) had no effect on the phenylalanine requirement of adult males (Zello et al, 1990).

Although direct oxidation has provided valuable information on amino acid kinetics and requirements, such a method is unsuitable for the estimation of phenylalanine requirement in a PKU population due to absence of activity in the 
enzyme responsible for controlling the initial step in the oxidative catabolism of phenylalanine.

\subsubsection{Indicator Amino Acid Oxidation}

The indicator amino acid oxidation technique is based on the principle that the partitioning of any indispensable amino acid between oxidation and protein synthesis is sensitive to the level of the most limiting amino acid in the diet. When an indispensable amino acid is limiting in the diet for protein synthesis, all other amino acids are in excess and therefore must be oxidized (Zello et al, 1995). It follows that as the dietary level of the limiting amino acid is increased in graded amounts, the uptake of all other amino acids for protein synthesis will increase, leading to a decrease in their oxidation. This decrease in oxidation occurs until requirements are met, after which further increases of the limiting amino acid (test amino acid) will have no effect on the uptake of other indispensable amino acids (the indicator) for protein synthesis or oxidation (Kim et al, 1983, Kim \& Bayley, 1983, Ball \& Bayley, 1984)

The indicator amino acid oxidation technique overcomes the problem of increased pool size of the test amino acid, which potentially leads to an overestimation of requirements, when direct oxidation technique is used. With the indicator amino acid technique, neither the level of the indicator amino acid in the diet nor the ratio of the label to the unlabelled amino acid in the diet changes. As a result, the pool size of the amino acid being oxidized remains 
constant throughout the study, with only the pool size of the test amino acid being allowed to change (Zello et al, 1995).

Of the indispensable amino acids, only phenylalanine, lysine and the branched chain amino acids; leucine, isoleucine and valine, have a carboxyl carbon atom that is irreversibly oxidized in breath (Zello et al, 1990). This allows for the calculations of their oxidation rates from appearance of a ${ }^{13} \mathrm{C}$ label in breath. Consequently, the technique of direct oxidation can only be used to estimate requirements for these indispensable amino acids. With indicator amino acid oxidation however, the requirement of any indispensable amino acid can be measured once a suitable indicator amino acid has been selected.

The suitability of lysine as an indicator was tested (Bross, 1997), when it was used for the first time in humans to estimate tyrosine requirement in a PKU population similar to the present population. Lysine metabolism has been discussed in detail in that body of work (Bross, 1997). Briefly, its suitability as an indicator is highlighted by the fact that its metabolism follows two major pathways, that of protein synthesis or oxidation with the consequent excretion of $\mathrm{CO}_{2}$ in breath. In addition, the pattern of oxidation observed was similar to that of previous studies in which phenylalanine was used as an indicator (LazarusBrunner et al, 1998, Duncan et al, 1996, Zello et al, 1993). The results of Bross's study (Bross, 1997) indicate that lysine can be used as a suitable indicator for the estimation of human amino acid requirements.

Prior adaptation is not necessary before measuring amino acid oxidation in response to changes in intake levels (Zello et al, 1990). This allows for the 
study of a wider range of intakes with less ethical concerns because the subjects receive the inadequate or excessive intake for only one day (Zello et al, 1995). This is especially advantageous in children with PKU because feeding excessive or deficient levels of phenylalanine over prolonged periods, (besides the ethical implications), may have adverse metabolic consequences.

Indicator amino acid oxidation provides a functional approach to measuring amino acid requirements. It is safe, non-invasive and can be used in vulnerable groups like children with PKU. The indicator amino acid oxidation applies the stochastic modeling technique (Waterlow et al, 1978) for the measurement of amino acid kinetics. This model makes the following assumptions: (1) the size of the metabolic pool with respect to both labeled and unlabeled indicator amino acid (lysine in present study) is constant during the plateau. (2) there is no significant re-entry of isotope into the metabolic pool during plateau. (3) ${ }^{13} \mathrm{C}$ is treated in the same way as ${ }^{12} \mathrm{C}$ and (4) amino acids derived from the diet and from the catabolism of protein are handled in the same way (Picou \& Taylor-Roberts, 1969).

With the sampling of the urinary enrichment being recognized as a viable alternative to the sampling of the plasma enrichment (De Benoist et al, 1984, Wykes et al, 1990, Bross, 1997), the indicator method has gained the added advantage of being a completely non-invasive method for the estimation of amino acid requirement. Consequently it is a most attractive method for estimating amino acid requirement in vulnerable groups like children with PKU. It is safe, subjects are only exposed to the deficient or excessive intake for a 
very short period (usually one day), and it give information about requirement as well as valuable information about amino acid kinetics and balance, in relation to protein balance.

\section{RATIONALE, OBJECTIVES AND HYPOTHESIS}

\subsection{Rationale}

The requirement for the aromatic amino acids is represented by a balance between phenylalanine and tyrosine of about 55:45. This balance is supported by data from human studies (Zello et al, 1990, Roberts, 1998), as well as data from animal studies (House et al, 1997). Further support for this balance is provided by a study looking at the composition of human fetal tissue (Widdowson, 1981).

Using indicator amino acid oxidation technique, the mean tyrosine requirement of a similar (to present study population) PKU population was estimated to be $19.2 \mathrm{mg} \mathrm{kg}^{-1} \cdot \mathrm{day}^{-1}$ (Bross, 1997). Using this estimate and the ratio presented, above the mean phenylalanine requirement can be predicted to be approximately $23.5 \mathrm{mg} \cdot \mathrm{kg}^{-1}$.day ${ }^{-1}$. However, individuals with classical PKU have negligible or very minimal capacity to oxidize phenylalanine (Treacy et al, 1997). In addition, requirement for phenylalanine or any other indispensable amino acid is the sum of the total of that needed for protein synthesis plus 
irreversible losses (Fuller \& Garlick, 1994). Because the main component of irreversible losses is irreversible (obligatory) oxidation (Fuller \& Garlick, 1994), it follows that phenylalanine requirement in PKU should be less than $23.5 \mathrm{mg} . \mathrm{kg}^{\circ}$ ${ }^{1}$. day $^{-1}$.

In a study on phenylalanine requirement in adult males (Zello et al, 1990), obligatory oxidation was estimated to be approximately $26 \%$. Since there are no studies in the literature from which obligatory phenylalanine oxidation in children can be estimated, this estimate of $26 \%$ in adults was used to represent the approximate obligatory phenylalanine oxidation in children. Using the predicted $23.5 \mathrm{mg} \mathrm{kg}^{-1}$.day ${ }^{-1}$ phenylalanine requirement and this $26 \%$ estimated obligatory oxidation, the obligatory loss can be calculated to be approximately $6.1 \mathrm{mg} . \mathrm{kg}^{-}$ ${ }^{1}$.day'. When this estimate of obligatory loss is subtracted from the predicted requirement of $23.5 \mathrm{mg} \cdot \mathrm{kg}^{-1} . \mathrm{day}^{-1}$, the resulting prediction of $17.4 \mathrm{mg} \cdot \mathrm{kg}^{-1} . \mathrm{day}^{-1}$ is the phenylalanine requirement predicted for children with PKU. This predicted phenylalanine requirement of $17.4 \mathrm{mg}^{\mathrm{kg}}{ }^{-1}$. day ${ }^{-1}$ is equal to or less than the mean tyrosine requirement in similar children with PKU.

\subsection{Hypothesis}

We hypothesized that the safe phenylalanine requirement of children with classical PKU will be approximately equal to the mean tyrosine requirement. 


\subsection{Objective}

The objective of this study was to determine the phenylalanine requirement of children with classical PKU using the technique of indicator amino acid oxidation, and to compare them to the estimated tyrosine requirement from the same laboratory using the same technique.

\section{METHODS}

\subsection{Study Population}

Five children with classical PKU, treated by the PKU Clinic at the Hospital for Sick Children, Toronto, ON participated in this study. All subjects were studied on an outpatient basis. Each subject was screened based on the following criteria:

Inclusion Criteria:

- plasma phenylalanine concentration $\geq 1200 \mu \mathrm{M}$ at diagnosis

- prepubertal males or females 5-13 years old in good health

- treated by dietary phenylalanine restriction from early infancy

- $\quad$ willingness to participate in the study 


\section{Exclusion Criteria:}

- use of any medication that may alter protein or energy metabolism

- recent illness

$-\quad 1 Q<80$

- history of endocrine disease or any other medical condition that may alter protein and energy metabolism

- significant weight changes ( $>10 \%$ of body weight) in the three months before the study.

Subject characteristics at the beginning of the study are summarized in Table 4.1. The purpose of the study, study procedures, benefits and potential risks were explained to the study participants and their parents. Written consent was obtained from each parent and assent was obtained separately from each child. In addition, detailed information sheets about the study day protocol were provided. The information sheet and consent forms are found in Appendix 10.1. 10.2., and 10.3. respectively. All procedures used in the study were approved by the Human Subjects Review Committee, of The Hospital for Sick Children. 
Table 4.1 Subject Characteristics of Children with Phenylketonuria (PKU) who participated in the Phenylalanine Requirement Study

\begin{tabular}{|c|c|c|c|c|c|c|c|}
\hline Subject & Sex & $\begin{array}{c}\text { Age } \\
\text { (years) }\end{array}$ & $\begin{array}{l}\text { WT. } \\
\text { (kg) }\end{array}$ & $\begin{array}{l}\text { HT. } \\
\text { (cm) }\end{array}$ & \% IBW' & $\begin{array}{l}\text { FFM- } \\
\text { BIA } \\
(\mathrm{kg})\end{array}$ & $\begin{array}{l}\text { FFM- } \\
\text { SF }^{3} \\
(\mathbf{k g})\end{array}$ \\
\hline$\overline{\mathbf{L F}}$ & $F$ & 10 & 39.5 & 148.2 & 85.9 & 32.0 & 30.8 \\
\hline DN & $M$ & 6 & 22.5 & 119.1 & 102.3 & 19.0 & 20.6 \\
\hline AS & $\mathbf{F}$ & 10 & 39.4 & 148.6 & 90.0 & 31.2 & 29.2 \\
\hline BS & $\mathbf{M}$ & 12 & 40.5 & 154 & 92.1 & 33.2 & 33.6 \\
\hline $\mathbf{A P}$ & $\mathbf{M}$ & 13 & 36.9 & 145.4 & 104.2 & 28.9 & 30.6 \\
\hline $\begin{array}{l}\text { Mean } \pm \\
\text { SEM }\end{array}$ & & $\begin{array}{r}10.2 \\
\pm 1.2\end{array}$ & $\begin{array}{l}35.8 \\
\pm 3.4\end{array}$ & $\begin{array}{l}143.1 \\
\pm 6.2\end{array}$ & $\begin{array}{r}94.9 \\
\pm 3.6\end{array}$ & $\begin{array}{l}28.9 \\
\pm 2.6\end{array}$ & $\begin{array}{r}29.0 \\
\pm 2.2\end{array}$ \\
\hline
\end{tabular}

IBW = Ideal body weight; determined by matching weight percentile to actual height percentile and dividing actual weight by matched weight $\times 100 \%$

${ }^{2} \mathrm{FFM}-\mathrm{BIA}=$ Fat free mass determined by bioelectrical impedance analysis

${ }^{3} \mathrm{FFM}-\mathrm{SF}=\mathrm{Fat}$ free mass determined by multiple skinfold thickness

$M=$ male,$F=$ female 


\subsection{Experimental Design}

Four of the five subjects were studied within a two-month period while the other subject was studied within a three-month period because minor illness prevented his attendance on two previously scheduled study days. All studies were conducted between May and August, 1998. On each study day, the subjects received one of each of the test phenylalanine intakes in an order that bracketed the mean phenylalanine requirement. Order of test phenylalanine intakes was not randomly assigned, as we were unaware of the exact position of the mean requirement. However, previous experiments have found that order was not significant (Zello et al, 1990, Duncan et al, 1997). Each subject was studied at all six levels of phenylalanine, $0,10,15,20,25$ and $35 \mathrm{mg} \mathrm{kg}^{-1}$. day $^{-1}$ to allow an estimation of each individual's requirement.

\subsection{Experimental Diet}

A flavored liquid formula (Protein-Free Powder, Product 80056, Mead Johnson, Evansville, IN) and protein free cookies (Zello et al, 1990) developed for use in amino acid kinetic studies supplied the energy in the diet. The diet was prepared and weighed (Sartorius Balance, model BP110 S, Sartorius Canada Inc.) in the research kitchen at The Hospital for Sick Children. The diet was administered on the study day as eight isocaloric, isonitrogenous, hourly meals. Each meal represented $1 / 8^{\text {th }}$ of the subject's total daily requirements. The macronutrient composition of the experimental diet, expressed as a 
percentage of dietary energy was approximately $37 \%$ fat, $52 \%$ carbohydrate and $11 \%$ fat (Zello et al, 1990).

The nitrogen content of the diet was in the form of a crystalline amino acid mixture. This was based on the amino acid composition of egg protein and provided the only source of dietary nitrogen (Table 4.2). The amino acid mixture (protein) was provided to each child on each study day as $1.5 \mathrm{~g} . \mathrm{kg}^{-1}$.day ${ }^{-1}$ (Table 4.3). The safe level of dietary protein intake for children is $1.06 \mathrm{~g}^{\mathrm{kg}}{ }^{-1}$ (age 4 to 6 years), $1.01 \mathrm{~g}^{\mathrm{kg}}{ }^{-1}$ (age 10 to 12 years), and 0.98 and $0.95 \mathrm{~g}^{\mathrm{kg}}{ }^{-1}$ (age 13 to 15 years) for male and female respectively, (Health \& Welfare Canada, 1990). Based on current recommendations, the study day protein intake of $1.5 \mathrm{~g}^{\mathrm{kg}} \mathrm{g}^{-1}$ was adequate to meet the protein needs of these children.

Total energy requirement for each subject was calculated from the subject's BMR determined using FAOMHO (1985) equation and multiplied by an activity factor of 1.5 for sedentary activities (Health \& Welfare Canada, 1990). Weight and height were estimated using the growth chart of each subject for calculation of the first study day energy and protein requirement. Thereafter, energy and protein requirements for subsequent study days were calculated using the height and weight obtained on the previous study day. Mean energy intakes for each child over the 6 study days are presented in Table 4.3. 
Table 4.2 Composition of L-Amino Acid Mixture

\begin{tabular}{|l|c|c|}
\hline \multicolumn{1}{|c|}{$\begin{array}{c}\text { AMINO } \\
\text { ACID }\end{array}$} & \multicolumn{2}{c|}{ MIXTURE (g/kg) } \\
\hline & EGG PROTEIN & A.A. MIX \\
\hline L-Alanine & 61.00 & Variable \\
\hline L-Arginine & 61.66 & 61.66 \\
\hline L-Asparagine & 33.00 & 33.00 \\
\hline L-Aspartic Acid & 33.00 & 33.00 \\
\hline L-Cysteine & 21.94 & 21.94 \\
\hline L-Glutamine & 56.20 & 56.20 \\
\hline L-Glutamic Acid & 56.20 & 56.20 \\
\hline L-Glycine & 33.00 & 33.00 \\
\hline L-Histidine & 22.53 & 22.53 \\
\hline L-lsoleucine & 62.35 & 62.35 \\
\hline L-Leucine & 82.64 & 82.64 \\
\hline L-Lysine & 60.12 & 42.67 \\
\hline L-Methionine & 29.45 & 29.45 \\
\hline L-Phenylalanine & 54.24 & 26.8 \\
\hline L-Proline & 41.62 & 69.72 \\
\hline L-Serine & 83.24 & 41.62 \\
\hline L-Threonine & 46.73 & 83.24 \\
\hline L-Tryptophan & 15.48 & 46.73 \\
\hline L-Tyrosine & 40.42 & 15.48 \\
\hline L-Valine & 69.72 & Varable \\
\hline & & \\
\hline
\end{tabular}

'United States Biochemical Corporation, Cleveland, Ohio, USA

Iysine weighed separately as Lysine plus $1 f^{13} \mathrm{C}$-Lysine]

phenylalanine weighed separately 
Tyrosine was provided at an intake of $32 \mathrm{mg} \mathrm{kg}^{-1} \cdot$ day $^{-1}$ (Table 4.3). This represented the 95\% safe population estimate as determined by Bross, (1997) plus an additional $20 \%$ and should have been more than adequate to meet the tyrosine needs of all the subjects.

Lysine, which was used as the indicator amino acid, was provided at 64 mg.kg-1.day ${ }^{-1}$. This is the amount used by Bross, (1997), in her study on tyrosine requirements for similar children with PKU, in which lysine was the indicator amino acid. Sixty four $\mathrm{mg}^{\mathrm{kg}} \mathrm{g}^{-1}$.day ${ }^{-1}$ represents the lysine requirements suggested by FAOMHO (1985) for children 2 years old and is higher that the requirement suggested for boys 10-12 years old for whom requirements is defined as $44-60$ mg.kg-1.day ${ }^{-1}$. Because normal daily dietary lysine intake of these subjects varied between 59 and $78.5 \mathrm{mg} \cdot \mathrm{kg}^{-1} . \mathrm{dy}^{-1}$ (calculated from food records), this level of lysine should have been sufficient to meet the lysine needs of all subjects in the study and would have ensured that lysine was neither in excess nor did it become the limiting amino acid.

Phenylalanine was provided at graded intakes of $0,10,15,20,25$, and 35 mg.kg-1.day ${ }^{-1}$. The 10 and 15 mg. $\mathrm{kg}^{-1}$. day $^{-1}$ levels represent 66, and $100 \%$ respectively of the minimum recommended daily intake for children with PKU (Elsas \& Acosta, 1988). The intake of $20 \mathrm{mg} \mathrm{kg}^{-1}$. day $^{-1}$ represents a predicted requirement equal to the tyrosine requirement determined by Bross, (1997) and $25 \mathrm{mg} \cdot \mathrm{kg}^{-1}$. day $^{-1}$ represents the level of phenylalanine equal to $55 \%$ of the total aromatic amino acid requirement. Finally, $35 \mathrm{mg} \cdot \mathrm{kg}^{-1}$.day ${ }^{-1}$ represents the upper 
limit of the phenylalanine recommendation for children with PKU between the ages of 4 to 7 years (Elsas \& Acosta, 1988).

Study day lysine and phenylalanine intakes were weighed separately from the other amino acids within the mixture in order to ensure that their intakes were tightly controlled. 
Table 4.3 Nutrient Intake of Children with Phenylketonuria During Six-Day Study Period

\begin{tabular}{|c|c|c|c|c|}
\hline Subject & $\begin{array}{l}\text { Energy Intake } \\
(\text { Mean } \pm \text { SEM) }\end{array}$ & $\begin{array}{l}\text { Protein Intake } \\
\text { (g. } \mathrm{kg}^{-1} \cdot \text { day }^{-1} \text { ) }\end{array}$ & $\begin{array}{l}\text { Lysine Intake } \\
\left(\mathrm{mg.kg}^{-1} . \text { day }^{-1}\right)\end{array}$ & $\begin{array}{l}\text { Tyrosine Intake } \\
\left(\mathrm{mg} \cdot \mathrm{kg}^{-1} \cdot \mathrm{day}^{-1}\right)\end{array}$ \\
\hline LF & $2129 \pm 15$ & 1.5 & 64 & 32 \\
\hline DN & $1505 \pm 18$ & 1.5 & 64 & 32 \\
\hline AS & $2139 \pm 5$ & 1.5 & 64 & 32 \\
\hline BS & $2099 \pm 5$ & 1.5 & 64 & 32 \\
\hline AP & $1993 \pm 7$ & 1.5 & 64 & 32 \\
\hline
\end{tabular}

${ }^{1}$ Energy in kilo-calories (kcal) per day 


\subsection{Body Composition Measurements}

Subjects' heights and weights were measured on the morning of each study day. Standing heights were measured without shoes, to the nearest $0.1 \mathrm{~cm}$ using a wall-mounted stadiometer. Subjects were weighed on a balance scale (Toledo Scale, Model 2020, Windsor, ON) to the nearest $0.1 \mathrm{~kg}$ while wearing light clothing.

Body composition, (fat and fat free mass) was determined using bioelectrical impedance analysis and multiple skinfold thickness measurements, because we wished to relate phenylalanine requirement to body composition and monitor changes in body composition over the study period. BIA was performed at the beginning of each study day prior to meal ingestion.

Resistance (R) and reactance (Xc) measurements were done using a 4-terminal bioimpedance analyzer (RJL Systems, Model 101A, Detroit, MI), while the subject lay in a supine position on a hospital bed with all four limbs apart. Two detector electrodes were placed on the dorsal surfaces of the right hand and foot, proximal to the metacarpal-phalangeal and metatarsal-phalangeal joints respectively. Two detector electrodes placed at the right pisiform prominence of the wrist, with the proximal edge dissecting the ulnar tubercle, and between the medial and lateral malleoli, with the proximal edges dissecting the medial malleolus. An excitation current of $800 \mu \mathrm{A}$ at a fixed frequency of $50 \mathrm{kHz}$ was introduced into the subject at the distal electrodes of the hand and foot, and the voltage drop was detected by the proximal electrodes. Three readings for both 
reactants and resistance (in Ohms) were taken for each subject and the mean of the three readings was used to determine Fat Free Mass (FFM). The equation used was; $F F M=0.61 \mathrm{Ht}^{2} / R+0.25 \mathrm{Wt}+1.31$ for ages 1 to 15 years (Houtkooper et al. 1992). Where $\mathrm{Ht}=$ height $(\mathrm{cm}), \mathrm{R}=$ resistance (ohms), and $W t=$ weight $(\mathbf{k g})$.

Multiple skinfold thickness measurements, like BIA, were performed at the beginning of each study day prior to meal ingestion. Measurements were taken from 4 different sites on the subject's non-dominant side; triceps, biceps, subscapula and suprailliac. In order to eliminate inter-observer variability in measurement each measurement was done by the same individual. A total of 3measurements from each site were taken using a skinfold caliper (British Indicators Ltd.) and the average value was used in the equation. Body density was derived from the sum of the 4 skinfolds using an age specific equation and another equation was used to predict percentage of body fat. The equations used for calculating body density were (Brook, 1971), age 1 to 11 years male: d $=1.1690-0.0788 \log (\Sigma S F)$, female: $d=1.2063-0.0999 \log (\Sigma S F)$. For ages 11 to 17 years (Durnin \& Rahaman, 1967), male: $d=1.1533-0.0643 \log (\Sigma S F)$. The equation used for calculating percentage body fat was (Siri, 1956), Fat \% = $(4.95 / d-4.5) \times 100$. 


\subsection{Oral lsotope Infusion Studies}

The stable isotope used in this study was $L-\left[1-{ }^{13} \mathrm{C}\right] l y s i n e . H C L$, with an enrichment of $99 \%$ (Mass Trace, Woburn, MA). Quality control tests were performed by the manufacturer. Chemical purity, isotope enrichment and position were confirmed by GCMS and a second confirmation was performed by nuclear magnetic resonance (NMR). Isometric purity (<0.2\% D-isomer) was confirmed by GC/FID. A stock solution of $10 \mathrm{mg} \cdot \mathrm{mL}^{-1}$ was prepared using sterile water. From the stock solution, the priming and continuous bolus doses were dispensed into multiple vials. Each subject was given a priming oral dose of L$\left[1{ }^{13} \mathrm{C}\right]$ lysine in the amount of $2.5 \mathrm{mg} \cdot \mathrm{kg}^{-1}\left(17.1 \mu \mathrm{M} . \mathrm{kg}^{-1}\right)$ and eight subsequent oral bolus doses of equal amounts; $1.4 \mathrm{mg} \cdot \mathrm{kg}^{-1} \cdot \mathrm{h}^{-1}\left(4.79 \mu \mathrm{M} . \mathrm{kg}^{-1}\right)$. The isotope doses used in this study were based on work done by Bross, (1997) in which it was determined that $L-\left[1-{ }^{13} \mathrm{C}\right]$ lysine, administered orally could produce an isotopic steady state in plasma, urine and breath of similar children, within two hours.

A total of $\mathbf{3 0}$ oral isotopic infusion studies were conducted. Each of the five subjects underwent six isotope studies. The studies were conducted in the calorimetry-research lab at The Hospital for Sick Children. A typical study day protocol is presented in Figure 4.1. Eight hourly, isocaloric, isonitrogenous meals were consumed beginning 4 hours before the start of the oral isotope infusion. The amount of lysine in each meal was held constant. This was achieved by reducing the amount of dietary lysine in the last four meals by the same amount corresponding to the $\left[{ }^{13} \mathrm{C}\right]$ lysine administered. 


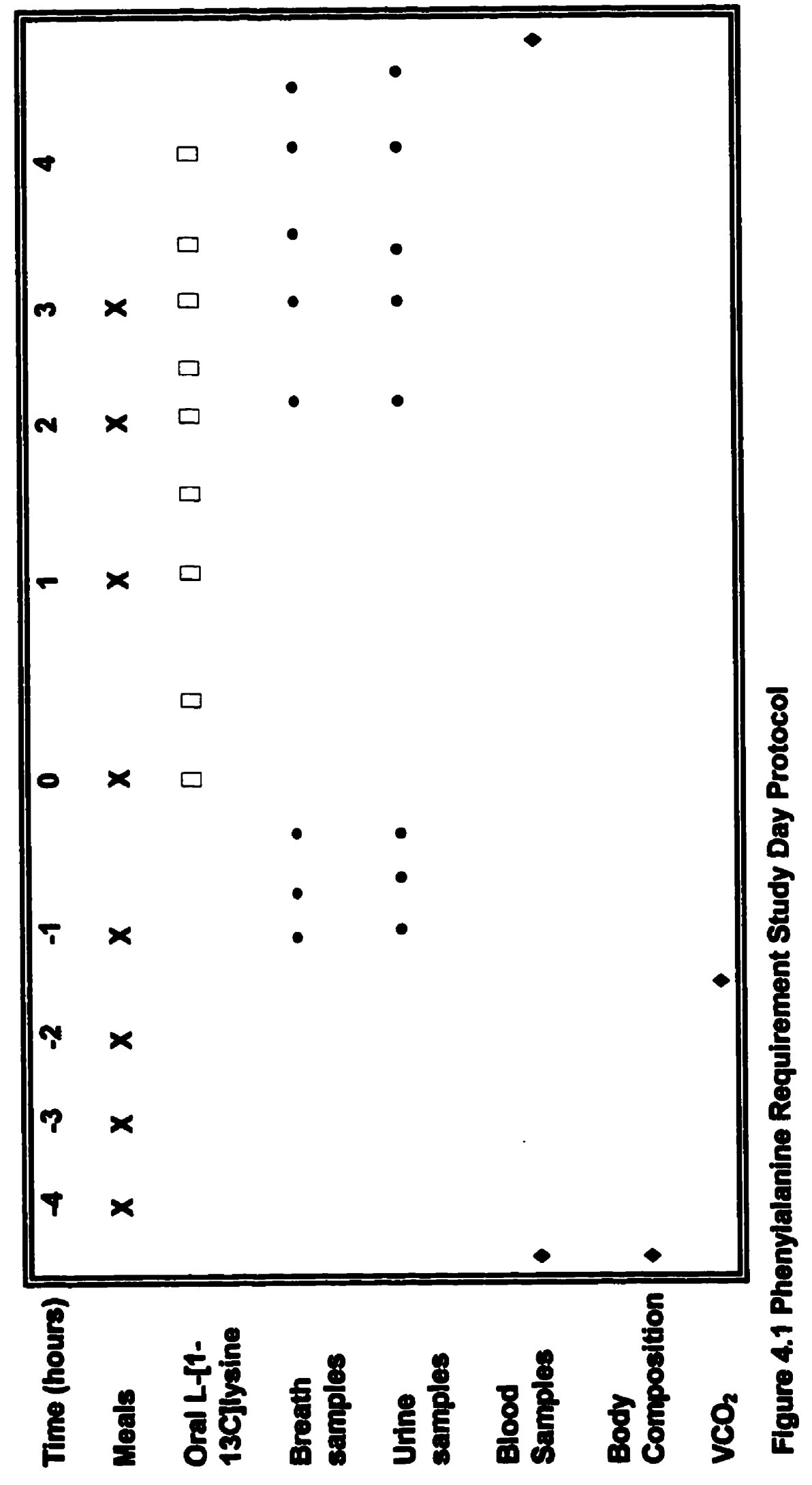


The amount of phenylalanine in each meal was dependent on the test level being studied on that particular study day. Because the amount of phenylalanine in the diet was manipulated, L-alanine was adjusted to keep the nitrogen content of the diet constant. See Appendix $\mathbf{1 0 . 4}$ to $\mathbf{1 0 . 6}$ for study day schedule and for forms used in the diet and isotope calculations and for the collection of study day data.

Between 50 to $75 \mathrm{~mL}$ of water was given with each meal in order to encourage a steady urine production. A practice breath collection was done 2 hours prior to the actual breath collection to acclimatize the subjects to the breath collection procedure. Three baseline samples each of urine and breath were collected at 15 to 20 -minute intervals during the hour prior to isotope infusion. The priming dose of $L-\left[1-{ }^{13} \mathrm{C}\right]$ lysine was administered at 0 hours. Each oral infusion dose was administered every $1 / 2$ hour beginning 15 minutes after the prime. Five samples each of breath and urine were collected to calculate plateau after the steady state dilution of the isotope in the plasma had occurred. These samples were collected at $2.25,2.75,3.25,3.75$, and 4.25 hours. The timing of the isotopic steady state and hence sample collection was based on previous work with the same diets in similar children (Bross, 1997) in which isotopic steady state was achieved within two hours after the start of the oral isotope infusion.

In order to collect the urine samples, subjects were instructed to void into a container from which 2 aliquots of $500 \mu \mathrm{L}$ and 1 aliquot of $1 \mathrm{~mL}$ were collected and stored at $-20^{\circ} \mathrm{C}$ until analysis. 
Breath samples were collected into vacuum tubes while the subjects stood or sat in an upright position. The instrument used for breath collection was The EasySampler, (QuinTron, Milwaukee, Wisconsin, USA). Subjects were instructed to take a normal breath and exhale normally into a bag with their mouths fitted over a mouthpiece. The subjects were instructed to breathe until the bag was filled with air (about $250 \mathrm{~mL}$ air) representing the dead space air. While the subjects continued to breathe, Exetainers@ (Labco Limited, Buckinghamshire, England) were pushed into the needle holder at the bottom of the mouthpiece until the rubber stopper was punctured. The sample was collected into the Exetainers while the subject kept their mouths tightly closed over the mouthpieces. The Exetainers were removed from the needle holder after the subjects stopped breathing. Thereafter, subjects were asked to remove their mouth from the mouthpiece. The Vacuum tubes were then kept at room temperature until analysis. All breath samples were analyzed within one week of study day.

The rate of production of $\mathrm{CO}_{2}\left(\mathrm{VCO}_{2}\right)$ was measured by indirect calorimetry (Vmax 29, SensorMedics Corporation, Yorba Linda, CA). Each measurement was performed while the subject lay comfortably in a supine position on a hospital bed. The Vmax 29 is equipped with two paramagnetic $\mathrm{O}_{2}$ analyzers and an infrared $\mathrm{CO}_{2}$ analyzer. A mass flow sensor regulates the $\mathrm{CO}_{2}$ concentration in the hood between 0.5 and $0.8 \%$. On each study day, prior to $\mathrm{VCO}_{2}$ measurement, the gas analyzers were calibrated with standard gases (Tank 1: $4 \% \mathrm{CO}_{2}, 16 \% \mathrm{O}_{2}$, balanced With $\mathrm{N}_{2}$, Tank 2: $26 \% \mathrm{O}_{2}$ balanced with $\mathrm{N}_{2}$. 
PraxAir Inc, Brampton ON). Each day at calibration the computer automatically updates barometric pressure and temperature at which time the computer readings are verified to ensure $\mathrm{VCO}_{2}$ measurements were taken under standard temperature and pressure.

\subsection{Blood Collection and Analysis}

Capillary blood samples were obtained from a finger prick incision made to the index finger of the non-dominant hand (Softlick Blood letting Device, Boehringer, Laval, Quebec). This was done in order to relate phenylalanine intake to plasma phenylalanine levels because nutritional support in PKU is mainly assessed through monitoring of plasma phenylalanine in response to dietary intake. In order to ensure adequate blood flow the hand was heated inside a thermostatic chamber maintained at $60^{\circ} \mathrm{C}$ for at least 15 minutes before the blood was sampled (Zello et al, 1990). While holding the finger, approximately 5 drops ( $<1 \mathrm{~mL}$ ) of blood was gently spotted on Guthrie filter paper (Ministry of Health, Newborn Screening Program) to totally saturate an area of about $1 \mathrm{~cm}$ in diameter. Blood was collected at the beginning of each study day, prior to meal ingestion while subjects was still in the fasted state and again at the end of the study day after each subject had received and consumed all eight meals. At each time, two blood spots were collected. The blood spots were left to air dry overnight, then analyzed for phenylalanine concentration. 
The method used for the quantitative determination of plasma phenylalanine was based on the NAD-dependent reductive deamination of phenylalanine in the presence of excess phenylalanine dehydrogenase (Dooley, 1992). Phenylalanine reacts with the enzyme phenylalanine dehydrogenase (PheDH) and in the process converts NAD to NADH. The NADH can be measured by reaction with indonitrotetrazolium chloride (INT) catalyzed by diaphorase, which forms a coloured formazan product. First, the blood spot was punched out from the sample card using a 3-hole paper punch with bottom removed. Punched out disks were then briefly dipped in methanol to fix the blood proteins then placed in appropriately labeled sample cups to dry overnight. On the day of analysis, $200 \mu \mathrm{L}$ of ultrapure water was added to each sample, which was, then briefly vortexed and then allowed to stand for 10 minutes. The samples, along with the calibrators (stock phenylalanine standards $2000 \mu \mathrm{M}$, working standards $0,3,10,50$ and $150 \mu \mathrm{M}$ ), working reagents 1: (potassium phosphate, triethanolamine buffer, NAD, diaphorase, indonitrotetrazolium chloride, ultrapure water) and working reagent 2: (phenylalanine dehydrogenase, Biocatalysts Wales, U.K.), were then placed on the Cobas Mira Analyzer (Roche Diagnostics, USA). The run was programmed after which the Cobas Mira did a calibration followed by the analysis of the programmed samples. The coefficient of variation over time of analyzed samples on the Cobas Mira is 21.9, 9.3 and 11.8 for samples with mean phenylalanine concentration of $67,204.6$ and $550.6 \mu \mathrm{M}$ respectively. 


\subsection{Analytical Procedures}

The ${ }^{13} \mathrm{CO}_{2}$ enrichment in expired $\mathrm{CO}_{2}$ was measured by a software driven (Ancant System Ver.1.999s) continuous flow isotopic ratio mass spectrometer (CF-IRMS, Model ANCA GSL) (Europa Scientific Inc. Crewe, UK). A CF-IRMS is an elemental analyzer, which converts samples into pulses of pure gas in a continuous helium stream. Excetainers containing breath samples were placed on an autosampler. Each set of eight samples was separated by two reference samples $\left(5 \% \mathrm{CO}_{2}\right)$ which were previously calibrated to an international reference standard (NBS-20), (National Institute for Standards and Technology, Gaithersburg, MD). Breath samples contained within the excetainers were sampled by the autosampler via a syringe. The sample was carried in a stream of helium which passed through the combustion and reduction tubes, then on to the water trap which removed any water molecules present. The sample then progressed through a packed GC column to the mass spectrometer. Following ionization, the ions were separated according to their mass/charge $(\mathrm{m} / \mathrm{e})$ ratio and collected into triple collector Faraday cups. For each mass detected, the machine recorded an area proportional to the number of ions contained. A drift correction between the 2 sets of references was calculated and applied to calculate the exact atom percent (AP) of the unknown sample. The results were obtained as atom percent (AP) which represented the absolute ${ }^{13} \mathrm{C}$ enrichment present in that sample. AP was calculated by the software using the formula: A $($ atom \% $)=($ Ratio amped $(1+$ Ratio sample $) \bullet 100$. The difference between the 
enrichments of samples taken at baseline and plateau were expressed as atom percent excess (APE).

Urine was analyzed for lysine enrichment by the method of Patterson et al (1991) using GCMS. Urine samples $(500 \mu \mathrm{L})$ were deproteinized and acidified with $100 \mu \mathrm{L} 40 \%$ trichloroacetic acid, vortexed, then centrifuged at $13000 \mathrm{rpm} x$ 10 minutes. The supernatant was then transferred to columns containing a cation exchange resin $\left(0.75 \mathrm{~mL}\right.$ ) (Dowex 50W-X8, 100-200 mesh, $\mathrm{H}^{+}$form, BioRad Laboratories, Hercules, CA) for amino acid separation. One $\mathrm{mL}$ of the effluent solution was freeze-dried (Freezone 12L, Labconco Corp., Kansas City, MO) and then derivitized to its $\mathrm{N}$-heptafluorobutyryl n-propyl esters.

The first step in the derivitization process was the addition of $500 \mu \mathrm{L}$ of esterification reagent (1:5 acetyl chloride: propanol made fresh on ice) to all the freeze-dried samples. Samples were vortexed, topped with $\mathbf{N}_{2}$ to avoid oxidation, then heated at $110^{\circ} \mathrm{C}$ for 1 hour. Samples were then cooled and dried under a steady stream of $N_{2}$ at $37^{\circ} \mathrm{C}$. After drying $200 \mu \mathrm{L}$ of the derivative (1:4 heptafluorobutyric anhydride: ethyl acetate) was added to the samples. Samples were vortexed, topped with $\mathbf{N}_{2}$, then heated for 30 minutes at $70^{\circ} \mathrm{C}$. The heated samples were then cooled and dried in the same manner as before. The dried samples were topped with $\mathrm{N}_{2}$ and stored at $5^{\circ} \mathrm{C}$ until analysis. When ready for analysis, samples were reconstituted in $300 \mu \mathrm{L}$ ethyl acetate.

Lysine enrichment was measured on a gas chromotograph (GC, Hewlett Packard, Model 5890 Series 2, Mississauga, ON) attached to a quadrupole mass spectrometer (MS, VG Trio-2, Cheshire, England). Separation of the amino 
acid was performed on a $30 \mathrm{~m} \times 0.32 \mathrm{~mm}$ (inner diameter) $\times 1.0 \mu \mathrm{m}$ (film thickness) fused silica capillary column (HP-5, Hewett Packard, Palo Alto, CA, USA) with helium serving as a carrier gas. The GC column was coupled directly to the ion source, which was set at $160^{\circ} \mathrm{C}$ and operated under negative chemical ionization with ammonia as the reactant gas. Selected ion chromatographs were obtained by monitoring the mass to charge ratio of 560 and 561 for lysine, corresponding to the unenriched $(m)$ and enriched $(m+1)$ ion respectively.

\subsection{Data Analysis}

A stochastic model was used to calculate lysine kinetics (Waterlow et al., 1978). This model assumes a common metabolic pool through which all amino acids move. Any exit of lysine from the pool is by protein synthesis or by oxidation with the consequent excretion of ${ }^{13} \mathrm{CO}_{2}$ in breath. Any entry of lysine into the pool is from dietary intake or from protein breakdown Figure 4.2. At isotopic steady state, the rate of appearance of ${ }^{13} \mathrm{C}$ lysine into the pool is equal the rate of it's disappearance from the pool. This was represented by a plateau of the isotopic enrichment in the breath and urine. At steady state, movement through the metabolic pool is referred to as flux, which is represented by the following equation (Matthews et al, 1980)

$$
Q=B+1=S+0
$$



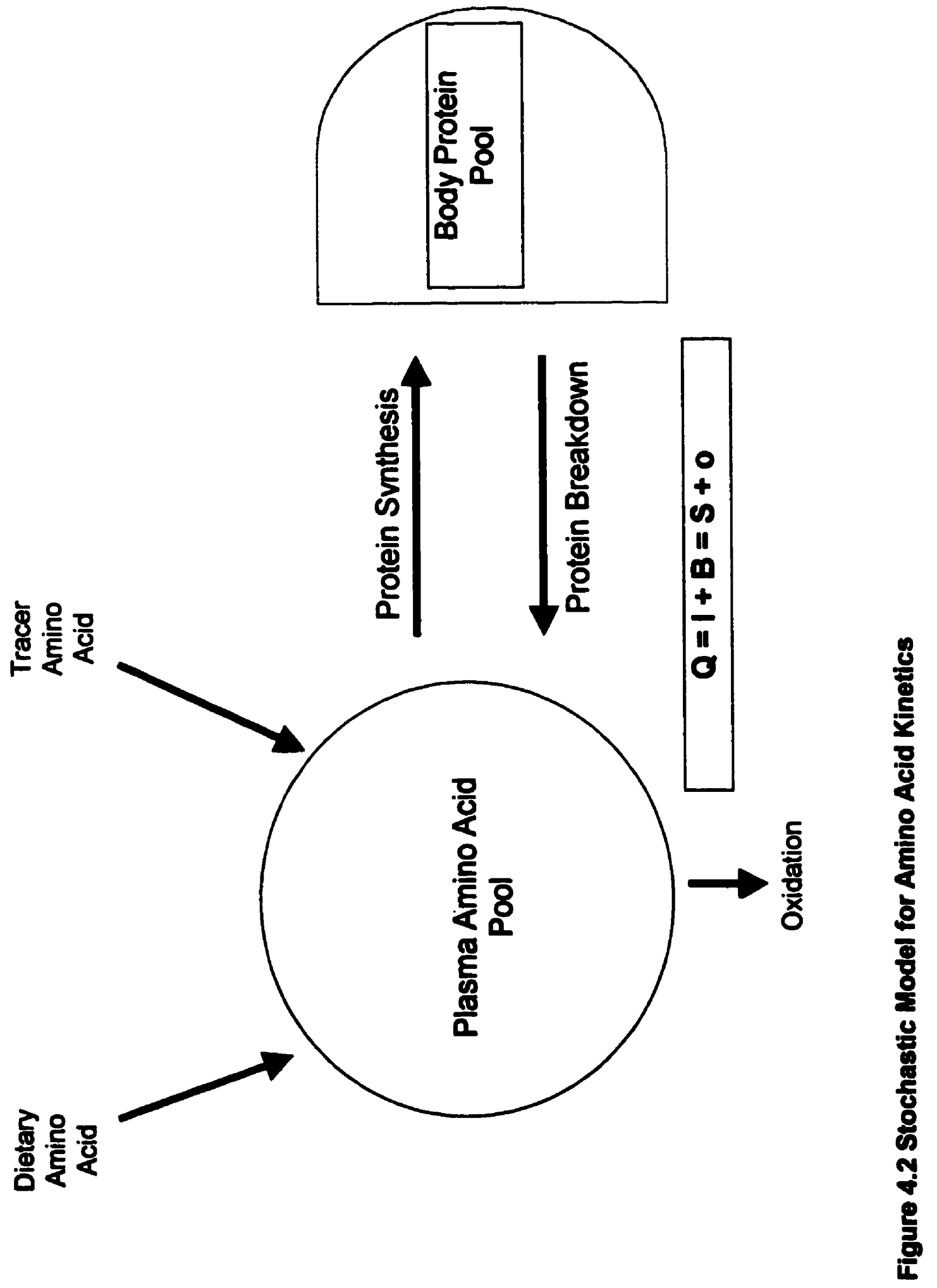
where Q equals the rate of turnover or flux of lysine, B is the rate of release of lysine from protein breakdown, $I$ is the rate of dietary lysine intake, $S$ is the rate of lysine incorporation into protein, and $\mathrm{O}$ is the rate of lysine oxidation.

Isotopic steady state in the metabolic pool was represented by plateau in ${ }^{13} \mathrm{CO}_{2}$ enrichment in breath and in $\left[{ }^{13} \mathrm{C}\right]$ lysine enrichment in urine. This was achieved by 2 hours after the start of the isotope infusion and was maintained to the end of the study at 4 hours. Figure 4.3 and 4.4 show a typical ${ }^{13} \mathrm{CO}_{2}$ and $\left[{ }^{13} \mathrm{C}\right]$ lysine enrichment in breath and urine respectively, at baseline and plateau for an individual study. Isotopic steady state in urine and breath were defined as a coefficient of variation of less than $5 \%$ between sampling time points and the absence of a significant slope. The difference between the mean breath isotope enrichment values of the 3 baseline and 5 plateau samples was expressed as atom percent excess (APE) above baseline at isotopic steady state. Also, the difference between the mean ratio of the enriched peak $(m+1)$ to the unenriched $(m)$ peak in urine for baseline and plateau samples was expressed as (MPE).

Flux (Q) was measured from the dilution of the infused tracer $L-\left[1-{ }^{13} \mathrm{C}\right]$ lysine in the metabolic pool at steady state using the following equation (Matthews et al, 1980)

$$
Q=I\left[\left(E_{i} / E_{p}\right)-1\right]
$$

Where $i$ is the rate of $\left[{ }^{13} \mathrm{C}\right]$ lysine infused ( $\left.\mu \mathrm{mol} . \mathrm{Kg}^{-1} \cdot \mathrm{h}^{-1}\right), E_{i}$ is the enrichment of $\left[{ }^{13} \mathrm{C}\right]$ lysine infused (MPE), $E_{p}$ is the enrichment of urinary lysine at isotopic 
steady state (MPE), and -1 is included as the factor which removes the contribution of the infusion to flux.

The rate of lysine oxidation ( $\left.\mu \mathrm{mol} . \mathrm{kg}^{-1} \cdot \mathrm{h}^{-1}\right)$ was calculated using the following equation (Mathews et al, 1980)

$$
\mathrm{O}=\mathrm{F}^{13} \mathrm{CO}_{2}\left(1 / E_{\mathrm{p}}-1 / \mathrm{E}_{1}\right) \times 100
$$

Where $\mathrm{F}^{13} \mathrm{CO}_{2}$ is the rate of ${ }^{13} \mathrm{CO}_{2}$ released $\left(\mu \mathrm{mol} . \mathrm{kg}^{-1} \cdot \mathrm{h}^{-1}\right)$ as a result of the oxidation of the tracer $\left[{ }^{13} \mathrm{C}\right]$ lysine.

The rate of ${ }^{13} \mathrm{CO}_{2}$ released by lysine tracer oxidation $\left(\mu \mathrm{M}{ }^{13} \mathrm{CO}_{2} \cdot \mathrm{Kg}^{-1} \cdot \mathrm{h}^{-1}\right)$ was calculated using the following equation (Matthews et al, 1980)

$$
\mathrm{F}^{13} \mathrm{CO}_{2}=\left(\mathrm{FCO}_{2}\right)\left(\mathrm{ECO}_{2}\right)(44.6)(60) /(w)(0.82)(100)
$$

where $\mathrm{FCO}_{2}$ is the $\mathrm{CO}_{2}$ production rate (mL/minute), $\mathrm{ECO}_{2}$ is the ${ }^{13} \mathrm{CO}_{2}$ enrichment in expired breath at isotopic steady state (APE), and $W$ is the weight of the subject (kg). The constants, $44.6 \mu \mathrm{mol}^{\mathrm{mL}}{ }^{-1}$ and $60 \mathrm{~min} \cdot \mathrm{h}^{-1}$, converts $\mathrm{FCO}_{2}$ to micromoles per hour and the factor 100 changes APE to a fraction. The correction factor of 0.82 represents the ${ }^{13} \mathrm{CO}_{2}$ that is released by $\left[{ }^{13} \mathrm{C}\right]$ lysine oxidation but not liberated from the body bicarbonate pool into expired air (Hoerr et al, 1989).

The mean requirement for phenylalanine was determined by breakpoint analysis using a two-phase linear regression crossover model (Seber, 1977) as previously described (Duncan et al, 1996). The upper and lower $95 \%$ confidence limits which represent the safe population requirement were determined using Fieller's theorem (Seber, 1977). Phenylalanine requirement for each individual 
subject was estimated by visual inspection of the breakpoint from the $\mathrm{F}^{13} \mathrm{CO}_{2}$ curves.

Statistical analyses were performed on primary and derived values. Differences between means were compared by t-lest. Repeated measures Analysis of variance (SAS Institute, 1989 to 1996, release 6.12) was used to assess the relationship between lysine flux, oxidation, $\mathrm{F}^{13} \mathrm{CO}_{2}$ and plasma phenylalanine and the experimental variables: phenylalanine intake and subject. Because order of test phenylalanine intake was manipulated, it was not included in the model. However, in previous studies in this laboratory (Duncan et al, 1996, Zello et al, 1990), order has not been found to have a significant effect on flux or $\mathrm{F}^{13} \mathrm{CO}_{2}$. Results were considered to be statistically significant at $\mathrm{P} \leq 0.05$. 


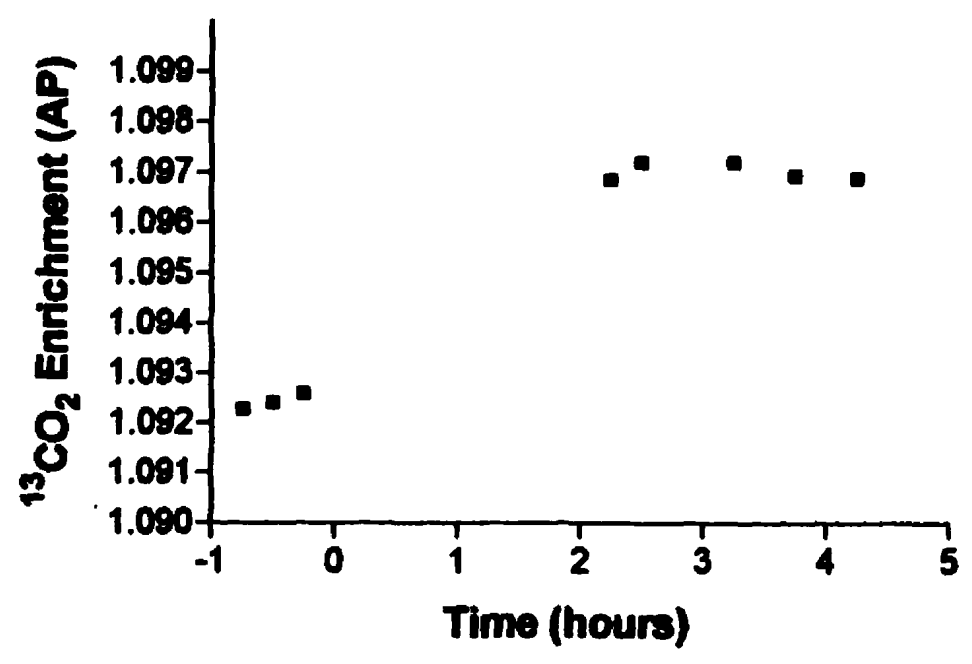

Figure 4.3. Typical Study Day ${ }^{13} \mathrm{CO}_{2}$ Enrichment in Breath

Isotope infused at time $=0$

Baseline samples; time $=-0.75 \mathrm{hrs},-0.50 \mathrm{hrs}$ and $-0.25 \mathrm{hrs}$

Plateau samples; time $=2.25 \mathrm{hrs}, 2.5 \mathrm{hrs}, 3.25 \mathrm{hrs}, 3.75 \mathrm{hrs}$ and $4.25 \mathrm{hrs}$ 


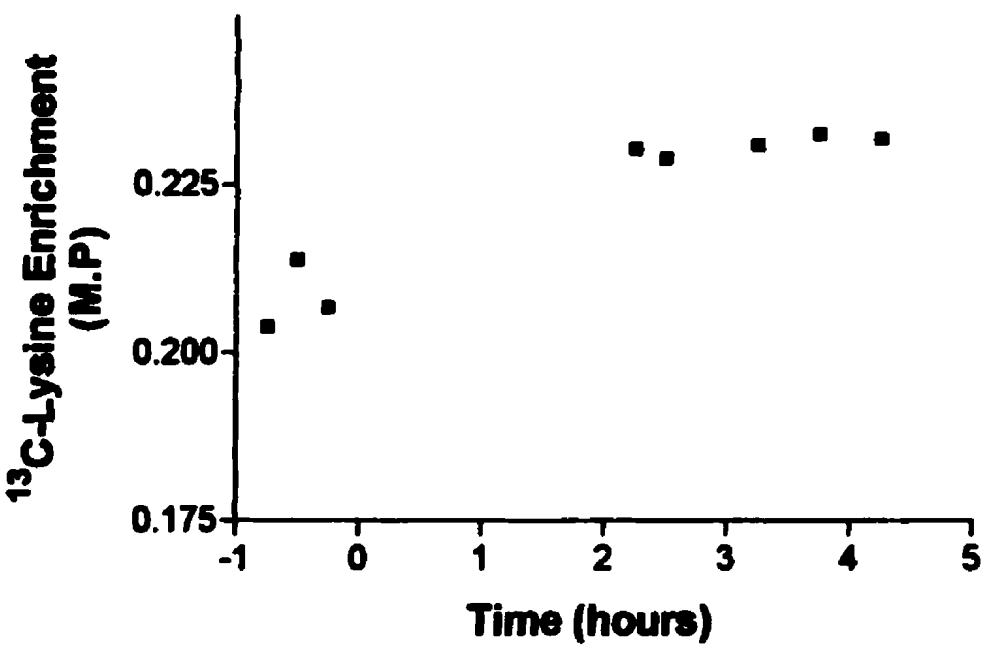

Figure 4.4 Typical Study Day 13C-Lysine Enrichment in Urine

Isotope infused at time $=0$

Baseline samples; time $=-0.75 \mathrm{hrs},-0.50 \mathrm{hrs}$ and $-0.25 \mathrm{hrs}$

Plateau samples; time $=2.25 \mathrm{hrs}, 2.5 \mathrm{hrs}, 3.25 \mathrm{hrs}$, and $4.25 \mathrm{hrs}$ 


\section{RESULTS}

The weights and heights that were observed for each child during the study period, are presented in Tables 5.1 and 5.2. Mean FFM of the six study days for each child as determined by BIA and skinfolds are presented in Table 5.3. Analysis done using a paired t-test showed that there was no significant difference between FFM determined by BIA or SF $(P=0.49)$.

$\mathrm{CO}_{2}$ production rate for each subject is shown in Table 5.4. Clearly, there was very little variation in $\mathrm{CO}_{2}$ production rates within subjects over the course of the study. Repeated measures analysis of variance showed that subject had a significant effect on $\mathrm{CO}_{2}$ production rates $(P=0.0001)$, however phenylalanine intake had no effect on $\mathrm{CO}_{2}$ production rates $(P=0.09)$

Means for lysine flux, oxidation and $\mathrm{F}^{13} \mathrm{CO}_{2}$ are presented in Table 5.5. There was a significant effect of subject on lysine flux $(P=0.02)$ (data not shown). However, phenylalanine intake had no effect on lysine flux ( $P=0.79$ ).

There was no effect of subject on lysine oxidation ( $P=0.098$ ). In addition phenylalanine intake had no significant effects on lysine oxidation ( $P=0.23)$. No significant model was found for lysine oxidation in response to phenylalanine intake when the data was analyzed using a two-phase linear regression crossover model.

There was a significant subject effect on $\mathrm{F}^{13} \mathrm{CO}_{2}(P=0.008)$. Also, phenylalanine intake had a significant effect on $\mathrm{F}^{13} \mathrm{CO}_{2}(P=0.004)$ (Table 5.5). 
Table 5.1 Wolght $(\mathrm{kg})$ of Children with Phenylketonuria During Study Period

\begin{tabular}{ccccccccc}
\hline \multicolumn{7}{c}{ Study Day Weight (kg) } & \multicolumn{1}{c}{$\begin{array}{c}\text { Weight } \\
\text { Change } \\
\text { (kg) }\end{array}$} \\
\hline Subject & 1 & 2 & 3 & 4 & 5 & 6 & \\
\hline LF & 39.5 & 39.5 & 39.6 & 39.5 & 40.3 & 40.6 & 1.1 \\
DN & 22.5 & 22.9 & 22.9 & 23.5 & 23.6 & 23.8 & 1.3 \\
AS & 39.4 & 40 & 40 & 40.4 & 40.6 & 40.3 & 0.9 \\
BS & 40.5 & 40.5 & 40.6 & 41.3 & 41.5 & 41.2 & 0.7 \\
AP & 36.9 & 37 & 37.7 & 37.9 & 38.3 & 39 & 2.1 \\
Mean \pm & $35.76 \pm$ & $35.98 \pm$ & $36.16 \pm$ & $36.52 \pm$ & $36.86 \pm$ & $36.98 \pm$ & $1.22 \pm$ \\
SEM & 3.37 & 3.33 & 3.35 & 3.30 & 3.36 & 3.31 & 0.24 \\
\hline
\end{tabular}


Table 5.2 Height $(\mathrm{cm})$ of Children with Phenylketonuria During Study Period

\begin{tabular}{ccccccccc}
\hline \multicolumn{7}{c}{ Study Day Height (cm) } & \\
\hline Subject & 1 & 2 & 3 & 4 & 5 & 6 & $\begin{array}{c}\text { Height } \\
\text { Change } \\
\text { (cm) }\end{array}$ \\
\hline LF & 148.2 & 148.2 & 148.2 & 148.4 & 148.3 & 148.6 & 0.4 \\
DN & 119.1 & 119.7 & 119.7 & 119.8 & 120.1 & 120.4 & 1.3 \\
AS & 148.6 & 148.6 & 148.6 & 148.6 & 149.2 & 148.7 & 0.1 \\
BS & 154 & 153.7 & 154.4 & 154 & 154.2 & 154.6 & 0.6 \\
AP & 145.4 & 146.1 & 145.8 & 146 & 145.6 & 145.7 & 0.3 \\
Mean \pm & 143.06 & 143.26 & 143.34 & 143.36 & 143.48 & 143.6 & 0.54 \\
SEM & \pm 6.15 & \pm 6.02 & \pm 6.08 & \pm 6.03 & \pm 6.01 & \pm 5.97 & \pm 0.21 \\
\hline
\end{tabular}


Table 5.3 Comparison of Mean Fat Free Mass (FFM) as Determined by Bioelectrical impedance (BIA) and Skinfolds (SF)

\begin{tabular}{ccc}
\hline Subject & $\begin{array}{c}\text { FFM-BIA }(\mathbf{k g}) \\
(\operatorname{moan} \pm \text { SEM) }\end{array}$ & $\begin{array}{c}\text { FFM-SF (kg) } \\
(\text { moan } \pm \text { SEM) }\end{array}$ \\
\hline LF & $32.41 \pm 0.22$ & $31.35 \pm 0.20$ \\
DN & $19.48 \pm 0.19$ & $21.11 \pm 0.22$ \\
AS & $31.53 \pm 0.29$ & $30.68 \pm 0.48$ \\
BS & $33.37 \pm 0.20$ & $34.27 \pm 0.28$ \\
AP & $29.8 \pm 0.31$ & $31.4 \pm 0.29$
\end{tabular}

By use of a paired, t-test no difference between means determined by BIA or SF $(P=0.49)$ 
Table $5.4 \mathrm{CO}_{2}$ Production Rates $\left(\mathrm{mL}^{\left.\mathrm{min}^{-1}\right)}\right.$ of Subjects on Study Days

\begin{tabular}{crrrrr}
\hline \multirow{2}{*}{ Study Day } & \multicolumn{5}{c}{ Subject } \\
\cline { 2 - 6 } 1 & \multicolumn{1}{c}{ LF } & DN & AS & BS & AP \\
\cline { 2 - 6 } 2 & 214.8 & 172.17 & 215.71 & 237.5 & 224.91 \\
3 & 213.1 & 194.4 & 219.93 & 221.57 & 217.43 \\
4 & 225.45 & 184.91 & 219.33 & 239.11 & 229.00 \\
5 & 225.83 & 195.71 & 215.42 & 239.77 & 224.25 \\
6 & 229.75 & 199.83 & 214.53 & 239.67 & 202.89 \\
Mean \pm SEM & $223.37 \pm 3.42$ & $188.81 \pm 4.48$ & $214.42 \pm 2.98$ & $235.12 \pm 3.17$ & $221.61 \pm 4.61$ \\
CV & 3.43 & 5.30 & 3.11 & 3.02 & 4.65 \\
\hline
\end{tabular}

With repeated measures analysis of variance, subject had a significant effect on $\mathrm{CO}_{2}$ production rates $(P=0.0001)$, phenylalanine intake had no effect on $\mathrm{CO}_{2}$ production rates $(P=0.09)$. 
Table 6.5 Effect of Phenylalanine Intake on Mean Lysine Flux, Oxidation and $F^{18} \mathrm{CO}_{2}{ }^{1}$

\begin{tabular}{|c|c|c|c|c|c|c|c|}
\hline \multirow[b]{3}{*}{ Lysine Flux } & \multicolumn{7}{|c|}{ Phenylalanine Intake (mg.kg-1.d-1) } \\
\hline & $\mathbf{0}$ & 10 & 15 & 20 & 25 & 35 & $\begin{array}{c}\text { Pooled } \\
\text { SE }\end{array}$ \\
\hline & 384.53 & 389.39 & 324.83 & 318.32 & 364.51 & 372.20 & 53.24 \\
\hline $\begin{array}{l}\text { Lysine } \\
\text { Oxidation }\end{array}$ & 44.802 & 36.534 & 26.970 & 31.998 & 37.264 & 40.296 & 10.16 \\
\hline $\mathrm{F}^{19} \mathrm{CO}_{2}$ & $1.15864^{\circ}$ & $0.91500^{\circ}$ & $0.78520^{d}$ & $0.92582^{c}$ & $0.97632^{b c}$ & $1.03824^{b}$ & 0.16 \\
\hline
\end{tabular}


The data presented in Table 5.5 show that there was a significant decrease in the rate of recovery of ${ }^{13} \mathrm{CO}_{2}\left(\mathrm{~F}^{13} \mathrm{CO}_{2}\right)$ from L- $\left[1-{ }^{13} \mathrm{C}\right]$ lysine oxidation at intakes of 0,10 and $15 \mathrm{mg} \mathrm{kg}^{-1} \cdot \mathrm{day}^{-1}$ of phenylalanine. Thereafter, at phenylalanine intakes of 20,25 and $35 \mathrm{mg} \cdot \mathrm{kg}^{-1}$.day the, rate of release of ${ }^{13} \mathrm{CO}_{2}$ from $\mathrm{L}-\left[1-{ }^{13} \mathrm{C}\right]$ lysine oxidation increased. As evidenced from the table, at intakes of 20 and 25 mg. $\mathrm{kg}^{-1}$.day the rate of release of ${ }^{13} \mathrm{CO}_{2}$ was not different from each other and was not different than the rate of release of ${ }^{13} \mathrm{CO}_{2}$ at an intake of $10 \mathrm{mg} \cdot \mathrm{kg}^{-1}$.day 1. However, at an intake of $35 \mathrm{mg} \cdot \mathrm{kg}^{-1}$.day the rate of release of ${ }^{13} \mathrm{CO}_{2}$, although not different from the rate of release seen at the intake of $25 \mathrm{mg} . \mathrm{kg}^{\circ}$ ${ }^{1}$. day ${ }^{-1}$, was different from that seen at all other intake levels.

Although the absolute $\mathrm{F}^{13} \mathrm{CO}_{2}$ values varied between subjects the pattern of release at varying phenylalanine intakes were similar within subjects (Figure 5.1). For every subject, $\mathrm{F}^{13} \mathrm{CO}_{2}$ decreased with increasing phenylalanine intakes up to a specific phenylalanine intake after which $\mathrm{F}^{13} \mathrm{CO}_{2}$ increased. Because all individuals were studied at all intake levels, individual requirement was estimated by visual inspection of the $\mathrm{F}^{13} \mathrm{CO}_{2}$ response curve. Estimated requirement varied from $13-20 \mathrm{mg}^{\mathrm{kg}}{ }^{-1}$.day-1. Estimates of individual phenylalanine requirements are presented in Table 5.6.

Figure 5.2 shows the mean breakpoint in the $\mathrm{F}^{13} \mathrm{CO}_{2}$ data. Using a twophase linear regression crossover model, a breakpoint of 14-mg phenylalanine. $\mathrm{kg}^{-1}$.day ${ }^{-1}$ was found. The upper and lower $95 \%$ confidence limits, which represent the safe population requirement, were determined at 8.5 and 19.5-mg phenylalanine. $\mathrm{kg}^{-1} \cdot \mathrm{day}^{-1}$. 
59
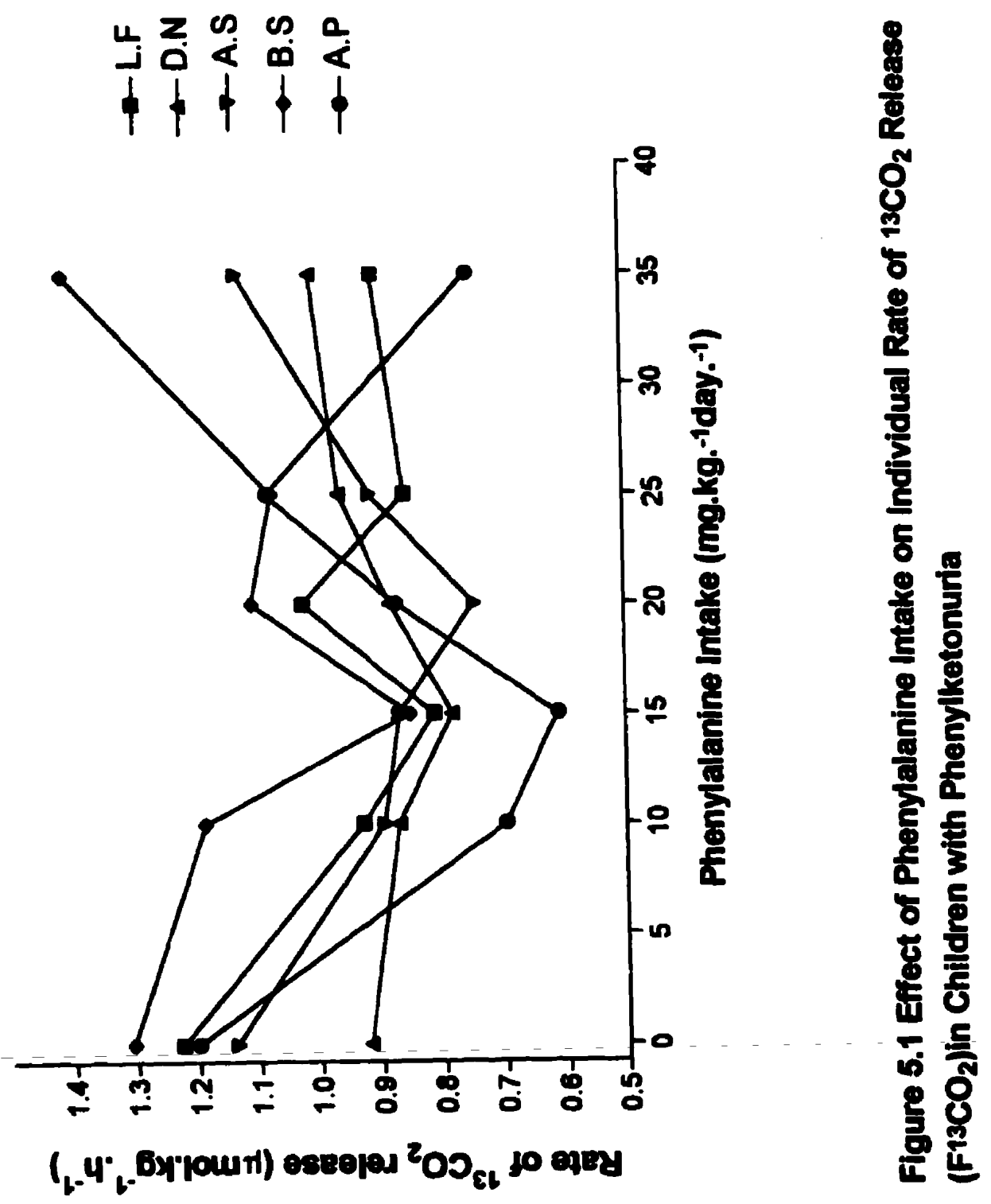
Table 5.6 Individual Phenylalanine Requirements for 5 Children with Classical Phenylketonuria (PKU) Based on $\mathrm{F}^{13} \mathrm{CO}_{2}$

\begin{tabular}{|c|c|c|}
\hline \multirow[b]{2}{*}{$\begin{array}{c}\text { Subject } \\
\text { LF }\end{array}$} & \multicolumn{2}{|c|}{ Phenylalanine Requirement } \\
\hline & $\frac{\left(m g . k g g^{-1} \text {.body woight.day }{ }^{-1}\right)^{-1}}{15}$ & $\frac{\left(m g \cdot \mathrm{kg}^{-1} \cdot \mathrm{FFM} \cdot \mathrm{day}\right)^{-6}}{18.28}$ \\
\hline DN & 13 & 15.00 \\
\hline AS & 20 & 25.00 \\
\hline BS & 15 & 18.20 \\
\hline AP & 13 & 16.10 \\
\hline Mean \pm SEM & $15.2 \pm 1.28$ & $18.52 \pm 1.74$ \\
\hline
\end{tabular}




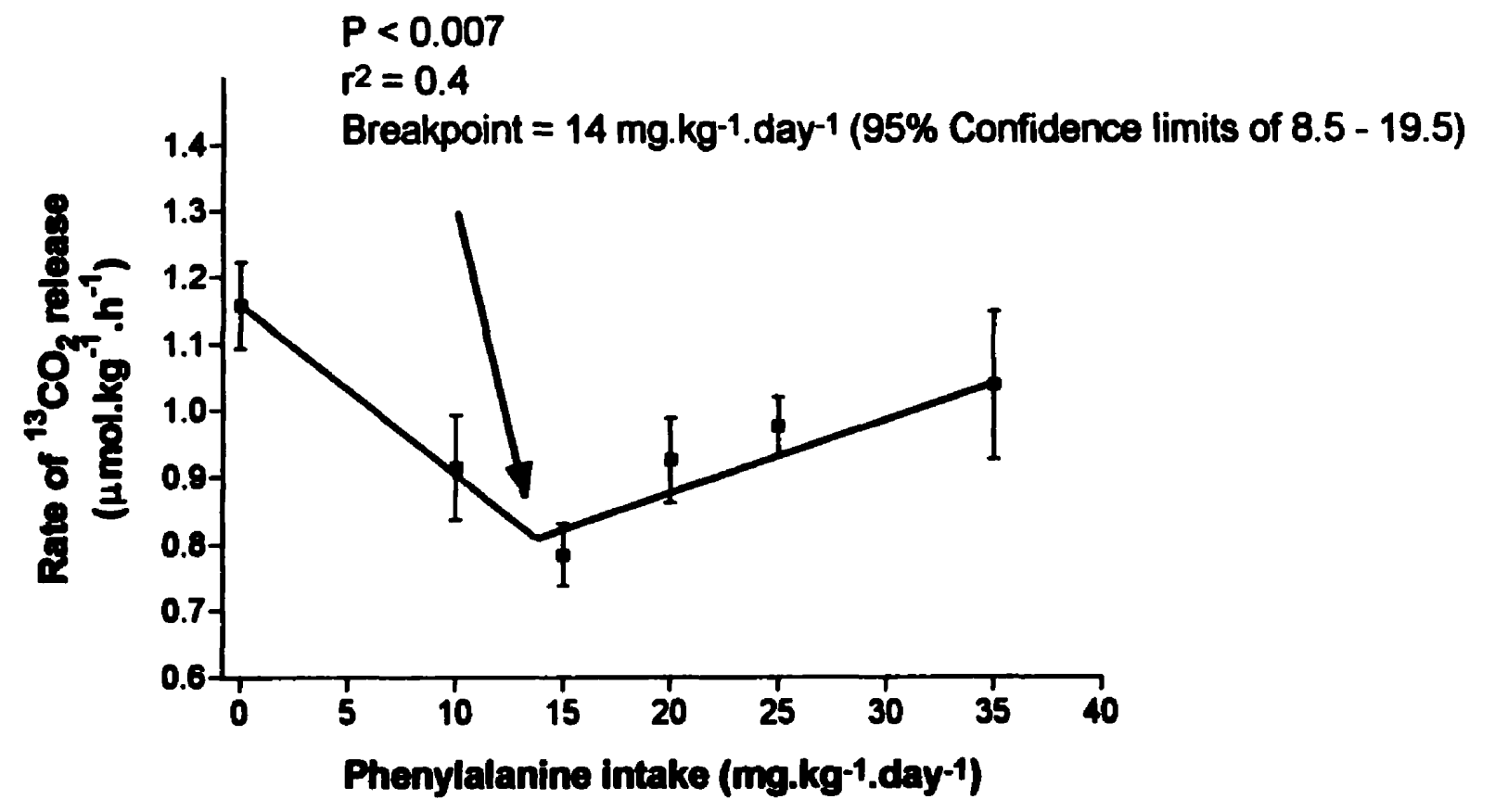

Figure 5.2 Effect of Phenylalanine Intake on Mean Rate of ${ }^{13} \mathrm{CO}_{2}$ Release $\left(\mathrm{F}^{13} \mathrm{CO}_{2}\right)$ in Children with Phenylketonuria

Mean ( \pm SEM) rate of $13 \mathrm{CO}_{2}$ release $\left(\mathrm{F}^{13} \mathrm{CO}_{2}\right)$ at 6 test phenylalanine intakes. Pooled data of all observations $(n=30)$ and all subjects $(n=5)$. The breakpoint estimates the mean phenylalanine requirement of the sample population. 
The model with the lowest standard error of the estimate and lowest coefficient of variation represented the best-fit model. The overall error for the model was lowest when phenylalanine intakes of 0 and 10 were partitioned to the first regression line and phenylalanine intakes of 15, 20, 25 and $35 \mathrm{mg} \mathrm{kg}^{-1}$. day $^{-1}$ were partitioned to the second regression line. The model was significant with a $P$ value $=0.007$ and $a r^{2}$ of 0.40

Table 5.7 presents fasted and fed plasma phenylalanine concentrations for each individual on each of the six study days. This table also presents the percentage change in plasma phenylalanine concentration in response to varying phenylalanine intake levels for each individual. Mean plasma phenylalanine concentrations at each intake level is also presented.

Mean fasted and fed state plasma phenylalanine concentrations are presented in Figure 5.3. In the fasted state, there was no difference in the mean plasma phenylalanine concentration at any of the intake levels. In the fed state, there was no difference in mean plasma phenylalanine concentration at phenylalanine intakes from 0 to $25-\mathrm{mg}$ phenylalanine. $\mathrm{kg}^{-1}$.day ${ }^{-1}$. However plasma phenylalanine concentration at an intake of $35 \mathrm{mg}$ of phenylalanine. $\mathrm{kg}^{-1} . \mathrm{day}^{-1}$, was increased and significantly higher than at all other phenylalanine intake levels.

Figure 5.4 shows the individual fed state plasma phenylalanine concentrations in response to varying phenylalanine intakes. The individual responses were similar to the mean response in that plasma phenylalanine seemed to show no change up to a certain intake level and then an increase at 
higher intake levels. Subject had a significant effect on plasma phenylalanine concentration $(p=0.0001)$. As expected, phenylalanine intake also had a significant effect on plasma phenylalanine concentration $(p=0.05)$.

Figure 5.5 presents the relationship between the mean differences between fed and fasted plasma phenylalanine concentration in response to varying phenylalanine intake levels. Linear regression showed that there was a direct relationship between phenylalanine intake and difference in (fed minus fasted) plasma phenylalanine concentration, with $98 \%$ of the difference in plasma phenylalanine concentration between fed and fasted states being accounted for by phenylalanine intake $\left(r^{2}=0.98\right), P<0.00$. The individual results are presented in Figure 5.6 and Table 5.7. The individual data for each subject share a similar pattern to that of the group as a whole. From Figure 5.5, at intakes of $20 \mathrm{mg}$ of phenylalanine. $\mathrm{kg}^{-1} . \mathrm{day}^{-1}$ or less, plasma phenylalanine concentration is less than or similar to the fasted concentration while at intakes of 25 and $35 \mathrm{mg}$ of phenylalanine. $\mathrm{kg}^{-1}$.day ${ }^{-1}$ the fed plasma phenylalanine concentration was much higher than fasted concentration. At an intake of about $20 \mathrm{mg}$ of phenylalanine. $\mathrm{kg}^{-1}$. day ${ }^{-1}$ there was a balance between phenylalanine intake and the difference in (fed minus fasted) plasma phenylalanine concentration. 
Table 5.7 Fasting, Fed and Percentage Change in Phenylalanine Concentration on Each Study Day for Each Individual Subject

\begin{tabular}{|c|c|c|c|c|c|c|c|}
\hline \multirow{4}{*}{$\begin{array}{c}\text { PHE Intake } \\
\text { (mg.kg-1.day }) \\
0\end{array}$} & \multicolumn{7}{|c|}{ Subject } \\
\hline & & $\mathbf{L F}$ & DN & AS & BS & AP & \multirow{3}{*}{$\begin{array}{l}\text { Mean } \pm \text { SEM } \\
1018.6 \pm 127.65\end{array}$} \\
\hline & \multicolumn{6}{|c|}{ Plasma Phenylalanine (PHE) Concentration ( $\mu \mathrm{M})$} & \\
\hline & Fasting & 691 & 729 & 1243 & 1155 & 1275 & \\
\hline & Fed & 600 & 581 & 990 & 1048 & 1125 & $868.8 \pm 115.66$ \\
\hline & \% Change & -13.2 & -20.30 & -21.90 & -9.26 & -11.76 & $-15.28 \pm 2.47$ \\
\hline \multirow[t]{3}{*}{10} & Fasting & 772 & 692 & 982 & 1062 & 815 & $864.6 \pm 68.40$ \\
\hline & Fed & 613 & 606 & 917 & 964 & 668 & $753.6 \pm 77.41$ \\
\hline & \% Change & -20.6 & -12.43 & -6.62 & -9.23 & -18.04 & $-13.38 \pm 2.62$ \\
\hline \multirow[t]{3}{*}{15} & Fasting & 678 & 705 & 1137 & 1185 & 618 & $864.6 \pm 122.06$ \\
\hline & Fed & 571 & 690 & 1250 & 1041 & 619 & $834.2 \pm 132.68$ \\
\hline & \% Change & -15.78 & -2.13 & +9.94 & -12.15 & +0.16 & $-3.99 \pm 4.58$ \\
\hline 20 & Fasting & 779 & 611 & 1080 & 829 & 1188 & $897.4 \pm 104.53$ \\
\hline
\end{tabular}


Table 5.7 Continued

\begin{tabular}{|c|c|c|c|c|c|c|c|}
\hline \multirow{4}{*}{$\begin{array}{c}\text { PHE Intake } \\
\left.\text { (mg.kg-1.day }{ }^{-1}\right)\end{array}$} & \multicolumn{7}{|c|}{ Subject } \\
\hline & & $\overline{\mathbf{L F}}$ & $\overline{D N}$ & AS & $\overline{\mathbf{B S}}$ & AP & \\
\hline & \multicolumn{6}{|c|}{ Plasma Phenylalanine (PHE) Concentration ( $\mu \mathrm{M})$} & Mean \pm SEM \\
\hline & Fed & 722 & 540 & 1114 & 860 & 1239 & $895 \pm 127.18$ \\
\hline & \% Change & -7.32 & -11.62 & +3.15 & +3.74 & +4.29 & $-1.55 \pm 3.31$ \\
\hline \multirow[t]{3}{*}{25} & Fasting & 756 & 540 & 1267 & 872 & 917 & $870.4 \pm 118.68$ \\
\hline & Fed & 760 & 616 & 1286 & 869 & 992 & $904.6 \pm 113.71$ \\
\hline & \% Change & +0.53 & +14.07 & +1.60 & -0.34 & +8.18 & $4.79 \pm 2.77$ \\
\hline \multirow[t]{3}{*}{35} & Fasting & 776 & 800 & 1600 & 1153 & 820 & $1029.8 \pm 158.36$ \\
\hline & Fed & 776 & 1105 & 1697 & 1228 & 905 & $1142.2 \pm 159.21$ \\
\hline & \% Change & 0 & +38.13 & +6.08 & +6.50 & +10.37 & $12.21 \pm 6.69$ \\
\hline
\end{tabular}



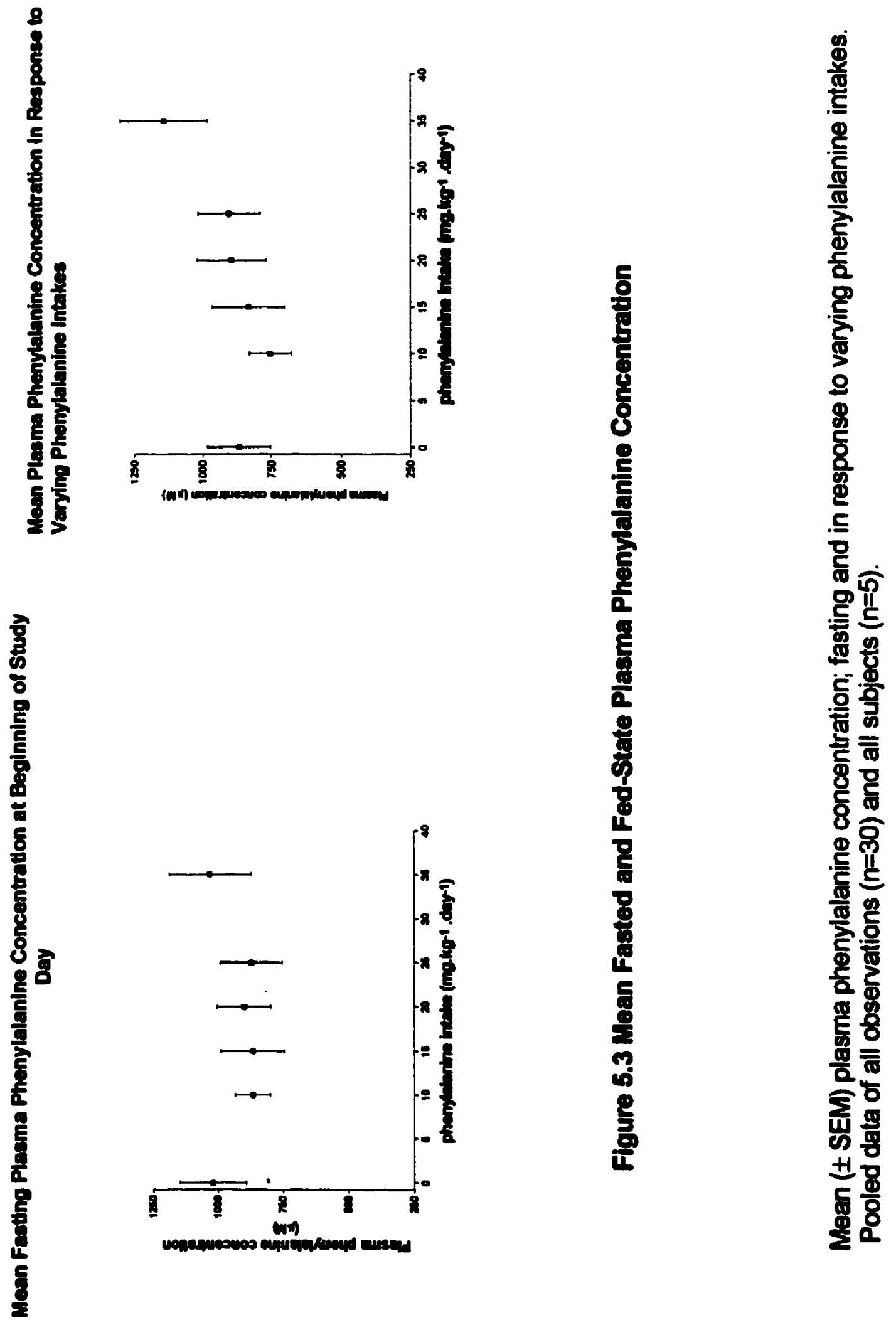


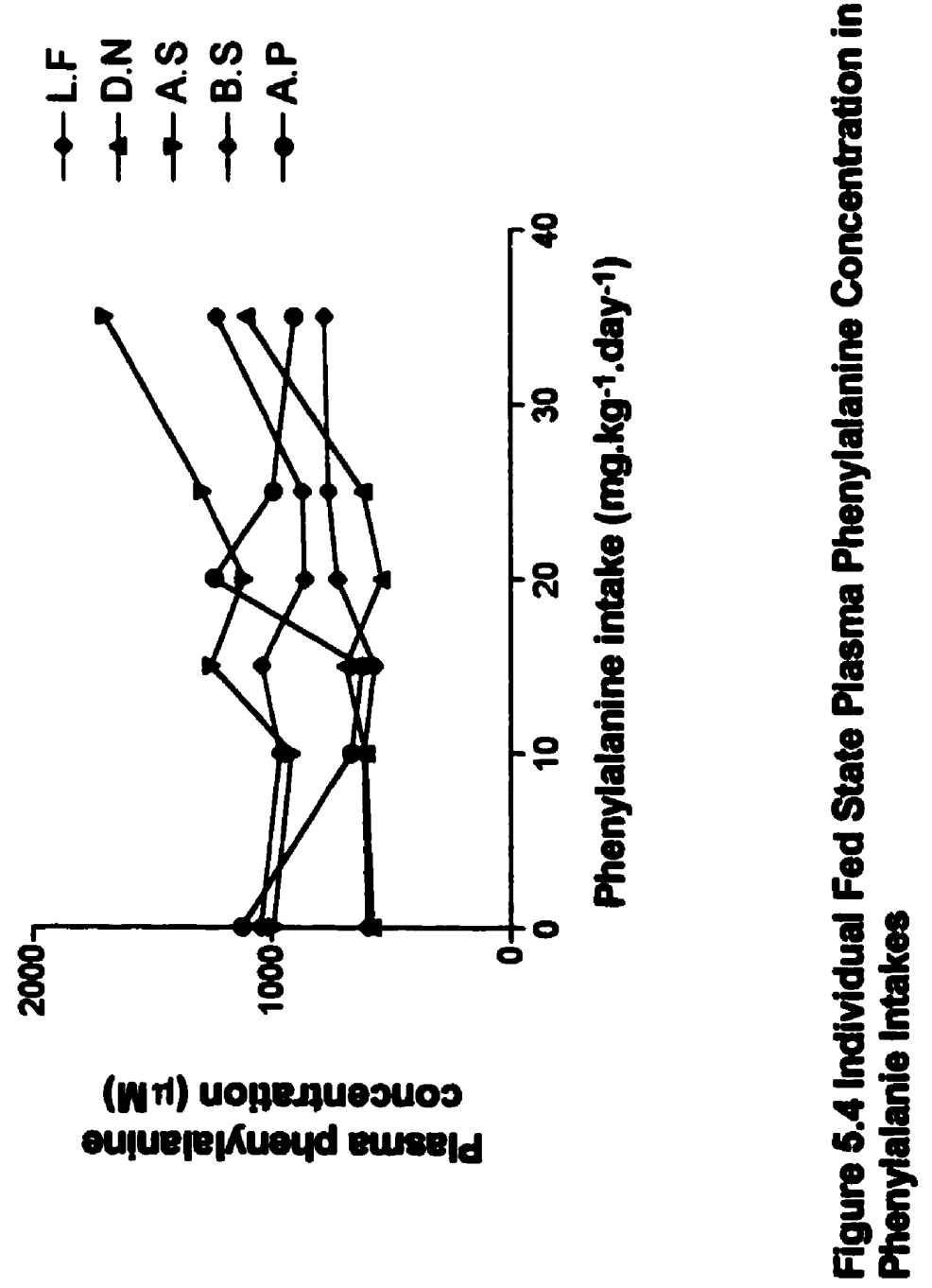



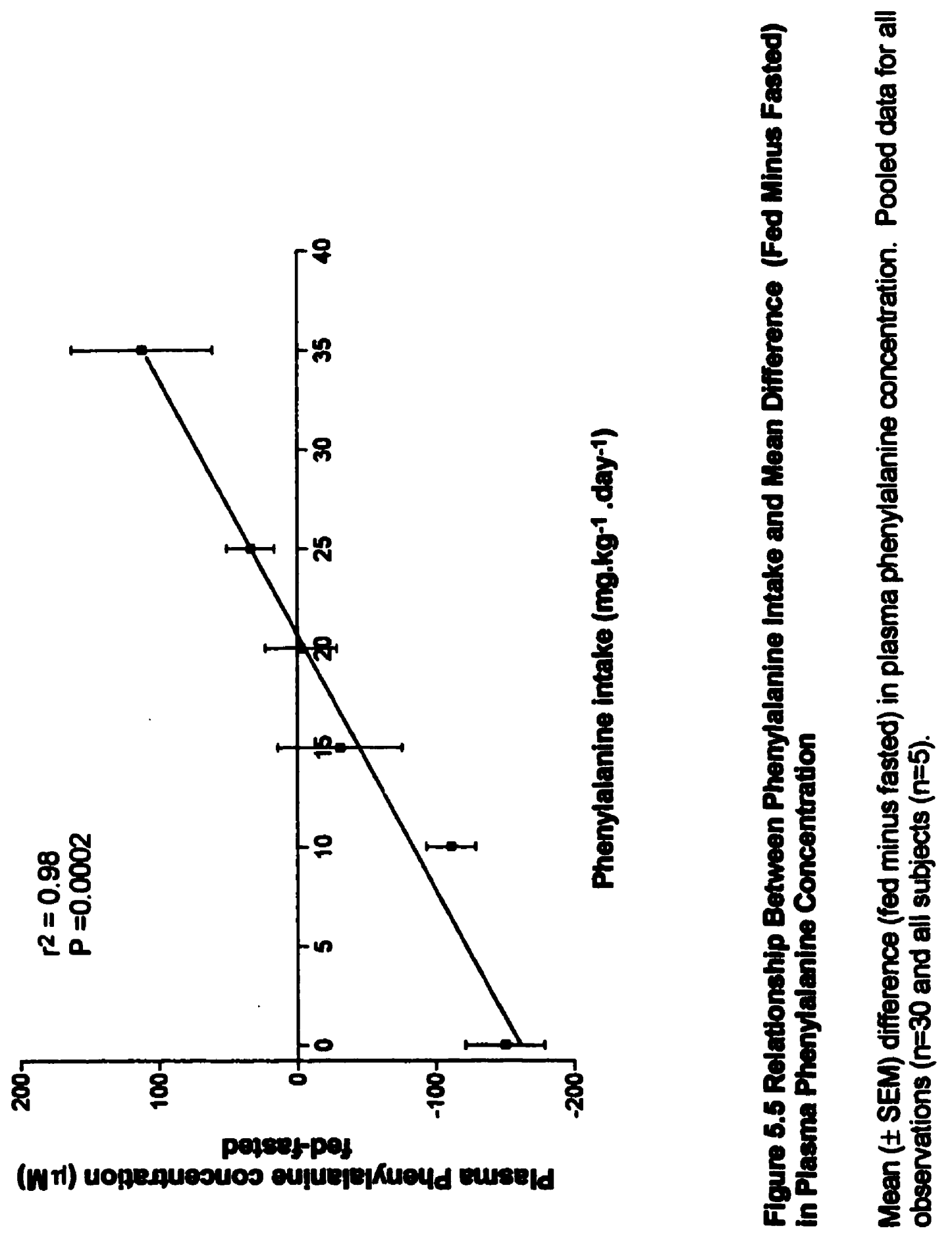


$$
\text { 出和车留是 }
$$
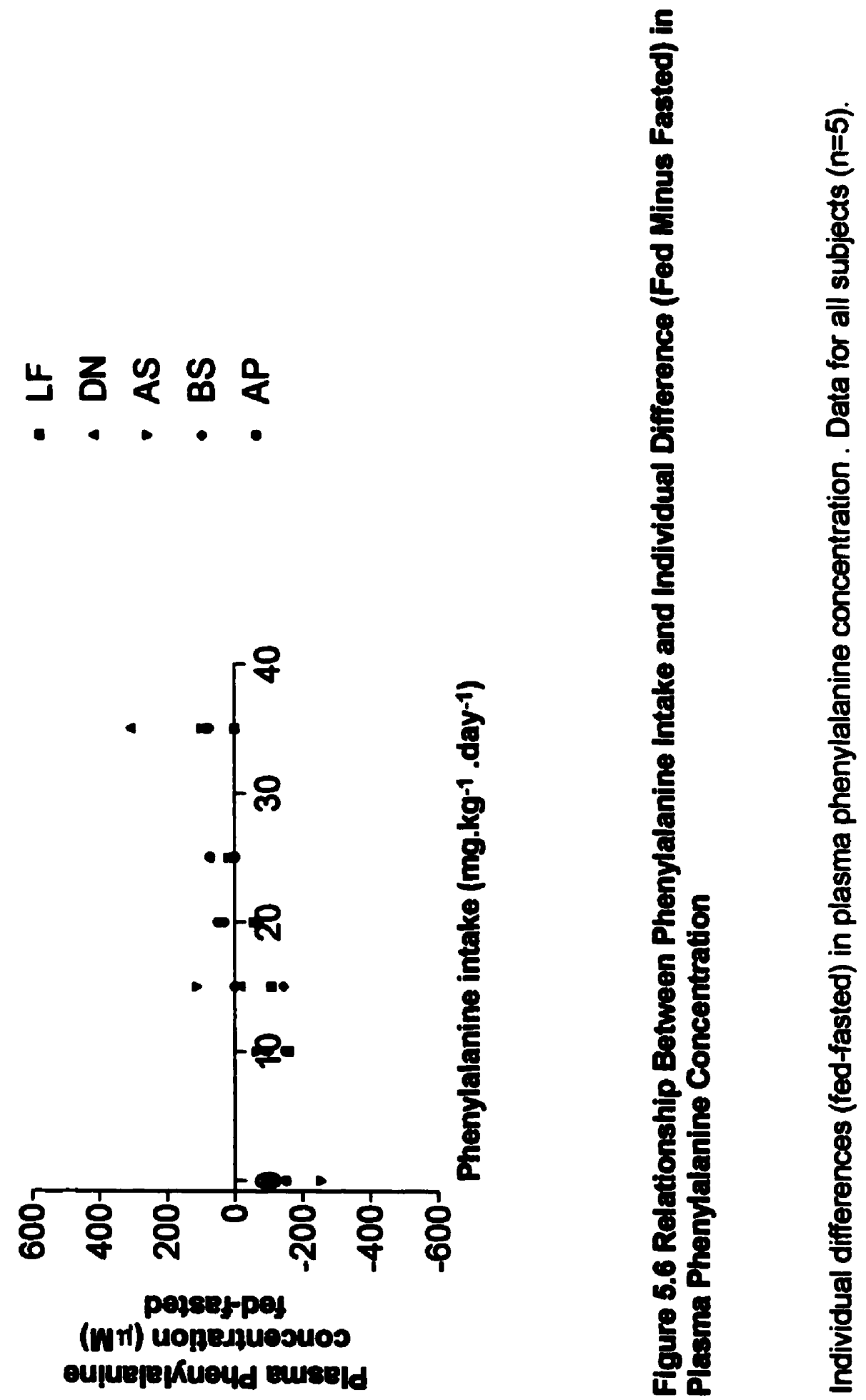


\section{DISCUSSION}

This study was carried out as the second in a two part series looking at aromatic amino acid requirement in classical phenylketonuria (PKU). These investigations were prompted by a lack of comprehensive studies on requirements for phenylalanine and tyrosine in PKU despite these being the two most affected amino acids in this disease. In addition, there was added concern surrounding the outcomes of treatment because despite the fact that the dietary treatment in PKU does prevent the overt clinical symptomology of severe mental retardation, outcomes of treatment are still not optimal (Section 2.2).

Current recommendations for phenylalanine alone in PKU are between 15 to $35 \mathrm{mg} \cdot \mathrm{kg}^{-1} \cdot$ day $^{-1}$ and 15 to $30 \mathrm{mg}^{\mathrm{kg}}{ }^{-1}$.day ${ }^{-1}$ for children between the ages of 4 $<7$ years, $7<11$ years, and $11<15$ years, respectively (Elsas \& Acosta, 1988) (Table 6.1). These requirements are based on retrospective studies using growth rates in response to dietary therapy, while also monitoring plasma amino acid concentration. Requirement for phenylalanine plus tyrosine in normal children ages 10 to 12 years has been set at $22 \mathrm{mg}^{\mathrm{kg}}{ }^{-1}$.day ${ }^{-1}$ (FAOMHO/UNU, 1985) (Table 6.1). These requirements were estimated using nitrogen balance. Zello et al (1990) using DAAO and Roberts, (1998) using IAAO, estimated the safe phenylalanine and tyrosine requirements in adult males to be 13.6 and 7 mg.kg-1.day ${ }^{-1}$ respectively for a total aromatic amino acid requirement of $21 \mathrm{mg} \mathrm{kg}^{-1} \cdot \mathrm{day}^{-1}$. This represented a balance between the aromatic amino acids of $60: 40$ phenylalanine to tyrosine. This balance is not unique to humans: 
Table 6.1 Summary of Current Recommended Daily Aromatic Amino Acid (Phenylalanine plus Tyrosine) Requirement in Healthy Children and Children with Phenylketonuria (PKU)

\begin{tabular}{|c|c|c|c|}
\hline Group & $\begin{array}{c}\text { Age } \\
\text { (years) }\end{array}$ & $\begin{array}{l}\text { Phenylalanine plus } \\
\left.\text { Tyrosine (mg.kg }{ }^{-1} \text {.day }\right)\end{array}$ & $\begin{array}{l}\text { Phenylalanine only } \\
\left(\mathrm{mg} \cdot \mathrm{kg}^{-1} \cdot \mathrm{day}^{-1}\right)\end{array}$ \\
\hline Healthy Boys ${ }^{1}$ & $10-12$ & 22 & \\
\hline \multirow{3}{*}{ PKU Children² } & $4<7$ & & $15-35$ \\
\hline & $7<11$ & & $15-30$ \\
\hline & $11<15$ & & $15-30$ \\
\hline
\end{tabular}

FAOWHO/UNU, 1985

2 Elsas \& Acosta, 1988 
Similar balances have been found in the piglet (House et al, 1997) and in human fetal tissue (Widdowson, 1981). Using this ratio and the FAOMHO's, (1985) requirement of $22 \mathrm{mg} \cdot \mathrm{kg}^{-1}$.day ${ }^{-1}$ for total aromatic amino acid in normal children 10 to 12 years old, phenylalanine requirement could be calculated to be between

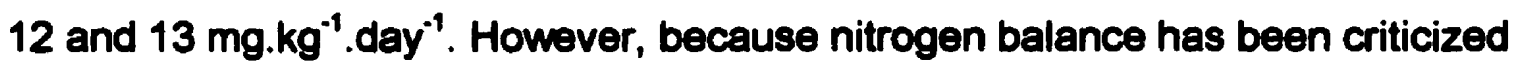
for underestimating requirements, (Matthews, 1992, Fuller \& Garlick, 1994, Young et al, 1987, Zello et al.1990) this $22{\mathrm{mg} . \mathrm{kg}^{-1} \text {.day }}^{-1} \mathrm{~N}$ balance estimate might be too low. Conversely, in Zello's study of phenylalanine requirement in adult males, obligatory oxidation was estimated to be about $26 \%$ of requirement. Because in classical PKU, due to the absence of phenylalanine hydroxylase activity (Treacy et al, 1997) obligatory oxidation is minimal, it is reasonable to predict that for PKU, the phenylalanine recommendations based on healthy subjects are too high.

The resuits of the present indicator amino oxidation study shows that the mean phenylalanine requirement estimated by a two-phase linear regression crossover model is $14 \mathrm{mg} \cdot \mathrm{kg}^{-1}$. $\mathrm{day}^{-1}$ for prepubertal children between the ages of 6 to 13 years with classical PKU (Figure 5.2). Because no comprehensive study looking at phenylalanine requirement has ever been done, the literature is sparse. Holt \& Snyderman, (1967), using growth and nitrogen balance, estimated the phenylalanine requirement (in the presence of dietary tyrosine) for 27 children with PKU. Their requirement estimates covered a broad range: 55 to $90 \mathrm{mg} \cdot \mathrm{kg}^{-1}$.day ${ }^{-1}$ at 2 months (mean $70 \mathrm{mg} \cdot \mathrm{kg}^{-1}$.day ${ }^{-1}$ ) to 25 to $80 \mathrm{mg} \cdot \mathrm{kg}^{-1}$.day ${ }^{-1}$ at 12 months (mean $35 \mathrm{mg}^{\mathrm{kg}}{ }^{-1} \cdot$ day $^{-1}$ ). Based on those results Holt \& 
Snyderman, (1967) concluded that the phenylalanine requirement of children with PKU is no different than that of normal children. However, these authors made no attempt to differentiate between classical or variant PKU in their study. In addition, when the requirement estimate from Holt \& Snyderman, (1967) study were used to treat children with PKU from birth, the children had prolonged periods of high plasma phenylalanine above treatment range (Berry et al, 1969).

The results of the present study support those of a retrospective study, Which looked at phenylalanine requirement in children with PKU who had normal rates of growth (Ruch et al, 1982). Those children were followed from birth to 2 years. Serum phenylalanine over the 2 year period averaged $345 \pm 285 \mu M$ therefore those children were fairly well controlled. These authors found that the intake of phenylalanine which was associated with moderately increased serum phenylalanine was only slightly greater than the intake associated with normal serum phenylalanine. They also found that between the ages of 0 to 4,4 to 12 and 12 to 24 months, phenylalanine intake needed to maintain a normal or moderately elevated plasma phenylalanine was approximately 68,58 and $50 \%$ respectively of the requirement of normal children (Holt \& Snyderman, 1967). Of importance is that there was a separation of the children into the classical or variant PKU groups based on their dietary tolerance of phenylalanine over those two years. When the authors compared their data with those of Holt \& Snyderman, (1967) they found that the lowest estimate corresponded with the intakes of the classical PKU children in their study, whereas the higher estimates from Holt \& Snyderman corresponded to the intakes of the variant PKU children. 
In addition to defining the mean phenylalanine requirement in the present study, a safe level of intake necessary to meet the requirement of $95 \%$ of the population (the $95 \%$ confidence limit) was estimated at $19.5 \mathrm{mg}^{\mathrm{kg}}{ }^{-1}$.day ${ }^{-1}$. This was necessary, because by definition, a requirement should be broad enough to cover the needs of almost all individuals (95\%) within a given population. When estimating phenylalanine requirement for a normal population, ensuring that $95 \%$ of the population is included in the requirement estimate is desirable and even advantageous. However, in a disease state like PKU the implications of setting a phenylalanine requirement at the $95 \%$ confidence level are unclear.

All individuals were studied at each of the 6 phenylalanine intake levels, therefore, individual estimation of requirement was possible and ranged from 13 to $20 \mathrm{mg} \cdot \mathrm{kg}^{-1}$.day ${ }^{-1}$ (Figure 5.1). At $19.5 \mathrm{mg} \mathrm{kg}^{-1}$.day ${ }^{-1}$, the $95 \%$ confidence limit is 6.5 and $4.5{\mathrm{mg} . \mathrm{kg}^{-1} \text {. day }}^{-1}$ higher than the individual estimate for 4 out of the 5 children studied. In the present study however, there was no change in mean fed-state plasma phenylalanine concentration between intakes of 0 to $25 \mathrm{mg} \mathrm{kg}^{-1}$ . day $^{-1}$ (Figure 5.3). This is evidence that the indicator method is highly sensitive, however it suggests that at such small differences in intake above requirement (4.5 to $6.5 \mathrm{mg} \mathrm{kg}^{-1}$.day ${ }^{-1}$ ), no significant changes would be detected in plasma phenylalanine concentration. On the other hand, there are a number of studies in which the consequence of inadequate intakes of phenylalanine in a PKU population have been described (Holm et al, 1979, Hanley et al, 1970). Severe mental and growth retardation have all been recorded. Because the impact on plasma phenylalanine is negligible with intakes in such a small excess of 
requirements, and because we have evidence of the consequences of intakes that are inadequate to meet requirements in children, we propose that the estimated $95 \%$ confidence limit of $19.5 \mathrm{mg}^{\mathrm{kg}^{-1}}$. day ${ }^{-1}$, be accepted as the estimated phenylalanine requirement in prepubertal children with classical PKU between the ages of 6 to 13 years old.

There was a very high degree of inter-individual as well as intra-individual variability in the baseline plasma phenylalanine concentrations in the present study (Table 5.7). However, when this was controlled for, by subtracting the fasting levels from the fed levels, a clearer picture emerged (Figure 5.5). These data showed that $98 \%$ of the change in plasma phenylalanine concentration with feeding was accounted for by phenylalanine intake alone. These data also lend support for the mean and $95 \%$ confidence requirement estimate determined from the indicator tracer studies. It shows that the least difference in plasma phenylalanine occurred at phenylalanine intakes between 15 and 20 mg. $\mathrm{kg}^{-1}$ .day ${ }^{-1}$ (Figure $5.5 \&$ Table 5.7). The fact that no change from baseline was detected in the mean fed-state plasma data at phenylalanine intakes from 0 to $25 \mathrm{mg} \mathrm{kg}^{-1}$.day ${ }^{-1}$ (Figure 5.3) is evidence that plasma levels of an amino acid (even in a disease as PKU with the absence of catabolic enzyme activity), is an insensitive measure and should not by used as a sole measure of requirement under any situation.

The technique of indicator amino acid is based on the premise that the partition of any indispensable amino acid between oxidation and protein synthesis is sensitive to the level of the most limiting amino acid in the diet (Zello 
et al, 1995). When an indispensable amino acid is limiting for protein synthesis, all other amino acids are in excess and must be oxidized. As the limiting (test amino acid) amino acid is increased in the diet in graded amounts, the uptake of all dietary amino acids increases for protein synthesis, and in turn, their oxidation decreases, until the requirement for the limiting amino acid is reached. Once the requirement is reached, further increases of the test amino acid will have no further effect on the uptake of other indispensable amino acids for protein synthesis or oxidation (Kim et al, 1983, Kim \& Bayley, 1983, Ball \& Bayley, 1974).

This pattern of oxidation has been observed in every indicator study performed in this lab (Zello et al, 1990, 1993, Lazarus-Brunner et al, 1998, Duncan et al, 1996) in which the requirement for an amino acid in normal individuals was determined. This pattern was also observed by Bross, (1997) in her study on tyrosine requirement in a similar population of children with PKU. In the present study however, an increase in the oxidation of the indicator was observed beyond the $\mathrm{F}^{13} \mathrm{CO}_{2}$ breakpoint (mean requirement) (Figure 5.2 \& Table 5.5). A similar pattern was observed for all individuals studied (Figure 5.1). This suggests that beyond requirement, further increase in the intake of phenylalanine in PKU, results in a decrease in protein synthesis.

A decrease in protein synthesis suggests that there may be a decrease in growth. However studies looking at growth in PKU children who were receiving adequate phenylalanine (Holm et al. 1979, Acosta et al, 1977) have shown that 
growth failure is not normally the problem in PKU. In addition, all the children in the present study were growing.

As to whether this decrease in protein synthesis is a function of plasma phenylalanine concentration, it is difficult to tell from this study because the individual baseline plasma phenylalanine concentrations were highly variable. Nevertheless, two of the subjects; LF and DN, did have baseline phenylalanine concentrations that were closer to the target treatment level than the others (Table 5.7). Despite tighter control in these subjects, they shared a similar pattern of oxidation as the other three subjects.

Wapnir \& Lifshitz, (1974) have shown that there is lower than normal plasma tryptophan levels in PKU when compared to controls even after the implementation of a low phenylalanine diet in PKU. Lipovac et al, (1979) have shown that there is increased amino acid catabolism in the tissues of rats in which hyperphenylalaninemia was induced. Decreased plasma tryptophan and/or increased catabolism of amino acids when intake of phenylalanine exceeded that needed for optimal protein synthesis (requirement) could have accounted for the decreased protein synthesis observed with phenylalanine intakes greater than $15 \mathrm{mg} \cdot \mathrm{kg}^{-1}$. day $^{-1}$ in this study.

This study lends further support to the suitability of indicator amino acid technique for the estimation of amino acid requirement in vulnerable groups of individuals. It also lends further support for the suitability of lysine as an indicator. This is underlined by the fact that phenylalanine intake had no effect 
on lysine flux (Table 5.5). This indicates that the pool size of the indicator and hence its overall metabolism was not altered during the study.

This research has implications for the PKU populations not only in Canada but worldwide. It represents the first study to comprehensively determine the requirement for phenylalanine in a PKU population. Although the results are lower than current recommendations, it is in agreement with Ruch et al, (1982) that the requirement for phenylalanine in PKU is lower than that of normal children.

The results of this present study together with the results from Bross's study (Bross, 1997), indicate that the mean requirement for the aromatic amino acids in PKU is $33.2 \mathrm{mg} \mathrm{kg}^{-1}$.day ${ }^{-1}$. This represents a proportional balance of phenylalanine to tyrosine of 42:58.

\section{CONCLUSION}

The indicator method is suitable for estimating phenylalanine requirement in PKU. Using this method the present study estimated the mean and safe phenylalanine requirement of prepubertal children with classical PKU to be 14 and $19.5 \mathrm{mg} \cdot \mathrm{kg}^{-1}$.day ${ }^{-1}$ respectively. This proves the hypothesis that the safe phenylalanine requirement of children with classical PKU will be approximately equal to the mean tyrosine requirement of $19.2{\mathrm{mg} . \mathrm{kg}^{-1} \text {.day }}^{-1}$ (Bross, 1997). 
Coupled with the results of Bross, (1997), the results indicate that the safe aromatic amino acid requirement in PKU is $44.7 \mathrm{mg}^{\mathrm{kg}}{ }^{-1}$.day ${ }^{-1}$, which represents a balance between the aromatics of $44: 56$, phenylalanine:tyrosine.

In conclusion, these results suggest that the current phenylalanine recommendation in PKU is too high. In addition the results suggests that beyond requirement, further increases in phenylalanine intake contributes to decreased protein synthesis in PKU.

\section{FUTURE DIRECTIONS}

The present study has completed the two part series of studies looking at aromatic amino acid requirements in PKU. There is now a need for a future long-term study to determine whether these estimated phenylalanine and tyrosine requirement promote optimal growth, IQ development and plasma phenylalanine levels in PKU children of similar ages.

There is also a need to determine rates of protein synthesis in PKU children when compared to normal children. This can probably be done using a different indicator than the one used in the present study. An indicator such as leucine is one such alternative.

Finally, because the indicator method is safe and non-invasive, there is great promise in its use in the estimation of amino acid requirements in 
vulnerable groups like women and small children. Presently, data are lacking on requirements for children between the ages of 3 to 10 years. The indicator method can be used to fill this gap. Finally, the indicator method is a suitable method for estimation of requirements in other groups of individuals with inborn errors of metabolism like maple syrup urine disease, and tyrosinemia. 


\section{REFERENCES}

1. Acosta, Phyllis B., Wenz, Elizabeth, Williamson, Malcolm (writing committee for the collaborative study) (1977) Nutrient intake of treated infants with phenylketonuria. Am. J. Clin. Nutr. 30: 198-208.

2. Ball, Ronald O., Bayley, Henry S. (1994) Tryptophan requirement of the 2.5$\mathrm{kg}$ piglet determined by the oxidation of an indicator amino acid. J. Nutr. 114: 1741-1746.

3. Basile-Filho, Anibal, El-Khoury, Antoine E., Beaumier, Louis, Wang, San Y., Young, Vernon R. (1997) Continuous $24-h L-\left[1-{ }^{13} C\right]$ phenylalanine and $L-[3,3-$ ${ }^{2} \mathrm{H}_{2}$ tyrosine oral-tracer studies at an intermediate phenylalanine intake to estimate requirements in adults. Am. J. Clin. Nutr. 65: 473-488.

4. Basile-Filho, Anibal, Beaumier, Louis, El-Khoury, Antoine E., Yon-Ming, Yu, Kenneway, Michael, Gleason, Ray E., Young, Vernon R. (1998) Twenty-fourhour $L-\left[1-{ }^{13} \mathrm{C}\right]$ tyrosine and $L-\left[3,3-{ }^{-} \mathrm{H}_{2}\right]$ phenylalanine oral tracer studies at generous, intermediate, and low phenylalanine intakes to estimate aromatic amino acid requirements in adults. Am. J. Clin. Nutr. 67: 640-659.

5. Berry, Helen K., Hunt, Melanie M., Sutherland, Betty K., (1970) Amino acid balance in the treatment of phenylketonuria. JADA 58: 210-214.

6. Brodehl, J., Gellissen K., Kaas, P. W. (1970) The renal transport of amino acid in untreated infants with phenylketonuria. Acta Paediat Scand 59: 241248.

7. Brook, C.G. (1971) Determination of body composition of children from skinfold measurements. Arch. Dis. Child.46: 182-184.

8. Bross, R. (1997) Tyrosine requirements and resting energy expenditure in patients with phenylketonuria. Ph.D Thesis

9. Burrill, Linda M., Schuck, Cecilia. (1964). Phenylalanine requirements with different levels of tyrosine. J. Nutr. 83: 202-208.

10. Byrd, D.J., Kochen W., Schurrle, L., Trefz, F. K. (1975) A study of urinary tryptophan metabolites in relation to the content of semi-synthetic diets in a patient with phenylketonuria. Acta Vitamin. Enzymol. (Milano) 29: 55-61.

11. Clemens, Peter C., Burmester, Jens Gunter, Prankel, Bernhard H., Halfmann, Editha, Erb, Norbert, Muller-Wickop, Jurgen (1993) Phenylalanine and other 
12. large neutral amino acid and RNA catabolites as markers for protein biosynthesis in phenylketonuria. Metabolism 42: (4) 531 - 534.

13. Denne, Scott C. (1992). Protein requirements. Fetal and neonatal physiology (Fox, W.W. \& Polin, R. A. eds). pp 223-233. W.B. Saunders, Philadelphia.

14. De Benoist, B., Abdularazzak, Y., Brooke, O. G., Halliday, D., Millward. D. J. (1984) The measurement of whole body protein turnover in the preterm infant with intragastric infusion of $L-[1-13 C] l e u c i n e$ and sampling of the urinary leucine pool. Clin. Sci. 66: 155-164.

15. Dooley, Dent C. (1992) Enzymatic method for phenyketonuria screening using phenylalanine dehydrogenase. Clin. Biochem. 25: 271-275.

16. Duncan, Alison M., Ball, Ronald O., Pencharz, Paul B. (1996) Lysine requirement of adult males is not affected by decreasing dietary protein. Am. J. Clin. Nutr. 64: 718-25.

17. Durnin, J. V., Rahaman, M. M. (1967) The assessment of the amount of fat in the human body from measurements of skinfold thickness. Br.J.Nutr. 21: 681689.

18. Efron, Mary L., Kang, Song Ellen, Visakorpi, Jarmo, Fellers, Francis X. (1969) Effect of elevated plasma phenylalanine on other amino acids in phenylketonuric and normal subjects. J. Pediatr. 74: (3) 399-405

19. Elsas, Louis J., Acosta, Phyllis B. (1988). Nutrition support of inherited metabolic disease. In: Modern nutrition in health and disease (Shils, Maurice E., Young, Vernon R), pp. 1337-1379.

20.FAOMHO/UNU Expert Consultation (1985). Energy and protein requirements. World Health Organization, Geneva, Switzerland.

21. Folling, A. (1934). Uber ausscheidung von phenylbrenztraubensaure in den harn als stoffwechselanomalie in verbindung mit imbezillitat. Z.Physiol. Chem. 227: 169

22. Fuller, Malcolm F., Garlick, Peter J. (1994). Human amino acid requirements: can the controversy be resolved? Annu. Rev. Nutr. 14: 217-241.

23. Hanley, W. B., Linsao, Lydia, Davidson, W., Moes, C. A. F. (1970) Malnutrition with early treatment of phenylketonuria. Pediat. Res. 4: 318-327.

24. Health and Welfare Canada (1990) Nutrition recommendations. Ministry of National Health and Welfare. 
25. Holm, Vanja A., Knox, Eugene. (1979) Physical growth in phenylketonuria: 1. A retrospective study. Pediatrics 63: (5) 694-699.

26. Holm, Vanja A., Kronmal, Richard A., Williamson, Malcolm, Roche, Alex F. (1979) Physical growth in phenylketonuria: II. Growth of treated children in the PKU collaborative study from birth to 4 years of Age. Pediatrics 63: (5) 700-707.

27. Holt, Emmett L., Snyderman, Selma E. (1967) The amino acid requirements of children. University Press, New York 381-389.

28. Hoerr, Robert A., Yong-Ming, Yu, Wagner, David A., Burke, John F., Young, Vernon R. (1989) Recovery of ${ }^{13} \mathrm{C}$ in breath from $\mathrm{NaH}^{13} \mathrm{CO}_{3}$ infused by gut and vein: effect of feeding. Am. J. Physiol. 257: E426-E438.

29. House, James D., Pencharz, Paul B., Ball (1997). Phenylalanine requirements determined by using $L-[1-14 C]$ phenylalanine in neonatal piglets receiving total parenteral nutrition supplemented with tyrosine. Am. J. Clin. Nutr. 65: 984-993.

30. House, J. D., Pencharz, P. B. Ball, R. O (1998) Lysine requirement of neonatal piglets receiving total parenteral nutrition as determined by oxidation of the indicator amino acid L-[1-14C]phenylalanine. Am.J.Clin.Nutr. 67: 67-73.

31. Irwin, Isabel M., Hegsted, Mark D. (1971). A concept of research on amino acid requirements of man. J. Nutr. 101: (4) 539-566.

32. Kim, Kyu-II, Bayley, Henry S. (1983) Amino acid oxidation by young pigs receiving diets with varying levels of sulphur amino acids. Br. J. Nutr. 50: 383-390

33. Kim , Kyu-II, McMillan, lan, Bayley, Henry S. (1983) Determination of amino acid requirements of young pigs using an indicator amino acid. Br. J. Nutr. 50: 369-382.

34. Kim, Kyu-Il, Elliot, James I., Bayley, Henry S. (1983) Oxidation of an indicator amino acid by young pigs receiving diets with varying levels of lysine or threonine, and an assessment of amino acid requirements. Br. J. Nutr. 50: 391-399.

35. Kindt, Elisabeth, Holversen, Sverre. (1980). The need of essential amino acids in children. An Evaluation based on the intake of phenylalanine, 
tyrosine, leucine, isoleucine, and valine in children with phenylketonuria, tyrosine amino transferase defect, and maple syrup urine disease. Am. J. Clin. Nutr. 33: 279-286.

36. Lazarus-Brunner, Georgina, Rafii, Mahroukh, Ball, Ronald O., Pencharz, Paul B. (1998) Tryptophan requirement in young adult women as determined by indicator amino acid oxidation with $\mathrm{L}-\left[^{13} \mathrm{C}\right]$ phenylalanine. Am J Clin. Nutr. 68: $303-10$

37. Leverton, Ruth M., Johnson, Norma, Ellison, Joan, Geschwender, Donna, Schmidt, Florence. (1956) The quantitative amino acid requirements of young women. IV. Phenylalanine with and without tyrosine. J. Nutr. 58: 341-353

38. Lipovac, Kreso, Zanic-Grubisic, Tihana, Juretic, Dubravka, Mihaljevic, Ivanka, Fuks, Zeljko. (1979) Disturbances of energy metabolism in rats with experimentally induced hyperphenylalaninemia. In: Models for the study of inborn errors of metabolism (Hommes, F. A. ed.), North-Holland Biomedical Press pp.133-140

39. Matthews, D. E., Motil, K. J., Rohrbaugh, D.K., Burke, J.F., Young, V. R., Bier, D. M. (1980) Measurement of leucine metabolism in man from a primed, continuous infusion of $\mathrm{L}-\left[1-{ }^{13} \mathrm{C}\right\}$ leucine. J. Am. Physiol. Soc. 238: E473E479

40. Matthews, Dwight E. (1992) General concept of protein metabolism. In: Fetal and neonatal physiology (Polin, R. A. \& Fox, W. W. eds). 420-428.

41. Meredith, Carol N., Zhi-Mei, Wen, Bier, Dennis M., Matthews, Dwight E., Young Vernon R. (1986) Lysine kinetics at graded lysine intakes in young men. Am. J. Clin. Nutr. 43:787-794.

42. Millward, D. J., Jackson, A. A., Price, Gillian, Rivers, J. P. W (1989). Human amino acid and protein requirements: current dilemmas and uncertainties. Nutr. Res. Reviews. 2: 109-132.

43. Millward, D. J., Rivers, J. P. W (1986). Protein and amino acid requirements in the adult human. J. Nutr. 116. 2559-2561.

44. Munro, H. N. (1970) Free amino acid pools and their role in regulation. In: Mammalian protein metabolism (Munro, H.N. ed.), Academic Press, New york.

45. Nakagawa, Itsiro, Takahashi, Tetsuzo, Suzuki, Takeshi, Kobayash, Katsumi (1962) Amino acid requirements of children: Minimal needs of threonine, valine and phenylalanine based on nitrogen balance method. J. Nut. 77:61- 
68.

46. Nakagawa, Itsiro, Takahashi, Tetsuzo, Suzuki, Takeshi, Kobayash, katsumi. (1964) Amino acid requirements of children: Nitrogen balance at the minimal level of essential amino acids. J. Nutr. 83: 115-118.

47. Patterson, Bruce W., Hachey, David L., Cook, Gary L., Amann, Joseph M., Klein, Peter D. (1991) Incorporation of a stable isotopically labeled amino acid into multiple human apolipoproteins. J. Lipid Res. 32: 1063-1072.

48. Picou, D., Taylor-Roberts, T. (1969) The measurement of total protein synthesis and catabolism and nitrogen turnover in infants in different nutritional states and receiving different amounts of dietary protein. Clin. Sci. 36: 283-296

49. Roberts, Susan A. (1998) Aromatic amino acid metabolism in the human: estimation of tyrosine requirement in the neonate and adult. PhD thesis.

50. Rose, William C., Leach, Byron E., Coon, Minor J., Lambert, Frederick G. (1955) The amino acid requirement of man. IX. The phenylalanine requirement. J. Biol. Chem. 213: 913-922.

51. Rose, William C., Wixom, Robert L. (1955) The amino acid requirement of man. XIV. The sparing effect of tyrosine on the phenylalanine requirement. J.Biol. Chem. 217: 95-101.

52. Ruch, Teresa, Kerr, Douglas. (1982) Decreased essential amino acid requirements without catabolism in phenylketonuria and maple syrup urine disease. Am. J. Clin. Nutr. 35: 217-228.

53. Seber, G. A. F. (1977) Linear regression analysis. New York: Wiley.

54. Scriver, Charles S, Kaufman, Seymour, Woo, Savio L. C. (1989) The hyperphenylalaninemias. In: The metabolic basis of inherited disease (Scriver, C. R., Beaudet, A. L., Sly, W. S., Valle, D. eds.) McGraw-Hill Information Services Co. New York. pp. 495-546.

55. Siri, W. E. (1956) Body composition from fluid spaces and density analysis of methods, Donner Laboratory of Bioshysics and Medical Physics, California.

56. Smith, I., Beasley, M.G., Ades, A. E.(1990) Intelligence and quality of dietary treatment in phenylketonuria. Arch. Dis. Child. 65: 472-478.

57. Thompson, Alan J., Smith I., Brenton, D., Youl, B.D., Rylance, G., Davidson, D. C., Kendall, B., Lees, A. J. (1990) Neurological deteriorations in young 
adults with phenylketonuria. The Lancet 336: 602-605.

58. Thompson, Alan J., Smith, I., kendall, B. E., Youl, B. D.Brenton D. (1991) Magnetic resonance imagine changes in early treated patients with phenylketonuria. Lancet 337: 1224.

59. Thompson, Alan J., Trittotson, Sarah, Smith, Isabel, Kendall, Brian, Moore, Susan, G., Brenton, David P. (1993) Brain MRI changes in phenylketonuria. Brain 116: 811-821.

60. Treacy, Eillen P., Delente, Jacques J., Elkas, Gay, Carter, Kevin, Lambert, Marie, Waters, Paula J., Scriver, Charles R. (1997). Analysis of phenylalanine hydroxylase genotypes and hyperphenylalaninemia phenotypes using L-[1- 13C]phenylalanine. Pediatr. Res. 42-4: 430-435.

61. Wapnir, Raul A., Lifshitz, Fima (1974) Intestinal transport of aromatic amino acids, glucose and electrolytes in a patient with phenylketonuria. Clin. Chima Acta 54:349-356.

62. Waterlow, John C., Golden, Michael H. N., Garlick, Peter J.(1978) Protein turnover in man measured with 15N: Comparison of end products and dose regimes. Am. J. Physiol. 235:(2) E165-E174.

63. Widdowson, E. M. (1981) Changes in body composition during growth. In: Scientific foundation of paediatrics (David, J, \& Dobbing, J. eds),pp. 330-342. Heinemann, London, UK.

64. Wykes, L. J., Ball, R. O., Menendez, C. E., Pencharz, P. B. (1990) Urine collection as an alternative to blood sampling: A noninvasive means of determining isotopic enrichment to study amino acid flux in neonates. 44: 605-608.

65. Young, Vernon R., Bier, Dennis M. (1987) Amino acid requirements in the adult human: How well do we know them? J. Nutr. 117: 1484-1487.

66. Zello, Gordon A., Pencharz, Paul B., Ball , Ronald O. (1993) Dietary lysine requirement of young adult males determined by oxidation of $L-f 1$ 13C]phenylalanie. Am. J. Physiol. 264: E677-E685.

67. Zello, Gordon A., Pencharz, Paul B., Ball, Ronald O. (1990). Phenylalanine flux, oxidation, and conversion to tyrosine in humans studied with L-[113C]phenylalanine. Am. J. Physiol. 259: E835-E843.

68. Zello, Gordon A., Wykes, Linda J., Ball, Ronald O., Pencharz, P. B. (1995) Recent advances in methods of assessing dietary amino acid requirements 
for adult humans. J. Nutr. 125:2907-2915.

69. Zello, G. A., Pencharz, P. B., Ball, R. O. (1990) The design and validation of a diet for studies of amino acid metabolism in adult humans. Nutr. Res. 10: 1353-1365.

70.Zello, Gordon A., Smith, John M., Pencharz, Paul B., Ball, Ronald O. (1990) Development of a heating device for sampling arterialized venous blood from a hand vein. Ann. Clin. Biochem. 27: 366-372. 


\title{
10.1 Research Information Form (for patients less than 16 years)
}

\author{
RESEARCH INFORMATION FORM
}

\section{Phenvlalanine Requirements In Patients with PKU}

Inveatioatore:

Glenda Courtney-Martin Dietitian, M.Sc Graduate Student

Dr. P. Pencharz

Senior Scientist

Dr. J. Clarke

Ms. V. Austin

Head - Clinical Genetics

Ph: 813-6175

Ph: 813-6176

Ph: 813-5753

Mrs. W. Schoonheyt

Dietitian - PKU Program

Ph: 813-5332

Director - PKU Program

Ph: 813-6356

Purpose of the Research:

It is hard to achieve normal blood phenylalanine levels in patients with PKU. This is partly because we don't have good estimates of it's requirements. We want to measure the phenylalanine requirements in children with PKU using a new technique. Using this same technique we recently determined tyrosine needs which we found to be approximately $19 \mathrm{mg} / \mathrm{kg} /$ day, much lower than current recommendations. Because we already know the tyrosine needs, knowing the requirements for phenylalanine will serve to complete the puzzle and improve the dietary treatment of your child and other individuals with PKU. We believe that this will lead directly to better outcome.

\section{Deacription of the Research:}

If you or your child decide that he/she will enter the study, we will be measuring the amount of phenylalanine that your child requires to be in metabolic control. This will involve six study days. The study days will not be consecutive, but, your child will be required to complete all seven days within a 2 month period.

On each study day, your child will be required to spend 8 hours beginning at 8:00 a.m., in the Clinical Nutrition Laboratory of The Hospital For Sick Children. During that time, breath, urine and 5 drops of blood from a finger prick will be collected. To collect breath, your child will have to wear a mask over his/her face and sit or lit still. He or she will be able to breath normally and can watch TV, read or listen to music while the breath is being collected. To collect the urine your child will need to go into the bathroom and pee into a bottle. You may be present with your child during the entire study period. 
Your child should arrive at the hospital after an overnight fast. No food or drink (except water) should be taken after the previous night's supper, which should be no later than 10:00 p.m. During each study day, your child will lie comfortably on a bed or sit in a chair and watch TV, read, or listen to music. We will start by measuring your child's height and weight. Body fatness will be determined by measuring skin thickness from the arm, waist and back using a caliper. After this, we will measure the amount of muscle in your child's body by placing four small stickers on the right arm and leg. These stickers are connected to a machine by wires. The machine calculates the amount of muscle in the body by passing a small current through it. The current used in this test is extremely small and the body does not feel anything. The body fat and muscle measurements are completely safe and painless and will be done on the first and last study days. Both measurements take a total of about ten minutes to complete.

During the study period, your child will eat 8 small meals spaced one hour apart. The meals will be made up of three parts: (1) a mixture of amino acid in which the amount of phenylalanine will either be less than adequate, adequate, or more than adequate; (2) an amino acid free flavored liquid formula; and (3) amino acid free cookies. Your child's individual nutritional requirements will be determined prior to beginning the study and the test diet will be determined to meet your child's energy and protein requirements. During the last 4 hours of each study day your child will also consume a solution made up of water and an amino acid that contains a naturally containing label. An amino acid which contains a label is different than a regular amino acid only in that it weighs more. This label (stable isotope), found naturally in small amounts in your child's body, is harmless and is used routinely in human nutrition research. It is the amount of this heavy isotope that we measure in your child's breath and urine that allows us to determine your child's requirements for phenylalanine.

\section{Potential Harms:}

All of the tests used in this protocol are harmless. However, we recognize that the length of the study day and the number of days required to complete the study might pose an inconvenience to you and your child. In addition, you should consider that your child will be required to spend 8-9 hours in the Clinical Nutrition Laboratory at the hospital and may become bored during this time.

\section{Potential Benefit:}

Your child will benefit directly from participating in this study. The results of the study will enable us to determine your child's individual phenylalanine requirement, which can lead to improved metabolic control. The results of this study will also be beneficial to other individuals with PKU, because they will by used to estimate the requirements for phenylalanine for other similar individuals. 
Confidentiality:

Confidentiality will be respected and no information that discloses the identity of your child will be released or published without your consent, unless required by law. For your information, the research consent form will be inserted in the patient's health record.

\section{Particjoation:}

Participation in research must be voluntary. If you choose not to participate, your child and other family members will continue to have access to quality care at HSC. You can withdraw your child anytime during the study and again your family will continue to have access to quality care at HSC. You may ask any questions now or during the study. 
10.2 Research Information Form (for children 7-15 years)

\section{PHENYLALANINE REQUIREMENTS IN CHILDREN WITH PKU}

Investigators:

Glenda Courtney-Martin

Dr. P. Pencharz

Dr. J. Clarke

Ms. V. Austin

Mrs. W. Schoonheyt
Dietitian, M.Sc Graduate Student

Senior Scientist

Head - Clinical Genetics

Dietitian - PKU Program

Director- PKU Program
Ph: 813-6175

ph: 813-6176

Ph: 813-5753

Ph: 813-5332

Ph: 813-6356

Why are doing this study? It is hard for children with PKU to achieve normal blood phenylalanine levels, partly because we don't know what the needs for phenylalanine are. We want to measure the needs for phenylalanine using a new technique. Recently we measured tyrosine needs and found it was about $19 \mathrm{mg} / \mathrm{kg} /$ day. This is much less than what people with PKU are now being asked to eat each day.

What will happen during the study period? On six different days, you will spend 8 hours at the Hospital For Sick Children. We will start by measuring your height and weight. We will also measure the amount of fat and muscle in your body. To measure the fat in your body we will need to pinch the skin in your arm, waist and back using a caliper. A caliper is a small tool that looks like a pair of ice tongs. We will measure the amount of muscle in your body by placing four small stickers on your right arm and leg. These stickers are connected to a machine by wires. The machine then works out how much muscle is in your body, by sending a small current through it. These two tests which measure the amount of fat and muscle in your body only take about ten minutes and they will not cause you any pain. Your breath, urine and 5 drops of blood will also be collected. To collect your breath you will have to put a mask on and sit or lie still. You will be able to breath normally and can watch TV, read or listen to music. To collect your urine you will need to go into the bathroom and pee into a bottle. To collect your blood you will receive a pin prick on the middle finger of your left hand, it will the be squeezed gently to remove 5 drops of blood.

Every hour you will eat a small meal made up of a mixture of amino acids, a flavored liquid formula and cookies. During the last 4 hours of each study day, you will also drink a solution made up of water and a special amino acid that contains something called a label. An amino acid which contains a label is different from a regular amino acid only in that it weighs more. This label (stable 
isotope), found naturally in small amounts in your body, is completely harmless. We will measure the amount of this heavy isotope in your breath and urine.

Are there good things and bad things about this study? All of the tests used in the study are harmless and when the study is over we will be able to tell you exactly how much phenylalanine you need to eat. If you decide to take part in the study, you will be expected to come to the hospital for seven separate days. On each day you will spend between 8 - 9 hours. This might seem a very long and boring time for you. We do have a wide selection of games you can play and music you can listen to. In addition, you can watch TV or read. These different activities may help to make the day go faster for you.

The mask which is put over your face to collect your breath may be scary especially if you have never seen or used it before. In addition, getting your finger pricked to collect the 5 drops of blood needed on each of the seven days may be a little painful for you. Finally, peeing into a bottle to collect your own urine may be hard for you to do. You may get urine on your hands and clothes and some might even end up on the floor.

Who will know about what I did in the study? If you are part of the study your name and address will not be given to anyone, unless needed by the law.

Can I decide if I want to be in the study? If you do not want to be part if this study that is O.K. No one will be upset. If you say yes now and change your mind, you can say no to the doctor and nurse and that is O.K. Your mother and father are also given this information. They will talk to you about it. Please ask the doctor and nurse any questions that you may have.

\section{Assent}

I was present when read this form and gave his/her verbal assent.

Name of person who obtain assent:

Signature:

Date: 


\subsection{Consent form}

\section{Phenvlalanine Requirements In Patients with PKU}

\section{Consent Form for Parents}

I acknowledge that the research procedures have been explained to me and that any questions that I have asked have been answered to my satisfaction. I have been informed of the alternatives to participation in this study, including the right not to participate and right to withdraw without compromising the quality of medical care at The Hospital For Sick Children for my child and other members of my family. As well, the potential harms and discomforts have been explained to $m e$ and I understand the benefits (if any) of participating in the research study. I know that I may ask now, or in the future, any questions I have about the study or the research procedures. I have been assured that the records relating to my child's care will be kept confidential and that no information will be released or printed that would disclose personal identity without permission, unless required by law.

I hereby consent for my child to participate.

Parent name:

Parent signature:

Person to contact about the research:

Telephone \# and Pager \#:

Name of person obtaining consent:

Signature:

Date: 


\subsection{Phenylalanine Study: Diet}

Study \#

Study Date :

Subject

Height : m Weight : kg Age : yrs

\section{Eneroy Requirement : kcal/day}

Female 3- 10 yrs : $22.5 W+499$ Male $3-10 \mathrm{yrs}: 11.7 \mathrm{~W}+495$

$$
10-18 \text { yrs : } 7.4 \mathrm{~W}+482 \mathrm{H}+217 \quad 10-18 \text { yrs }: 16.6 \mathrm{~W}+77 \mathrm{H}+572
$$
$\mathrm{kcal} / \mathrm{day} \times 1.5=$ $\mathrm{kcal} / \mathrm{day}[\mathrm{A}]$

\section{Diet Constituents}

Amino Acids

Formula

Butterscotch Cookies

Cornflake Cookies
$=10 \%$ total energy intake

$=65 \%$ total energy intake

$=12.5 \%$ total energy intake

$=12.5 \%$ total energy intake

Amino Acids

$=1.5 \mathrm{~g}$ Prot $/ \mathrm{kg} /$ day $\mathrm{x}$ $\mathbf{k g}=$ g Prot/day [B]

Formula $=0.427 \mathrm{ml} / \mathrm{kcal} \times 65 \% \times[\mathrm{A}] \mathrm{kcal} / \mathrm{day}=$ $\mathrm{mL} /$ day [C]

BS Cookies $=0.234 \mathrm{~g} / \mathrm{kcal} \times 12.5 \% \times[\mathrm{A}] \mathrm{kcal} / \mathrm{day}=$ g/day [D]

CF Cookies $=0.229 \mathrm{~g} / \mathrm{kcal} \times 12.5 \% \times[\mathrm{A}] \mathrm{kcal} / \mathrm{day}=$ g/day [E]

\begin{tabular}{|l|l|l|l|l|l|l|}
\hline & Amount & & Fat (g) & & CHO (g) & Prot(g) \\
\hline Amino Acids & {$[\mathrm{B}]$} & & - & & - & \\
\hline Formula & {$[\mathrm{C}]$} & $\times 0.1$ & & $\times 0.36$ & & - \\
\hline BS Cookies & {$[\mathrm{D}]$} & $\times 0.223$ & & $\times$ & & - \\
\hline CF Cookies & {$[\mathrm{E}]$} & $\times 0.244$ & & $\times .565$ & & \\
\hline Total (g) & & & & & & - \\
\hline Total (kcal) & & & & & & \\
\hline
\end{tabular}


Energy Distribution = $\%$ Fat, $\% \mathrm{CHO}$, $\%$ Prot

Amino Acid Mix \# 1 (study day)

Study day includes $100 \%$ of the total intake, a total of 8 meals. g Prot/day [B]

Mix \# 1 represents $79.63 \%$ of the total AA reqt $=$ g Mix \# 1 / study day g Mix \# 1 / study day $\div 8$ meals $=$ g Amino acid mix \# 1 / meal

The total of the other amino acids (Lys, Phe, and $\mathrm{Ala})=\mathbf{2 0 . 3 7 \%}$ of reqt $=$ $\mathrm{g}[\mathrm{BB}]$

Lysine Intolse

Lys reqt/day

Tracer Lys intake [G]

Dietary Lys

$$
=64 \mathrm{mg} / \mathrm{kg} \mathrm{x}
$$$$
=[2.5+(8 \times 0.7)] \times
$$
$\mathbf{k g}=$ $\mathrm{mg}[\mathrm{F}]$ $\mathrm{kg}=$ mg Lys

The dietary Lys should be distributed between the meals to standardise the intake of each meal. Initially balance the intakes to the highest intake at meal \#5.

Meal \# 5 Lys isotope intake

$$
\begin{aligned}
& =[2.5+(2 \times 0.7)] \mathrm{mg} / \mathrm{kg} \times \_\mathrm{kg}=\ldots \mathrm{mg} \text { Lys }[\mathrm{a}] \\
& =(2 \times 0.7) \mathrm{mg} / \mathrm{kg} \mathrm{x} \_\mathrm{kg}= \\
& =[\mathrm{a}]-[\mathrm{b}]= \\
& \mathrm{mg} / \mathrm{meal} \# 6 \text { - \#8 [c] } \\
& =[\mathrm{a}]= \\
& \mathrm{mg} / \mathrm{meal} \# \mathrm{l} \text { - \#4 [d] } \\
& =[\mathrm{H}]-4 \times[\mathrm{d}]-3 \times[\mathrm{c}]= \\
& =[e]+8= \\
& \mathrm{mg} / \mathrm{meal}[\mathbf{f}]
\end{aligned}
$$$$
\text { Meal \#1 - \#4 balance Lys }
$$

Dietary Lys is in the form of $\mathrm{Lys} . \mathrm{HCl}$, therefore all amounts must be mulyplied by a correction factor of 1.24. The lys isotope on the other hand is in the form of Lys.HCl or Lys. $2 \mathrm{HCl}$, in which case we must use a correction factor of 1.24 or 1.47 .

Dietary intake meal \#1 - \#4

Dietary Intake meal \# 5

Dietary intake meal \#6 - \#8 $=([\mathbf{f}]+[\mathrm{d}])=$

$=[\mathrm{f}]=$

$=([\mathbf{f}]+[\mathrm{c}])=$ $\mathrm{mg} \times 1.24=$ $\mathrm{mg} \times 1.24=$ mg $\times 1.24=$ $\mathrm{mg}[1]$ mg [2] mg [3] 
Isotope intake meal \#5 (Lys.HCl) $=[\mathrm{a}](\mathrm{P}) \times 1.24=\ldots \mathrm{mg}$ [aa] CI x Isotope intake meal \#6-8 $=[\mathrm{b}] \times 1.24=$ $\mathrm{mg}[\mathrm{bb}] / 2$ for each $\mathrm{CI}$ mg

[Isotope intake meal \#5 (Lys.2HCl)= [a] x $1.47=$ Isotope intake meal \#6-8 $=$ [b] $\times 1.47=$ $\mathrm{mg}$ [a] 1.24 $\mathrm{mg}[\mathrm{bb}]]$
PHE Intake

Phe intake/day

Phe intake/meal

Alanine Intake

Ala reqt

Ala balance/meal
Level

$=\ldots \mathrm{mg} / \mathrm{kg} / \mathrm{d} \mathrm{x}$ $\mathrm{kg}=$ mg [i] $=[j] / 8=\ldots m g$ $\mathrm{mg} / \mathrm{CI}$ $\mathrm{mg} / \mathrm{kg} / \mathrm{d}$ 
Formula Renuisition (Study dav) Need 100\% requirement i,e. 8 meals

Formula required per study day $=[C] \mathrm{mL}=$ $\mathrm{mL} /$ day $[\mathrm{C}]$

Formula required per meal/d $=[C] \mathrm{mL} \div 8=$ $\mathrm{mL} / \mathrm{meal}[0]$

** Each meal is served in a $40 z$ bottle.

Formula requisition $=9 \times 40 z$ bottles $x$ $\mathrm{mL} / \mathrm{meal}[0]=$ $\mathrm{mL} /$ day $[\mathrm{P}]$

\section{Formula Recine}

\begin{tabular}{|l|l|l|l|}
\hline Ingredient & $\begin{array}{l}\text { Conc'n } \\
(\mathrm{g} / \mathrm{mL})\end{array}$ & $\begin{array}{l}\text { Study day } \\
\text { vol(mL) } \mathbf{P}]\end{array}$ & $\begin{array}{l}\text { Study day } \\
\text { amt(g) }\end{array}$ \\
\hline $\begin{array}{l}\text { Product } \\
\# 80056\end{array}$ & 0.281 & & \\
\hline Orange Tang & 0.0832 & & \\
\hline $\begin{array}{l}\text { Koolaid } \\
\text { Crystals }\end{array}$ & 0.0832 & & \\
\hline Corn Oil & 0.033 & & \\
\hline Sterile water & 0.64 & & \\
\hline
\end{tabular}

- Study day amt $(g)=$ Conc'n $(g / m L) \times$ study day vol $[\mathrm{P}]$

\section{Butterscotch Cookiea (study day)}

BS Cookies required per study day

$$
\begin{aligned}
& =[D]=\ldots \text { g/day }[D] \\
& =[D] \div 8=\ldots g / \mathrm{meal}
\end{aligned}
$$

g BS Cookies required per meal

\section{Comflake Cookies (otudy dav)}

CF Cookies required per study day

$$
\begin{aligned}
& =[E]=\ldots \text { g/day }[E] \\
& =[E] \div 8=\ldots \text { g/meal }
\end{aligned}
$$

g CF Cookies required per meal

** Each meal is served in a separate plastic bag 
Diet Requisition Form:

Subject's Name:

Delivery Date:

Eormula Recipe: Study Day

g Product \#80056

g Orange Tang

g Koolaid Crystals

Flavour:

g Corn Oil

g Sterile Water

Total volume of formula: $\mathbf{m L}$

_9 $40 z$ Bottles _ $\mathrm{mL}$ per bottle 


\section{Butterscotch Cookie: Study Day}

g BS cookie per day

8 ___ meals per day

g BS Cookie per meal

\section{Cornflake Cookie:___ Study Day}

g CF cookie per day
8
meals per day
g CF Cookie per meal

*** All meals should be divided into separate plastic bags, each labelled as follows:

-Subject name

-Meal Number

-Type of Cookie

-Weight (grams) of cookie per bag 
Amino Acid Recipe'

First column $=\mathrm{mg}$ of amino acids

Second column $=\mathrm{mL}$ of isotope solution

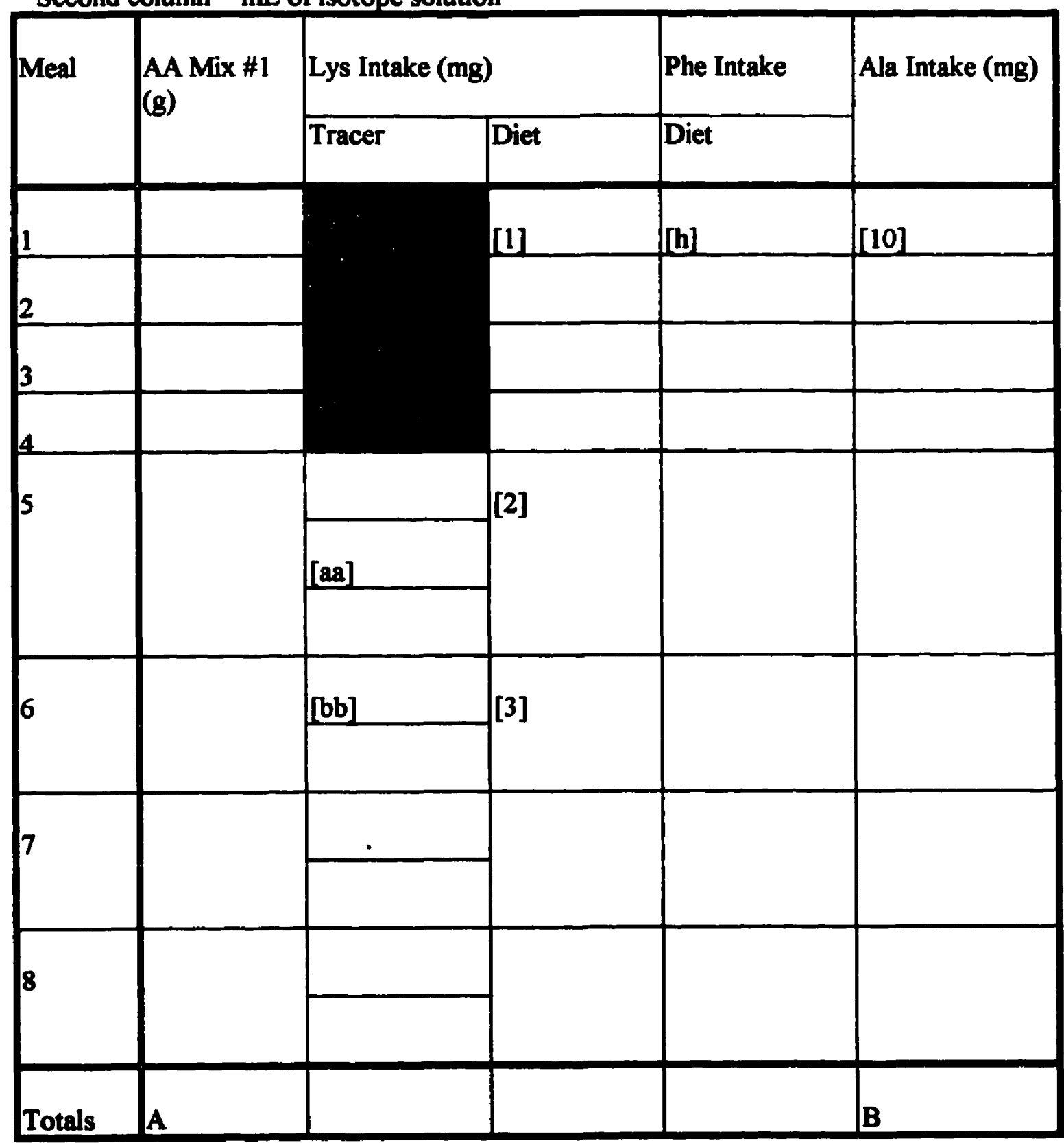

Level of phe

Subject $\mathrm{mg} / \mathrm{kg} / \mathrm{d}$

$m g / k g / d$ 


\subsection{PKU Study Day Schedule}

Pt Name:

Pt Weight:

Pt Height:

Date:

Lraine intake as tracer

Prime $=2.5 \mathrm{mg} / \mathrm{kg} \mathrm{X}$ $\mathrm{kg}=$

$\mathrm{Cl}=0.7 \mathrm{mg} / \mathrm{kg} / \mathrm{T} / 2 \mathrm{hr} x$

Total $(\mathbf{P}+\mathrm{Cl})=$ $\mathbf{k g}=$ $\mathrm{mg}$ Lysine $\times 1.24=$ $\mathrm{mg} / 1 / 2 \mathrm{hr} \times 8=$ mg mg Lysine

Volume of Lysine as Tracer (stock solution $10 \mathrm{mo} / \mathrm{mL}$ )

\begin{tabular}{|c|c|c|}
\hline \multicolumn{3}{|c|}{$\begin{array}{l}\text { Prime }=\quad \times 1.24= \\
\mathrm{Cl}=\quad \times 1.24=\end{array}$} \\
\hline \multirow[t]{2}{*}{ Time (Hour:Min) } & \multicolumn{2}{|l|}{ List of Events } \\
\hline & $\begin{array}{l}\text { Breath Collection } \\
\text { Body Composition (BIA + } \\
\text { Skinfolds) } \\
\mathrm{VCO}_{2}\end{array}$ & $\begin{array}{l}\text { Food \& Water } \\
\text { lsotope } \\
\text { Blood \& Urine }\end{array}$ \\
\hline Pre-study & $\begin{array}{l}\text { Collect ice } \\
\text { Patient set-up } \\
\text { Bag for breath collection } \\
\text { Tubes, Epindorfs, Guthrie } \\
\text { test paper } \\
\text { Container for urine }\end{array}$ & $\begin{array}{l}\text { Collect diet \& Water } \\
\text { Get lsotope Ready } \\
\text { Isotope } \\
\text { prime_mis } \\
\text { Cl_mis/ } 1 / 2 \mathrm{hr} \\
\text { patient voids yes/no }\end{array}$ \\
\hline Pre-study & BIA: body composition & $1^{4}$ Finger prick blood \\
\hline $0: 00$ & Skin-folds: body composition & $\begin{array}{l}1^{2} \text { Meal } \\
150 \text { mls. Water } \\
\text { (bulk urine collection) }\end{array}$ \\
\hline $1: 00$ & Practice breath collection & $\begin{array}{l}2^{\text {nd }} \text { meal } \\
150 \text { mls. Water } \\
\text { (bulk urine collection) }\end{array}$ \\
\hline $2: 00$ & & $\begin{array}{l}3^{\text {rd }} \text { meal } \\
150 \text { mls. Water } \\
\text { (bulk urine collection) }\end{array}$ \\
\hline $2: 30-2: 55$ & $\mathrm{VCO}_{2}$ measurement & \\
\hline $3: 00$ & $1^{2}$ Breath collection $\times 3$ (B) & $\begin{array}{l}4^{\text {th }} \text { meal } \\
150 \text { mls. Water } \\
1^{*} \text { urine collection (B) } \\
\text { (bulk + isotope) }\end{array}$ \\
\hline $3: 15-3: 30$ & $2^{\text {nd }}$ Breath collection $\times 3$ (B) & $\begin{array}{l}2^{\text {nd }} \text { Urine collection (B) } \\
\text { (bulk + isotope) }\end{array}$ \\
\hline
\end{tabular}




\begin{tabular}{|c|c|c|}
\hline $3: 30-3: 50$ & $3^{\text {rd }}$ Breath collection $\times 3$ (B) & $\begin{array}{l}3^{\text {rd }} \text { Urine collection (B) } \\
\text { (bulk + isotope) }\end{array}$ \\
\hline $4: 00$ & & $\begin{array}{l}5^{\text {th }} \text { meal } \\
150 \mathrm{mls} \text {. Water } \\
\text { Prime } \\
\text { Rinse with water }\end{array}$ \\
\hline $4: 15$ & & $\begin{array}{l}1^{\prime \prime} \mathrm{Cl} \\
\text { Rinse with water }\end{array}$ \\
\hline $4: 45$ & & $\begin{array}{l}2^{\text {nd }} \mathrm{Cl} \\
\text { Rinse with water }\end{array}$ \\
\hline $5: 00$ & & $\begin{array}{l}6^{\text {th }} \text { Meal } \\
150 \text { mis water } \\
\text { Urine collection (bulk) }\end{array}$ \\
\hline $5: 15$ & & $\begin{array}{l}3^{\mathrm{r}} \mathrm{Cl} \\
\text { Rinse with water }\end{array}$ \\
\hline $5: 45$ & & $\begin{array}{l}4^{\text {th }} \mathrm{Cl} \\
\text { Rinse with water }\end{array}$ \\
\hline $6: 00$ & & $\begin{array}{l}7^{\text {th }} \text { Meal } \\
150 \text { mls water } \\
\text { Urine collection (bulk) }\end{array}$ \\
\hline $6: 15$ & $4^{\text {TH }}$ Breath collection $\times 3(P)$ & $\begin{array}{l}5^{\text {th }} \mathrm{Cl} \\
\text { Rinse with water } \\
4^{\text {th }} \text { Urine collection (P) } \\
\text { (bulk + isotope) }\end{array}$ \\
\hline $6: 45$ & & $\begin{array}{l}6^{m} \\
\text { Rinse with water }\end{array}$ \\
\hline $6: 45-7: 00$ & $5^{\text {th }}$ Breath collection $\times 3(\mathrm{P})$ & $\begin{array}{l}5^{\text {th }} \text { Urine collection (P) } \\
\text { (bulk + isotope) }\end{array}$ \\
\hline $7: 00$ & & $\begin{array}{l}8^{\text {th }} \text { Meal } \\
150 \mathrm{mls} \text { water }\end{array}$ \\
\hline $7: 15$ & & $7^{7 \text { hinse with water }} \mathrm{mls}$ \\
\hline $7: 15-7: 30$ & $6^{\text {th }}$ Breath collection $\times 3$ (P) & $\begin{array}{l}6^{\text {th }} \text { Urine collection (P) } \\
\text { (bulk + isotope) }\end{array}$ \\
\hline $7: 45$ & & $\begin{array}{l}8^{m} \mathrm{Cl} \\
\text { Rinse with water }\end{array}$ \\
\hline $7: 45-8: 00$ & $7^{\text {th }}$ Breath collection $\times 3$ (P) & $\begin{array}{l}7^{\text {th }} \text { urine collection (P) } \\
\text { (bulk + isotope) }\end{array}$ \\
\hline $8: 30$ & $8^{\text {th }}$ Breath collection (P) & $\begin{array}{l}8^{\text {hh }} \text { Urine collection } \\
\text { (P)(bulk + isotope) } \\
2^{\text {nd finger-prick blood }}\end{array}$ \\
\hline
\end{tabular}




\subsection{Body Composition Data Form}

Name: Study Number:

Date: Age:

Weight: Height:

IBW:

MAC:

(mid-arm circumference)

TSF:

(tricep skin fold)

SSSF:

(sub scapula skin fold)

BIA:R:

(resistance)
MAMC:

(mid-arm muscle circumference)

BSF:

(biceps skin fold)

SISF:

$$
\text { (super iliac skin fold) }
$$

$\mathrm{xC}$ :

(reactance)

Body Composition Profile

\%Body Fat (Skinfolds)

Lean Body Mass BIA

Comments: 


\subsection{Details of Linear Regression Crossover Model (Breakpoint Analysis)}

A two phase linear regression crossover model (Seber, 1977) was done allowing a partition of the data points between two separate regression lines that minimized the residual error. This resulted in a crossover value termed the breakpoint.

The data points used were all the individual observations for the rate of ${ }^{13} \mathrm{CO}_{2}$ released from $\mathrm{L}-\left[1-{ }^{13} \mathrm{C}\right]$ lysine oxidation for all phenylalanine intake levels tested.

Before the program was executed (SAS Institute 1996 release 6.12 for Windows), visual inspection of the possible location of the breakpoint was done in order to separate the test phenylalanine intakes ( $x$-axis) to the two regression lines. For each estimated separation of the $x$-axis, that data was fitted into 4 different statistical models:

1. Only one line is sloping, unweighted regression

2. Only one line is sloping, weighted regression

3. Both lines are sloping, unweighted regression

4. Both lines are sloping, weighted regression

SLOPING: Based on the concepts of Indicator Amino Acid oxidation (IAAO), a slope in the second line should be minimal or absent.

WEIGHTING: Variances along a sloping regression line are proportionally equal with respect to their distance from the lowest value. Therefore, the numerically higher values at the end of the regression lines have both a higher variance and more effect on the slope of the line than the points closer to the lowest value which have a proportionally smaller variance and less effect on the slope of the line.

The purpose of weighting the data is to reduce the numerical effect such that the points at the end of the line have a similar effect on the slope as the points closer to the mean. This is done by multiplying each variance by its inverse. This causes all variances to become numerically equal, but not proportionally equal.

RECRESSION EQUATIONS: The determining factors of the overall regression equations were whether one or both lines were sloping.

\section{Both Lines Sloping: $y=A 2+(A 1-A 2) C+B 2 x+(B 1-B 2) C x$ One line Stoping: $\quad y=A 2+(A 1-A 2) C+(B 1-B 2) C x$}

Where $\quad A 1=$ intercept of the first line

$A 2=$ intercept of the second line

$B 1=$ slope of the first line 


$$
B 2=\text { slope of the second line }
$$

The independent variable $C$ (choose) was used to determine the equations of the individual regression lines: $C=1$ for observations before the breakpoint (first line) and $\mathrm{C}=0$ for observations after the breakpoint (second line)

Both Lines Sloping: First line $(C=1)$

$$
\begin{aligned}
& y=A 2+(A 1-A 2)+B 2 x+(B 1-B 2) x \\
& y=A 1+B 1 x \\
& \text { Second line }(C=0) \\
& y=A 2+B 2 x
\end{aligned}
$$

One Line Sloping: First line $(\mathrm{C}=1)$

(B2=0 since second $y=A 2+(A 1-A 2)+(B 1-B 2) x$

line has no slope) $y=A 1+(B 1-B 2) x$

Second line $(C=0)$

$$
\mathbf{Y}=\mathbf{A} \mathbf{2}
$$

The breakpoint (mean requirement estimate) is where the two lines intersect.

Both Lines Sloping: $A 1+B 1 x=A 2+B 2 x$

$$
X=-(A 1-A 2) /(B 1-B 2)
$$

One Lines Sloping: $A x+(B 1-B 2) x=A 2$

$$
X=-(A 1-A 2) /(B 1-B 2)
$$

(A1-A2) and (B1-B2) are represented in the SAS output as the parameters choose and phein"choose

CHOOSING THE MODEL: Once all 4 models were executed (all possibilities of the separation of the $x$-axis to the two regression lines), the model that best fit the data was chosen. The value that indicated this was the lowest standard error of the largest parameter (choose). The model with the lowest error was taken as the model with the best fit for the data. Other factors looked at were the coefficient of variation (CV), and the $r^{2}$. The lowest $C V$ was an indication that variation around the mean was lowest for that model. The higher $r^{2}$ was an indication that the slope of the line more closely matched the data. 


\section{Setting up the SAS Program for Breakpoint Analysis}

STEP ONE: $\quad$ Set up Raw Permanent Data Set

VARIABLES INCLUDED

SUBS

Phein

subject

$\mathrm{FCO} 2$

test phenylalanine intake levels in order fed to subjects

Varox individual $\mathrm{f}_{13 \mathrm{CO} 2}$ values standard error of the mean of each phenylalanine intake level (used for weighting)

\section{PROGRAM:}

Libname perm 'a:';

data perm.fco2;

INPUT SUB\$ phein fco2 varox;

CARDS;

(all individual data entered here)

$\downarrow$

title 'Raw F13CO2 Data For All Individuals';

PROC PRINT;

RUN;

STEP TWO:Two Phase Linear Regression Crossover Model Program

The following program was run with phenylalanine intakes of 0 and 10 $\mathrm{mg} \mathrm{kg}^{-1}$.day ${ }^{-1}$ on the first regression line and intakes of 15, 20, 25 and $35 \mathrm{mg} . \mathrm{kg}^{-}$ 1. day $^{-1}$ on the second regression line. Following trial and error with all possible separation of the x-axis, the following model was found to minimize the error.

\section{Both Lines Have a Slope, Unweighted Regression}

Options pagesize $=60$;

Libname perm 'a:';

Data perm.phobpt;

Set perm.fco2;

Proc sort data=perm. phebpt;

by phein;

proc print data=perm. phebpt;

var phein sub fco2 meanfco2;

title1 'GCM dataset';

data lev123;

set perm.phebpt;

choose=0; 
if phein $=0$ or phein $=10$ then chose=1;

phechoo=phein"choose;

proc gim data=lev123;

model fco2=phein choose phein choose;

title1 'PHE $0+10$ vs PHE $15+20+25+35$ ';

title2 'All Individuals';

title3 'Both Lines have a slope';

title4 'Unweighted Regression';

proc reg outest=out 123 covout outsscp=outsums;

model fc02=phein choose phechoo;

plot r. "p.;

proc print data=out123;

proc print data=outsums;

run;

\section{The SAS Output Statement of the Linear Regression Crossover Analysis}

The following is the output for the above model, which resulted in the best fit: Both lines have a slope, unweighted regression. Phenylalanine intakes of 0 and $10 \mathrm{mg} \cdot \mathrm{kg}^{-1}$.day on the first line (choose=1), and intakes of 15, 20, 25 and $35 \mathrm{mg} \mathrm{kg}^{-1}$. day ${ }^{-1}$ were on the second line (choose=0).

Dependent Variable: ${ }^{13} \mathrm{CO}_{2}$

General Linear Models Procedure

$\begin{array}{llllll}\text { Source } & \text { DF } & \text { Sum of Squares } & \text { Mean Square } & \text { F Value } & \operatorname{Pr}>F \\ \text { Model } & 3 & 0.37209209 & 0.12403070 & 5.05 & 0.0069 \\ \text { Error } & 26 & 0.63903730 & 0.02457836 & & \\ \text { Corrected Total } & 29 & 1.01112939 & & & \end{array}$

R-Square

0.367997

Source

PHEIN

CHOOSE

PHEIN*CHOOSE

Source

PHEIN

CHOOSE PHEIN*CHOOSE
C.V

16.22027

Root MSE

0.1567749

F13CO2 Mean

\subsection{7}

Mean Square $F$ Value $\operatorname{Pr}>F$

0.01137932

0.46

0.5022

0.09612713

3.91

0.0587

0.26458564

10.76

0.0029

\subsection{4}

Mean Square

F Value $\operatorname{Pr}>F$
0.14959477
0.33305579
0.26458564

0.14959477

0.33305579

6.09

13.55

0.26458564

10.76

0.0205

0.0011

0.0029 


$\begin{array}{llccc}\text { Parameter } & \text { Estimate } & \begin{array}{c}\text { T for HO: } \\ \text { Parameter=0 }\end{array} & \operatorname{Pr}>|\mathrm{T}| & \begin{array}{c}\text { Std Error of } \\ \text { Estimate }\end{array} \\ \text { INTERCEPT } & \mathbf{0 . 6 5 3 6 3 9 4 2 8 6} & 5.54 & 0.0001 & 0.11791661 \\ \text { PHEIN } & 0.0116949714 & 2.47 & 0.0205 & 0.00474043 \\ \text { CHOOSE } & \mathbf{0 . 5 0 5 0 0 0 5 7 1 4} & 3.68 & 0.0011 & \mathbf{0 . 1 3 7 1 8 6 0 0} \\ \text { PHEIN*CHOOSE } & -.0360589714 & -3.28 & 0.0029 & 0.01099023\end{array}$

Determination of the Breakpoint

Because the model used was "Both Lines Have a Slope," the breakpoint was calculated directly from the SAS output using the following regression equation:

$$
\begin{aligned}
& A 1+B 1 X=A 2+B 2 x \\
& X=-(A 1-A 2) /(B 1-B 2)
\end{aligned}
$$

Using the values generated by the SAS output:

$$
\begin{aligned}
& (A 1-A 2)=\text { Choose }=-0.5050006 \\
& (B 1-B 2)=\text { Phoin }{ }^{*} \text { Choose }=-0.036059
\end{aligned}
$$

The breakpoint is therefore $=$ Choose/phein ${ }^{*}$ choose $=(-0.5050006 /-$ $0.036059)=14 \mathrm{mg}$ phenylalanine $\cdot \mathrm{kg}^{-1} \cdot \mathrm{day}^{-1}$.

\section{Determination of the $95 \%$ Confidence Interval}

The 95\% confidence limit was estimated using Fieller's theorem (Seber, 1997). This program was run on SAS (SAS Institute 1996 release 6.12 for Windows). The $95 \%$ confidence limit represents the safe population requirement for prepubertal children with PKU within the ages of 6 to 13 years old. This is assuming the sample studied is representative of the general population of prepubertal PKU children between the ages of 6 and 13. Where

The $95 \%$ Confidence limit = Breakpoint $\pm t(n)$ SE (Breakpoint)

Breakpoint $=-$ choose/ phein ${ }^{*}$ choose

$T=1.699$ ( $t$ distribution, 29 degrees of freedom; $n-1$ )

SE (Breakpoint)=calculated from 3 sources of variation

(1) variation of choose

(2) variation of phein"choose

(3) Covariances of (1) and (2)

The variances (1) and (2) are the standard error of the estimates squared. 
The covariances (3) is derived from the output of the two-phase linear regression crossover model (proc reg outest = out123 covout).

STEP ONE: $\quad$ Set up Raw Permanent Data Set

\begin{tabular}{ll} 
VARIABLES INCLUDED \\
\hline Beta2 & choose \\
Vbeta2 & choose"choose \\
Beta12 & phechoose \\
Vbeta12 & phechoose"phechoose \\
Covebeta & choose"phechoose
\end{tabular}

PROGRAM:

Libname to 'a:';

Data to.oci;

Input beta2 vbeta2 beta12 vbeta12 covbeta t;

Cards;

$0.505000 .01882-0.0360590 .000121-0.001031 .699$

;

proc print;

run;

options pagesize $=60$;

libname perm 'a:l';

data perm.oci;

set perm.oci;

$t=1.699$;

ratio=- (beta2/beta12);

aa=vbeta2/ (beta2-2); bb=vbeta12/(beta12 2);

$a b=$ covbeta/ (beta2"beta12);

varratio $=\left(\right.$ ratio $\left.{ }^{* *}\right) *\left(a a+b b-2^{*} a b\right)$;

seratio=sqrt (varratio);

clower=ratio-t"seratio;

cupper=ratio+t"seratio;

proc print;

title1 'The lower and upper 95\% confidence limits of the breakpoint';

run; 
Output Statement of the $95 \%$ Confidence Limits Analysis

OBS BETA2 VBETA2 BETA12 VBETA12 COVBETA T RATIO AA

$\begin{array}{llllllllll}1 & 0.505 & 0.01882 & -0.036059 & .000121 & -.00103 & 1.699 & 14.0048 & 0.073797\end{array}$

$\begin{array}{lllllll}\text { OBS } & \text { BB } & \text { AB } & \text { VARRATIO } & \text { SERATIO } & \text { CLOWER } & \text { CUPPER } \\ 1 & 0.093059 & 0.056563 & 10.5383 & 3.24627 & \mathbf{8 . 4 8 9 4 1} & \mathbf{1 9 . 5 2 0 2}\end{array}$

RATIO = Breakpoint

CLOWER = Lower $95 \%$ confidence limit

CUPPER = Upper $95 \%$ confidence limit $=19.5 \mathrm{mg}$ phenylalanine. $\mathrm{Kg}^{-1} . \mathrm{day}^{-1}$. 